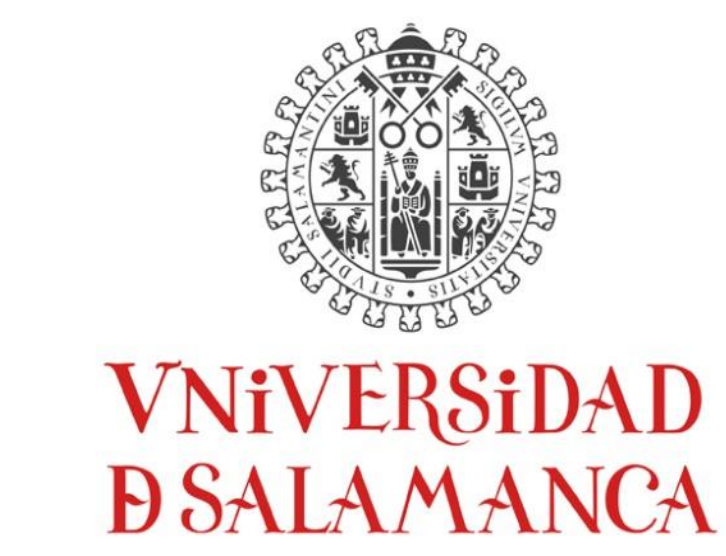

CAMPUS DE EXCELENCIA INTERNACIONAL

\title{
Mythopoesis, Aesthetics and Artistic Creation \\ Towards a Tautegorical Interpretation of the Cinematic Image
}

by

Mahmoud Rasmi

Universidad de Salamanca

April, 2015 


\title{
Mythopoesis, Aesthetics and Artistic Creation Towards a Tautegorical Interpretation of the Cinematic Image
}

\author{
by \\ Mahmoud Rasmi \\ Dissertation Advisor: Dr. Victor del Río
}

\section{A DISSERTATION}

Submitted to

The Faculty of Philosophy at the University of Salamanca in partial fulfillments of the requirements for the degree of

Doctor of Philosophy

Universidad de Salamanca

April, 2015 
(C) 2015

Mahmoud Rasmi

All Rights Reserved 


\begin{abstract}
:
The present thesis consists of a close examination and a thorough reading of Schelling's Historical-Critical Introduction to the Philosophy of Mythology in order to grasp the ground of his call for a new mythology as the ultimate form of artistic creation. This, I hope, will serve as the basis for looking into the status quo of a possible philosophy of mythology. The objectives of the research include reaching a thorough understanding of how mythology - as an engaging artistic creation - has been perpetually present in the collective unconscious of the societies throughout the ages; nevertheless, it is not until we start to reflect upon the possibility of a philosophy of mythology that our awareness of mythological creation retroactively comes to the surface. There is a subtle difference between engaging and actively participating in creating myths, on the one hand; and intending to create a philosophy of mythology or reflecting about the existing ones in order to come up with a new one, respectively. This conclusion would lead the research to point out a difference between what could be called myth creation and the philosophy of mythology. Consequently, the conclusion would be that one cannot disengage from doing both actions at the same time: the act of actively creating and the act of reflecting upon the oeuvre to acquire a certain sense of awareness and understanding of that which one has created. This is a fluctuating process (although one that always reaches equilibrium) which drives humanity to a richer experience and an advanced process of knowledge acquisition and, thereby, evolution. Otherwise, art - insofar as it is a creative activity - would hence be ontologically insignificant, stripped of any possible meaning or value. For this reason, I would like to investigate the possibility that the cinema nowadays is the ultimate form of artistic creation and would therefore try to reach a possible philosophy of the cinema as the contemporary form of mythology.
\end{abstract}




\section{Acknowledgments:}

Writing a PhD dissertation is a long and a tedious process. Although it is enjoyable, there are times that would make one doubt the worth of such an investment. However, this process is rejuvenated on occasions whereby one is able to scrutinize one's work, but through the eyes of others, who play the roles of interlocutors, readers and critics. Accordingly, first and foremost I would like to thank my thesis supervisor Victor del Río who guided me through the writing process by his insightful suggestions and criticisms. I also would like to thank Dr. Rainer E. Zimmermann for his constructive criticism as well as for providing me with many opportunities to be present at conferences in Germany and Italy where I had the chance to meet and converse with people who contributed to this work directly and indirectly. I would like to thank Diana Khamis for the reading, rereading and editing of the thesis, as well as for being a great interlocutor. I would also like to thank those who helped me in my research: Amr Tamimi, Ana Carrasco Conde, Ben Berger, Carlos Padrosa Alzamora, Daniel Whistler, Iain Hamilton Grant, Jason Wirth, José María Díaz Nafría, Richard Khuri, Roberto Lago Fernández and Tyler Tritten. I would also like to thank my wife Vanina Palomo as well as my parents for their continuous support. 


\section{Table of Contents}

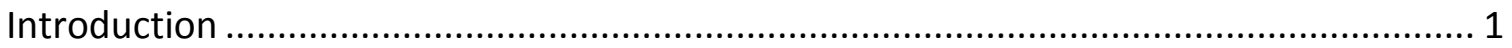

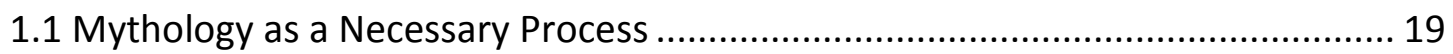

1.2 Necessity and Freedom in Artistic Creation ................................................ 24

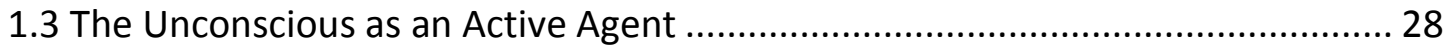

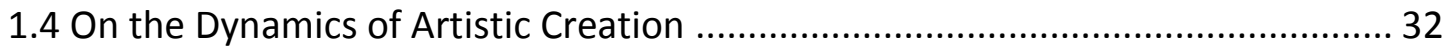

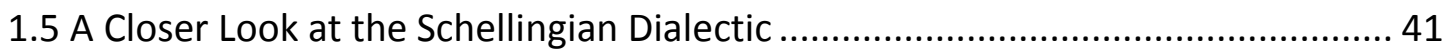

2. Imagination as a Mediator between the Infinite and the Finite .............................49

2.1 The Subject of Cognizance Re-Introduced ...................................................... 50

2.2 On the Orphic and Promethean approaches to Knowledge............................. 56

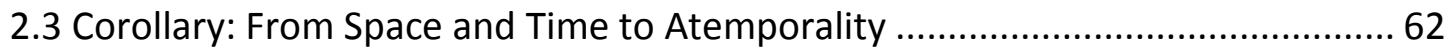

2.4 Creative Imagination: A Synthesis of Intellectual and Aesthetic Intuition ............ 65

2.5 Steppenwolf: Mythology and the Creative Imagination ....................................69

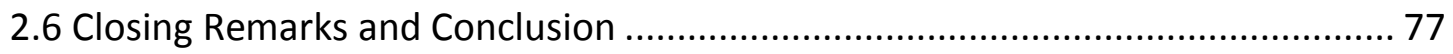

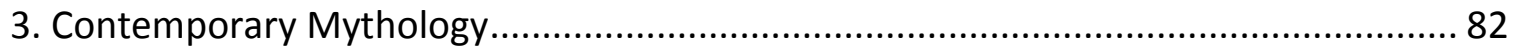

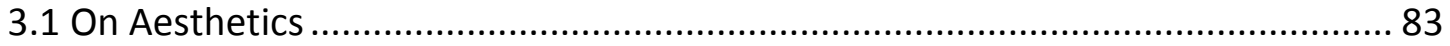

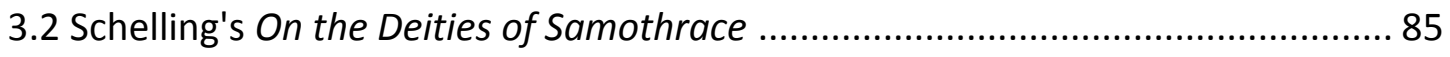

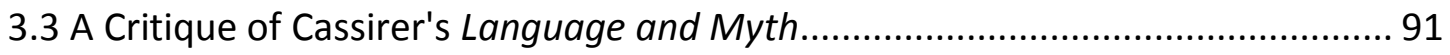

3.4 On the Archetypes and the Collective Unconscious....................................... 95

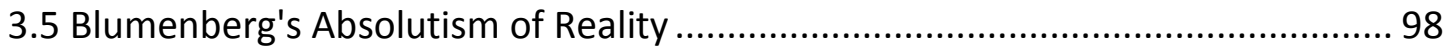


3.6 Roland Barthes: On Mythopoesis and the Mythicization of the Narratives ...... 101

3.7 From Naturphilosophie to the Philosophy of Mythology ................................ 108

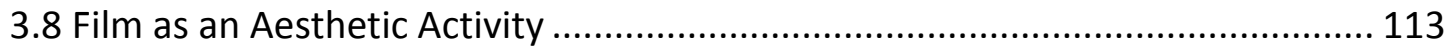

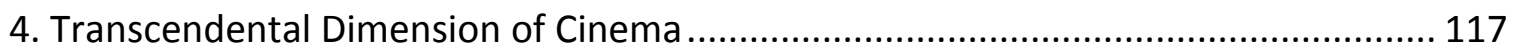

4.1 Takovsky's Sculpting in Time: Art as a Longing for the Ideal ........................... 122

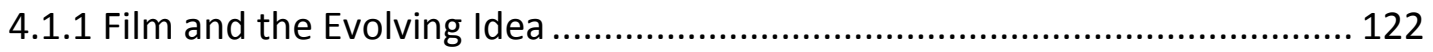

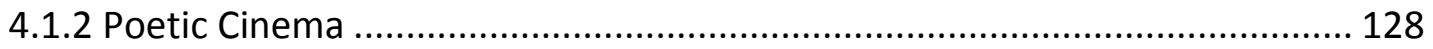

4.1.3 Cinema as an Autonomous Artistic Domain ........................................... 135

4.1.4 On the Relation between Truth and Beauty........................................... 139

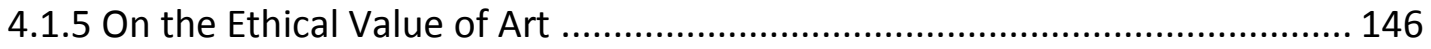

4.2 A Schellingian Reading of Tarkovsky's Sculpting in Time .................................. 154

4.2.1 On Freedom and Necessity in Aesthetic Creation .................................... 154

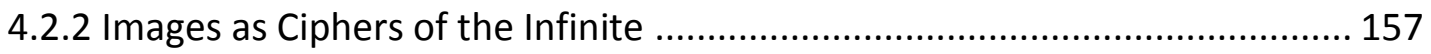

4.2.3 On the Tautegoricality of the Cinematic Image ......................................... 167

5. Aesthetic Activity as the Negation of Negation ................................................ 174

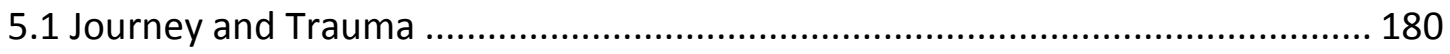

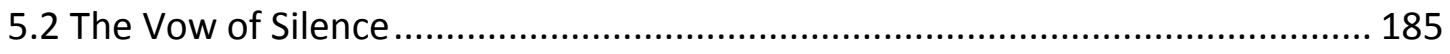

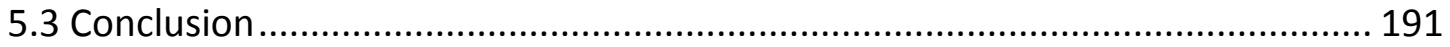

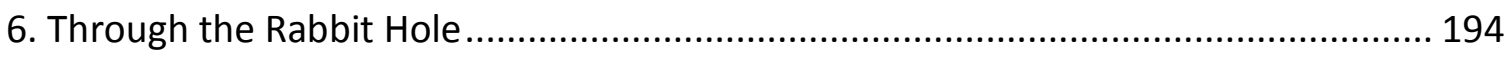

6.1 The Emergence of Space through Aesthetic Activity.................................... 196

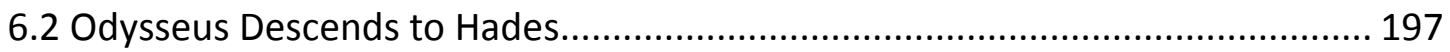

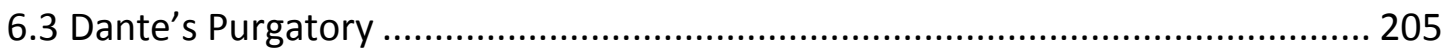

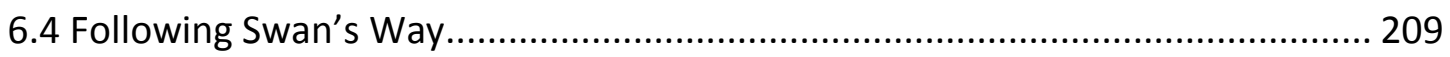


6.5 A Peak into the Tarkovskian Zone........................................................... 215

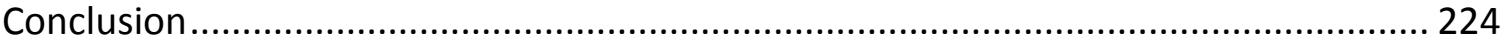

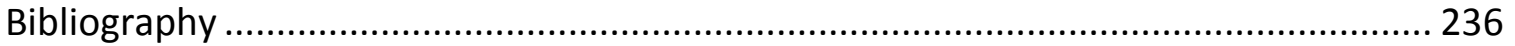




\section{Introduction}

\section{I}

The question which has always been recurring to me ever since I started my graduate studies in philosophy was precisely why philosophy? I would be lying if I said I knew the answer to that question. But if there is one thing that philosophy has taught me over the past years, first while I was taking classes and then as I worked on my Master's thesis and even later on my $\mathrm{PhD}$ dissertation is that first and foremost philosophy teaches one to ask questions. Philosophy as an autonomous discipline, I have come to realize, is futile if not accompanied by an object of reflection which would serve as a medium for the reception of the interminable questions that present themselves to the reflecting agent and would stimulate further discoveries in the respective domains of research. 
Philosophy has gone down the line of academia such that to do philosophy nowadays means to ask historical, and only such, questions about a certain concept as discussed by this or that philosopher without much relevance to our current state of affairs. Academic philosophers have confined themselves to the cell of scholarly research without paying much attention to contemporary problems, or to the big questions that should be tackled.

These recent developments have led to the isolation of philosophy, making it one of the very first victims, in humanities in general, targeted by cost cuts and restructurings which in some cases put philosophy departments on the verge of disappearance and in others on the defensive after they have been helplessly catcornered with no other solution than to stick their claws into whoever tries to question the status quo of philosophy.

The outcome of such happenstances has been ironic. The outbreak of the economic crisis which deeply affected the educational panorama has been confronted with more research into notions that have long since lost their meaning and instead of trying to find a solution for the crisis philosophy withdrew itself into the background and took a vow of silence such that its absence more often than not went unnoticed.

With that in mind, I saw in philosophy an activity that is always tied to an object of reflection. The object of reflection in the present work is film, and the philosopher Friedrich Schelling is taken as a starting point for the philosophical 
reflection. Schelling's distinction between a negative and a positive philosophy, in fact, calls for a kind of philosophical activity which would occupy itself with what could be added to the object of reflection rather than just trying to delimit the precincts of knowledge. Accordingly, with that in mind, and to ground the arguments and thereby contextualize the thesis, I will first center my focus on the late Schelling's philosophy of mythology. This dissertation does not by any means intend to defend or attack Schelling, nor is it intended to be focused on him in a scholarly sense. Throughout the chapters I will be returning very often to Schelling because the point of departure will be his positive philosophy in hopes to show that after Kant, the philosophical panorama was turned upside down in such a way that philosophy as a speculative domain, instead of being the mother of all sciences, has become the ultimate science in that it now started to speculate over empirical data (whether physical, biological or sociological or even artistic). Philosophy as the mother of all sciences was given the term of 'negative' philosophy by Schelling, and philosophy as the ultimate science of all the sciences: 'positive' philosophy.

The present research delves into 'positive' philosophy insofar as I hope to show that contemporary cinema could be one form of contemporary mythology. What is ought to be done is an analysis of the cinematography of one of the most acclaimed cinematic directors of all time: Andrei Tarkovsky. Therefore the core of the research will revolve around the abovementioned thesis by considering two of Tarkovsky's movies, more specifically Andrei Rublev and Stalker in order to argue in what way cinema could be a form of contemporary mythology and the relation of this 
field to the people as spectators. The concepts which will be referred to throughout the research are based on Schelling's late philosophy of mythology and religion.

\section{II}

"Myth is born along with human beings." 1 Its inception is traced back to the Paleolithic era; its contents would evolve by time to include feminine and masculine deities, and its subjects deal with varied issues such as the origin of the cosmos, fertility and death. ${ }^{2}$ Mythical narratives are omnipresent in different cultures; however, the focus in the present work will be on ancient Greek myth because of the special attention that would be given to the tension that surge between mythos and logos with the birth of philosophy which plays an important role in the evolution of occidental thought. ${ }^{3}$ Until the birth of philosophy in the sixth century B.C. the significant role of myths in Greek social life is perceived as a normal part of the Greek culture without being approached critically and the values of these narratives are not subject to scrutiny due to the absence of a self-consistent concept of truth. ${ }^{4}$

\footnotetext{
${ }^{1}$ Molpeceres Arnáiz, Sara, Pensar en Imágenes, Los conceptos de mito, razón y símbolo en la cultura occidental, Universidad de Murcia, Servicio de Publicaciones, 2013, p. 13.

${ }^{2}$ Ibid., p. 13.

${ }^{3}$ Colli, Giorgio, El nacimiento de la filosofía,

${ }^{4}$ Molpeceres, Arnáiz, Sara, Ibid., p. 24.
} 
However, mythical discourse would be closely examined by Plato who would refer to it as fictional or fantastical. ${ }^{5}$ Therefrom the mythical would be associated with the fictional as opposed to the real on the one hand, and the non-rational as opposing the rational, on the other hand. ${ }^{6}$ It is this strict distinction that will be of utmost interest in the present thesis. The reception and interpretation of myths throughout the different epochs have varied largely. Plato would attack the fact that mythical discourse is created by the poets and would attribute a rational and pedagogical role to the myth put forward by the philosopher (e.g. the allegory of the cave). ${ }^{7}$ During the medieval times however, the pagan myths would mostly be ignored, except for very few ones that would be adapted to concord with the Christian beliefs and teachings. ${ }^{8}$ The underlying texts would be subject to interpretation which presupposes a crucial problem for the religious thinkers of the time. The interpretation of the symbolic language of the texts was mainly allegorical, influenced by the application of Platonic philosophy through which the rhetoric is adapted to a rational thought in order to decode the text by paying close attention to the real meaning behind the language used. ${ }^{9}$ An allegorical interpretation of the biblical text or the mythical text presupposes that there is an occult esoteric meaning behind the text itself to which it remits. Thus the role of the philosopher would be to dissect it in order to unveil the rational meaning that the text holds within itself. Accordingly, prominent figures such as Thomas Aquinas would pay special attention to the problem of interpretation

\footnotetext{
${ }^{5}$ Ibid., p. 24.

${ }^{6}$ Ibid., p. 24.

${ }^{7}$ Ibid., p. 26.

${ }^{8}$ Ibid., p. 39.

${ }^{9}$ Ibid., p. 40.
} 
of the mythical narrative and would compare it to the biblical one, giving more importance to the latter which, at the end of the day, is the word of God as opposed to the former which is nothing more than a human construct lacking real meaning. ${ }^{10}$

During the Renaissance, the rediscovery of the Classics plays an important role in closing the gap between the theological and the poetical insofar as both are viewed as symbolic texts that need to be interpreted allegorically. ${ }^{11}$ Nevertheless, the interest in Greek myths would gradually fade away as human reason slowly become the protagonist, paving the way for the birth of the rational philosophy of Descartes, Spinoza and Leibniz. ${ }^{12}$ The interest in what could be measured as being the only thing on which science could be based, and the endeavor to find a universal mathematical language theorized to be the only rational language through which human beings could access and interpret reality portrayed myths as some sort of superstitious beliefs that characterized the period of infancy of human beings. Human beings can depend on their reason alone to explain different world phenomena instead of relying on fantasies to explain natural phenomena such as that of thunder, lightning or rain. This condescending view of myths will only become harsher during the age of Enlightenment especially with Kant's transcendental philosophy which seeks to find the limits of reason and the conditions of possibility of experience beyond which knowledge of the noumena is almost completely impossible.

\footnotetext{
${ }^{10}$ Ibid., p. 41.

${ }^{11}$ Ibid., p. 46.

${ }^{12}$ Ibid., p. 55.
} 
It is this one-sided view and strict rejection of human sentiments or intuitions that will be the subject of criticism by the romantics and the German idealists ${ }^{13}$ among whom is Friedrich Schelling, the philosopher to whom a great part of the present thesis will be dedicated. The romantics and the German idealists saw in mythology the solution for the absolute domination of reason. ${ }^{14}$ "This interest will materialize in different proposals and theories that will go on to form the appropriate context for the formulation and creation of the idea of new mythology. $15^{\prime \prime}$ The goal of the Romantics and the German Idealists (Herder, Schelling, Hegel, Hölderlin, Creuzer) was to highlight another kind of reason that would be synthetic as opposed to the analytic one that dominated the Enlightenment. The former, unlike the latter which seeks to only analyze specific parts of any given phenomena, would seek to establish a synthetic view of the whole with the help of both reason and sentiment in order to understand and not merely explicate a certain phenomenon. ${ }^{16}$ Hence, a revival of the poetic language rendered it a source of knowledge which cannot be accessed through logical-rational discourse because it encompasses non-rational regions proper to the imagination that reason cannot possibly get a grasp of. It is for this reason that myth and poetry were to be viewed as symbols insofar as the symbol is understood as thought based in images.17 Accordingly, different theories would be put forward, each having its own nuances, in order to interpret myths symbolically. These theories would set the grounds for the gradually rising interest in myths therefrom, and for

\footnotetext{
${ }^{13}$ Ibid., p. 115.

${ }^{14}$ Ibid., p. 115.

${ }^{15}$ Ibid., p. 115.

${ }^{16}$ Ibid., p. 121.

${ }^{17}$ Wellek, p. 54.
} 
the development of future theories on myths and their interpretations. ${ }^{18}$ Among the different philosophers and schools of thought that would dedicate parts of their research to myths are: Friedrich Nietzsche, the English anthropological school of thought, Sigmund Freud, Otto Rank, Carl Gustav Jung, Ernst Cassirer, Hans Blumenberg, hermeneutics, pragmatism and deconstruction. ${ }^{19}$

\section{III}

The romantics' call for a new mythology might have been instigated by the derision of the same by the analytical conception of reason during the epoch of Enlightenment, which treated as superstitious any form of transcendentalism in the mythology itself. Although Schelling stressed the need not only to move from the many to the one (the Absolute) through reason, but also to freely move from the one to the many through imagination and the aesthetical intuition, he had not intended to revive what was thought to be superstitious. His idea of a new mythology was to revive a long lost artistic form of creativity which, as he considers, is the ultimate form of artistic creation. This form of artistic creation has at its core poesy as a ground out of which the mythological corpus is constructed. Poesy is a free action, for a mythology generated by poesy has neither an intentional truth nor an educational

\footnotetext{
${ }^{18}$ See Molpeceres, Sara, Ibid.

${ }^{19}$ See Molpeceres, Sara, Ibid. See also Todorov Tzvetan, Teorías del símbolo, Monte Avila Editores.
} 
goal20, although this doesn't exclude mythology suggestively hinting at truth out and of itself.

The difference between ancient Greek mythology and modern mythology, says Schelling, lies in that the former symbolized nature itself rather than only historical individuals, like in the modern mythology. The ancient gods from Greek mythologies were universal potencies that maintained their eternal nature whereas the characters of the modern mythology were inspired by their epoch. ${ }^{21}$ Contrary to the 'partial symbolism' of the modern mythology, that of the 'total symbolism' springs out of nature and comes back to it, because things in nature are and signify what they are. If one were to take a second glance at cinema and what it represents, one would most likely sense an existing similarity between gods as potencies and what each and every character represents in a film. The immortal world which once hosted the gods of the Greek mythology might have been evolutionarily transformed and reproduced from epic to film. ${ }^{22}$ This transformative process did not only entail a change in the 'receptacle' of mythology, but also in the revival of transcendence which is autogenerated by the film itself rather than imposed from without, giving cinema a metaphysical dimension. Film serves as the basis of the 'return to the Absolute' not through intellectual intuition, but rather aesthetical intuition. The Russian director Andrei Tarkovsky intended to create a poetical cinema which engaged the spectator

\footnotetext{
${ }^{20}$ See Schelling, Friedrich, Historical-Critical Introduction to the Philosophy of Mythology.

${ }^{21}$ See Schelling, Ibid.

${ }^{22}$ See Irving Singer, Irving, Cinematic Myth Making, MIT Press, 2008. See also, Markus Gabriel, Gabriel, Markus and Zizek, Slavoj, Mythology, Madness and Laughter. Subjectivity in German Idealism, Continuum International Publishing Group, 2009.
} 
at a deeper level of grasp of the film, to actively engage in the continuity of the same beyond the screen.

Preliminarily, this present thesis would reach out to eventually constitute a close examination and a thorough reading of Schelling's Historical-Critical Introduction to the Philosophy of Mythology in order to grasp the ground of his call for a new mythology as the ultimate form of artistic creation. This, I hope, will serve as the basis for looking into the status quo of a possible philosophy of mythology. The objectives of the research would include reaching a thorough understanding of how mythology - as an engaging artistic creation - has been perpetually present in the collective unconscious of the societies throughout the ages; nevertheless, it is not until we start to reflect upon the possibility of a philosophy of mythology that our awareness of mythological creation retroactively comes to the surface. There is a subtle difference between engaging and actively participating in creating myths, on the one hand; and intending to create a philosophy of mythology or reflecting about the existing ones in order to come up with a new one, respectively. This conclusion would lead the research to pinpoint a difference between what could be called myth creation and the philosophy of mythology. Consequently, the conclusion would be that one cannot disengage from doing both actions at the same time: the act of actively creating and the act of reflecting upon the oeuvre to acquire a certain sense of awareness and understanding of that which one has created. This is a fluctuating process (although one that always reaches equilibrium) which drives humanity to a richer experience and an advanced process of knowledge acquisition and, thereby, evolution. 
Otherwise, art - insofar as it is a creative activity - would hence be ontologically insignificant, stripped of any possible meaning or value. For that reason, I would like to investigate the possibility that the cinema nowadays is the ultimate form of artistic creation and would therefore try to reach a possible philosophy of the cinema as the contemporary form of mythology.

In order to be able to carry out the research, the bibliography consulted is primarily that in which Schelling discusses mythology and the philosophy of mythology, on the one hand and the writings of Tarkovsky in which he presents his thoughts and contemplations on art, artistic creation and cinema on the other. Accordingly, both Schelling's Historical-Critical Introduction and Tarvkosky's Sculpting in Time will be examined in depth throughout the thesis. Many other books and articles that dealt with the topic of mythology and artistic creation similarly to the line of thought traced by Schelling have been consulted throughout the period of research. Both, mythology and cinema are too broad and rich topics so as to be covered in their entirety in a thesis; hence the bibliography is delimited to that which calls for a symbolic interpretation of mythology in the Schellingian sense. With that in mind, the main interest of the thesis is not to trace a certain historical evolution of a certain concept, but to opt for an eclectic approach to mythology as proposed by Schelling. Schelling's philosophical thought is usually divided into four different epochs during which Schelling tackles different philosophical subjects, which are Naturphilosophie, Identity Philosophy, the Philosophy of Freedom and Positive Philosophy. Although these transitions are not rigorously demarcated, and even though they don't always 
seamlessly blend into each other as all periods are characterized by certain nuances and are rather the result of Schelling's perpetual reflection on his philosophical project as a whole, one could still pinpoint at least certain similarities which constitute the core of the Schellingian thought throughout. Accordingly, the present thesis hopes to trace this certain core line of thought in hopes of taking a wider approach to mythology and the philosophy of mythology which would include the different stages of Schelling's thought instead of separating them and dealing with each one in its own right.

The itinerary of the present thesis, hence, begins with a theoretical discussion of Schelling's philosophy of mythology by paying special attention to the concept of tautegory $^{23}$ in relation to the symbolic interpretation of the mythical image. This building block will allow us to delve into the cinematic dimension, more specifically, the thought of Andrei Tarkovsky, in order to trace certain similarities between the two in relation to the image; therefrom, Tarkovsky's filmography will be closely examined in order to give concrete examples about the dynamics of the tautegorical interpretation of the cinematic image. Moreover, besides the attention that will be given to Tarkovsky's filmography, other literary texts will be used in order to show how it is that along the same line of narrative of the symbolic language - be it

\footnotetext{
${ }^{23}$ The concept of tautegory has been lately treated in more detail by Jason Wirth. This topic will be treated in more detail throughout the present work, but for more information see Wirth, Jason, Op. cit., 2015. See also Wirth, Jason, Schelling and the Future of God, Analecta Hermeneutica. No 5 (2013): The Many Faces of F.W.J. Schelling. Edited by Sean J. McGrath and G. Anthony Bruno. Analecta Hermeneutica. International Institute of Hermeneutics. http://journals.library.mun.ca/ojs/index.php/analecta/article/view/1365/995 Link accessed on March 30, 2015.
} 
mythological, literary or cinematic - is constituted by the same act of mythopoesis which expresses that which cannot be explained logically but only forms the ground for the rationalization of that which would have been expressed by the help of reason.

The thesis therefore does not pretend to delve into the Schellingian thought in a scholarly manner, but will tend to approach a very specific Schellingian idea - that of the interpretation of the symbol and the concept of tautegory - in order to apply it to a certain theoretical conception of cinema as that presented to us by Tarkovsky. On the other hand, as is the case with many researches, the present thesis has its determined scope and limitations taking into consideration more than one factor. First, the fact that many theories of interpretation of the symbol and the image have been given throughout centuries. ${ }^{24}$ Second, many schools of thought have emerged ever since cinematic art was established as an autonomous domain per se. Accordingly, on the one hand, different directors vary in views regarding the nature and the function of the cinematic domain; and on the other hand, as film started capturing the attention of different analysts and thinkers, these tended to differ regarding the interpretation of the cinematic image as well. Thus, by choosing Schelling as a philosophical basis from which to start the research followed by the theoretical and applied thought of Tarkovsky, many other schools of thought are automatically discarded. For example, the kind of cinema that Tarkovsky does couldn't be farther from Hollywood's blockbusters, which more often than not, are

\footnotetext{
${ }^{24}$ See Molpeceres, Sara, Ibid.
} 
used as an ideological gateway ${ }^{25}$ to bombard the spectators with as they go to the cinema for some entertainment. Tarkovsky opted for a different kind of cinema, one that, as he continuously stressed, shouldn't be viewed as containing interpretations beyond what the image shows. It is this kind of cinema which the present work would like to deal with in hopes of showing that, at the end of the day, a certain kind of art could be produced which would act as a ground for the ethical and the political and not the other way around.

The question of interpretation of the cinematic image in relation to Tarkovsky was brought to me as I was defending my master's thesis where it was pointed out that, in fact, Tarkovsky doesn't seek any remote significance of his cinematography because the image is all what there is. Tarkvosky stresses that the cinematic image is not symbolical, where his understanding of the symbolical includes any interpretation that presupposes a meaning which is there beyond the image. Thus, having read Schelling back then, I realised that the Schellingian approach to the mythical image which is to be viewed tautegorically is similar to that which Tarkovsky stressed time and again in relation to his films.

\footnotetext{
${ }^{25}$ On this subject see Zizek, Slavoj, The Sublime Object of Ideology, Verso, 1989. And Slavoj Zizek and Geert Lovink (Interviewer). "Reflections of Media and Politic and Cinema." in: InterCommunication. No. 14, 1995. (English). http://www.egs.edu/faculty/slavoj-zizek/articles/reflections-of-media-and-politic-andcinema/. Link accessed on March 24, 2015. See also The Pervert's Guide to Ideology, Dir. Sophie Fiennes, Perf. Slavoj Zizek, 2012, DVD.
} 
Schelling's philosophy has been reemerging in the English speaking countries in the past two decades. ${ }^{26}$ Schelling's works have been closely examined in the different works of contemporary writers such as Rainer E. Zimmermann, Iain Hamilton Grant, Jason Wirth and Bruce Matthews. ${ }^{27}$ Different concepts have been tackled including Schelling's Naturphilosophie, the philosophy of freedom and the philosophy of mythology. The present work, seeks to deal with the latter, but not from a historical perspective; however, it seeks to generate a dialogue with Schelling's thought, more specifically regarding art and mythology, seeking a more contemporary application on cinema. Accordingly, and as Jason Wirth Argues in his book Schelling's Practice of the Wild:

"Now that the basic case for both Schelling's intrinsic interest and contemporary relevance has been made, there is an opportunity to move beyond issuing reports on Schelling and merely explicating these admittedly difficult texts. We can now think with and through Schelling, accompanying him as an opportunity to explore and develop the fundamental issues at stake in his thought. One need not restrict oneself to reportage-even of the most hermeneutically savvy kind. One can also appreciate the questions that Schelling often developed in such startling and original ways as philosophical problems that are worthy in their own right. Moreover, one can insist that these are commanding issues, problems that speak to some of the great matters of human living and dying." 28

With that in mind, the present work seeks to 'think with and through Schelling' in order to call for a new interpretation of the cinematic image examining different

\footnotetext{
${ }^{26}$ Wirth, Jason, Schelling's Practice of the Wild: Time, Art and Imagination, SUNY Press, Preface.

${ }^{27}$ For a glimpse at the actuality of Schelling see: Wirth, Jason, Schelling's Contemporary Resurgence: The Dawn After the Night When All Cows Were Black,"Philosophy Compass 6/9 (2011), 585-598.

No 5 (2013): The Many Faces of F.W.J. Schelling. Edited by Sean J. McGrath and G. Anthony Bruno. Analecta Hermeneutica. International Institute of Hermeneutics. http://journals.library.mun.ca/ojs/index.php/analecta. Link accessed on March 9, 2015.

${ }^{28}$ Wirth, Jason, Op. cit., 2015.
} 
topics that Schelling tackled such as art, mythology, the philosophy of art, the philosophy of mythology and the concept of tautegory. The dialogue with Schelling's philosophy will be accompanied with concrete examples drawn from Tarkovsky's movies and his reflections about art.

\section{IV}

In the following chapters the following subjects will be treated closely:

1) Myth as poesy.

2) Film as Myth.

3) The symbolic interpretation of the image as tautegorical.

4) Aesthetics as a secular form of interpreting reality and as ground for the politicoethical.

The present work devotes the first three chapters to Schelling's conceptual framework regarding the philosophy of mythology and the symbolic interpretation, as well as the concept of tautegory. The first chapter begins with an examination of Schelling's Philosophy of Art and Historical-Critical Introduction to the Philosophy of Mythology in order to present an overview of the dynamics of artistic creation and what Schelling refers to when he talks about mythopoesis and the concept of tautegory. The key to the dynamics of artistic creation for Schelling, as it will be shown, is the dialectic interplay between the conscious and the unconscious that Schelling bases first and foremost in nature and which humans merely continuously re-create as products of nature. 
This will take us to the second chapter which shows that the important faculty that mediates the dynamics of artistic creation according to Schelling is the creative imagination. The imagination acts as a mediator between the infinite and the finite and as a synthesizer in the process of artistic creation. In order to be able to tackle the issue, we will closely examine Schelling's System of Transcendental Idealism and the Philosophy of Art. The conclusion of the first two chapters will contain different concepts that will figure throughout the present work as we move to the cinematic domain in the subsequent chapters.

The third chapter acts as a link between the first part and the second part of the thesis whereby it examines a selection of contemporary theories of mythology in order to show the relevance of mythology, and more specifically the act of mythopoesis which is perseverant throughout the different epochs. The selection of the authors is limited to those whom I think form a certain line of thought that is academically related in a way or another to the objectives of the present work. In this chapter, it will be argued first that the aesthetic, as a pre-conceptual activity, acts as a foundation for the rational, the ethical and the political; second, that myth creation is perennially present; third, that film, which according to Tarkovsky is understood as an aesthetic activity, could as well be a form of mythopoesis which acts as ground for the rational.

The fourth chapter treats Tarkovsky's conception of cinema by examining his book Sculpting in Time. It also traces similarities between the Tarkovskian conception 
of the cinematic image, the Schellingian understanding of tautegory and the symbolic interpretation of the image. Therefrom, some of Tarkovsky's movies will be tackled in order to show concrete examples of the tautegorical interpretation or what Tarkovsky would rather call images as ciphers of the infinite, to be viewed for what they are.

The fifth chapter focuses mainly and in depth on Tarkvosky's acclaimed movie Andrei Rublev which serves as a further example of how the image is a source of abundance of meaning, the ethical role of art and the dynamics of artistic creation as the negation of negation.

The sixth chapter argues for a non-theological understanding of the Schellingian conception of aesthetics and the philosophy of mythology, and argues for a substitution of the theological and the dogmatic for the aesthetic. This could be well supported by a variety of literary writers which will be covered in this chapter on the one hand and by the understanding of the very same Tarkovsky who saw in art in general and in cinema particularly an activity that prepares humans for death on the other. Instead, therefore, of a dogmatic presentation of a transcendental message that is generated from without, the chapter will argue for a continuous flux and interaction between the aesthetic and the rational, as meaning is generated from within the cinematic image and based in it - for as both Schelling and Tarkovsky argue, the image is and signifies what it is. 


\section{Philosophy of Mythology}

"For a philosophical investigation is in general every investigation that proceeds beyond the mere fact (here the existence of mythology) and inquires about the nature, the essence of mythology-while the merely scholarly or historical research is content to find and state the mythological facts. ${ }^{29 \prime}$

\subsection{Mythology as a Necessary Process}

Mythology as a whole, Schelling says, is a necessary process: a necessary process of becoming through the particularities of peoples' mythologies which, ever since a split occurred and peoples became, have been in a continuous creation and development. This means that people are necessarily creating mythology in a more or

\footnotetext{
${ }^{29}$ Schelling, F.W.J., Historical-Critical Introduction to the Philosophy of Mythology, trans. Mason Richey and Markus Zisselsberger, SUNY Press, 2007, p. 8.
} 
less continuous manner, whether consciously or unconsciously. Even during the epoch of Enlightenment, the perseverance of philosophers and scientists to disengage both fields of research of any mythological pertinence was in fact done through the creation of myths. ${ }^{30}$ The mythical discourse is beyond logical discourse; it is an unprethinkable unmediated outburst (emergence). ${ }^{31}$ That is to say, it is what drives the rational discourse onto a new level of consciousness; it is thus the condition of possibility of evolution at all. It is what Schelling called a natural religion; or in other words, mythology will perennially be present as a form of natural and necessary process through which human beings interact with their surroundings (be it nature, society or the universe). The very fact that mythology is unprethinkable hints towards assuming that there is more to mythopoesis than merely the symbolic, metaphoric, or even scientific interpretation of mythological texts. Mythology is not the result of long periods of intellectual deliberation over a certain conceptual problem or mystery which one might face. Rather, it is the result of a deeper level of unconsciousness that plays an important role in mythopoesis.

“Chaos, which only those who come later first explain as empty space or even as a coarse mixture of material elements, is a purely speculative concept, but it is not the product of a philosophy that precedes mythology, but rather of one that follows mythology, a philosophy that strives to grasp it, and for this reason proceeds through it and beyond it. Only the mythology that has arrived at its end and, from there, is

\footnotetext{
${ }^{30}$ See Wertheim, Margaret, The Pearly Gates of Cyberspace. A History of Space from Dante to the Internet, W. W. Norton, 2000.

${ }^{31}$ See Wirth, Jason, Op. cit. 2013. See also, With, Jason, Op. cit. 2015.
} 
looking back into the beginning, seeking from there to conceptualize and grasp itself, was able to place chaos at the beginning. ${ }^{32 "}$

This passage from the Historical-Critical Introduction to the Philosophy of Mythology best explains what Schelling means when he refers to mythology as the unprethinkable natural religion. The intent to conceptualize and understand what chaos really is was not preemptively realized through the creation of mythology. It was in fact an intent to grasp it ipso facto, when the mythology had already mentioned chaos as the origin of the universe. Schelling's explication of mythology as such lies en contraire to what he wrote in The Oldest Systematic Program of German Idealism in 1797 a text whose authorship is unknown but which is usually taken to be the result of cooperation between Hegel, Schelling and Hölderlin. The difference lies in that the New Mythology called for at the time was intended as a purely intentional, rational and pedagogical tool which was meant to educate the people in order to achieve a utopian state in complete harmony and unity, which would be similar to that of the ancient Greek philosophy. Nevertheless, this utopian project was later discarded by the same Schelling who leaned towards a metaphysical, religious, ontological explication of mythology which was now a universal, unintentional, unconscious and necessary process. Mythology and mythopoesis, in turn, become important factors in the evolutionary process of human beings instead of being pedagogical material to teach the posterity. Such conception entails that mythology is no more a merely passive act of transmission and preservation of myths throughout generations; rather

\footnotetext{
${ }^{32}$ Schelling, Friedrich, Op. cit., 2007, p. 35.
} 
it requires the active participation of people whether be it at the level of mythcreation or the creative and imaginative engagement in the act of engulfing the mythological corpus. That is why Schelling referred to the mythological gods not as allegorical but as tautegorical. 33 The world of the immortal gods exists in the consciousness of society. Mythological gods and heroes are present in the consciousness of the society irrespective of whether or not they really are gods or existed in the past. This tautegorical conception is crucial because now the gods and heroes are not looked at superstitiously as naïve explanations of the natural world or even naïve religious beliefs; they are now visualized as potencies lurking in the collective unconscious of any society which stimulate the imagination of its members in order to continuously create and posit new ideas consciously which will in turn be rationally understood. Therefore, if gods and heroes are the form by which these potencies were expressed previously, I will contend in a comparative chapter later in the thesis, that one way in which the important unconscious potencies widely present as our mythological archetypes manifest nowadays is as movie characters.

The New Mythology that the romantics - among them Schelling - once called and aspired for is not, therefore, as the late Schelling realized, an intentional goal to achieve; as it seems, mythology has perpetually been present with us, but it is not until we have reflected upon what could that mythology be, will we be able to determine what the new mythology, nowadays, is. The aim of the present chapter will focus on the main themes present in the late Schelling's writings (Historical-

\footnotetext{
${ }^{33}$ Ibid., p. 136.
} 
Critical Introduction to the Philosophy of Mythology, Grounding of Positive Philosophy and An Investigation into the Essence of Human Freedom) in order to analyze them and adumbrate an overall scheme that will guide us through the subsequent analysis of the chapters to come.

Reading through the above-mentioned works of the late Schelling, one can pinpoint several important ideas that reverberate throughout the Schellingian system. Mainly:

1) No-thingness as a groundless ground (Ungrund): the unprethinkable being is the indifferent ground of all what there is.

2) Will at the center of all what there is; in other words, the 'beginning' is volitional.

3) Freedom and necessity are identical.

4) The beginning has to be un-identical to itself. Hence the grounding of rationality is non-rationality.

5) There is a continuous interplay between conscious vs. unconscious creation.

6) Systems are vortexed and closed in a circuitrical sense.

My approach to Schelling's late philosophy will not be unorthodox. For what I am interested in throughout the thesis is to develop my proper viewpoint and not defend, criticize or argue with or against the aforementioned philosopher. I shall look into the points I have just mentioned focusing mainly not on Schelling's ontology and his argument for the existence of God as a prius to all that which exists, nor about the 
beginning of Creation as such; but rather the focus will be on human creation, more specifically artistic creation in its ultimate sense as mythopoesis. Our focal point, as a result, shall be the poetic artist as such. But before embarking on the journey of artistic creation, I shall discuss the role of the unconscious in artistic creation.

\subsection{Necessity and Freedom in Artistic Creation}

"§19. Necessity and Freedom are related as the unconscious and conscious. Art, therefore, is based on the identity of conscious and unconscious activity. The perfection of a work of art as such increases to the degree it expresses this identity within itself, or to the degree purpose and necessity interpenetrate one another within it. ${ }^{34}$

This small section from Schelling's The Philosophy of Art establishes a cornerstone distinction and parallelism between necessity and freedom, and unconsciousness and consciousness. Both necessity and freedom are the two sides of the same coin of indifference. On the one hand, necessity represents the real side of the potency which manifests itself through conscious Nature, whereas freedom represents the ideal side of the potency which manifests itself through the Unconscious. Both manifestations are 'reconciled' through the work of art. In other words, in the work of art, the artist is capable of reconciling the ideal and the real potencies because of the dynamics of artistic creation. Through the philosophy of art, Schelling was able to demonstrate how this dynamic works, concluding that:

\footnotetext{
${ }^{34}$ Schelling, Friedrich, The Philosophy of Art, trans. Douglas W. Scott, University of Minnesota Press, 1989, p. 31.
} 
1) Art is the organ of philosophy.

2) The artist is capable of representing objectively what the philosopher apprehends and thenceforth represents subjectively.

3) Mythology is the ultimate form of artistic creation.

The state of indifference is realized through a dialectical process which is radically different from that of Hegel. Unlike the Hegelian dialectic, the Schellingian dialectic (Erzeugungsdialektik) ${ }^{35}$ "[...] seeks to infuse the process of reasoning with a strong volitional component, so as to be capable of recovering the willing that allegedly precedes rational thought itself. 36 " Two important factors are at hand here: will and experience, the interaction and aggregation of which can be productive of truth $^{37}$. The Schellingian dialectic is, therefore, an archetype fundamental to all the systems, and not only visualized as Mind coming to the consciousness of itself. That is to say, the ontological unfolding, development and progressivity of any system is determined by the dialectic, be it the system governing the whole universe or that governing the process of artistic creation. So what is eternally being reproduced is the very act of how God artistically creates the universe, Nature constantly reproduces itself as Natura Naturans, and human beings continuously create as creative beings. Nevertheless the intrinsic characteristic of the Schellingian dialectic is that it is

\footnotetext{
${ }^{35}$ Allen Beach, Eduard, The Potencies of the God(s). Schelling's Philosophy of Mythology, SUNY Press, 1994, p. 85.

${ }^{36}$ Ibid., p. 85.

${ }^{37}$ Ibid., p. 85.
} 
inconclusive and incomplete until it is supported by historical evidence. ${ }^{38}$ Hence the need to conceptualize what was non-conceptually created, in order to phenomenologically contextualize the facts based on our frame of mind.

In the very same manner this dialectic governs the dynamic of mythopoesis. Mythological creation is unmediated insofar as it is not intentional. The intentionality, and thereby consciousness, of creation are merely a response to the unconscious constant drive of nature creating through the individual. It is as though one is caught by surprise in front of her own work, undecided whether the work produced was one's own or not. This movement is one in which ideas are constantly actualized through a creative act and 'thrown out into being' to form a corpus upon which individuals would subsequently reflect. It is almost the same process through which the 'I' reflects upon its self. There has to be a necessary split between the subject of the ' $\mathrm{I}$ ' and the object of the ' $\mathrm{I}$ ' in order for its essence to be grasped. Schelling argues that God has the ground of his existence in himself. God necessarily has the ground of his existence within himself for there is nothing outside of Him. However, the grounding of progress of human reason and intellect, of the process of mythological creation, necessarily lies outside of the human being, constituting an object of reflection for people in general because of the universality of the symbolism and metaphors suggested by the mythological discourse. It is for that reason that Schelling considers art to be the organ of philosophy, where mythology is considered to be the ultimate form of artistic creation. The universality of myths, metaphors and symbolism,

\footnotetext{
${ }^{38}$ Ibid., p. 85.
} 
present in the collective unconscious of the people, paves the way for transcendence beyond the mythological corpus. The ontological dimension of mythology lies in the space generated in between the spectator and the work itself; the space creates a mutual tension between the object and the subject taking place in the consciousness of the latter, as the former plays the role of grounding the existence of the subject. The formed space is a participative one where the subject positively engages and participates in the object of art until both dissolve within each other, in an erotic manoeuvre in which Eros and Logos are unified, the result of which is a complete dissipation of the observer (the subject as a conscious ego); the level of perception is thenceforth taken one step deeper onto the unconscious level. It is not merely a onesided channel comprising of a source and a receptor; but rather a quasi-hypnotic, oneiric state such that the subject is captivated, engaged and actively participating in the work of art. The Cartesian paradigm is rendered useless in such a case. When I am watching a movie, it's not a discrete ' $\mathrm{I}$ ' who is watching, for I cannot meddle in between the movie and myself and know for a fact that I am watching the movie and completely conscious of the fact that I am engaging in the activity of watching the movie. Apperception disintegrates by the time I am absorbed in the film being played on the screen, and one cannot pinpoint out where the space of the movie projection stops and my receptive space begins. If it were otherwise, i.e., were we conscious of the fact that we are watching the movie, we wouldn't have been able to bear watching something that is two hours long. This kind of immersion - a "let go" attitude triggers the outflow of the unconscious, allowing a vivid perception of the object of art, consequently widening the subject's scope to include a broader terrain of tacit 
knowledge. ${ }^{39}$ Therefore, we don't only visualize a movie, but we also experience it with all our senses and we perceive it at a rather unconscious level. This explains why after watching a certain movie, we seem to either forget some of the details or scenes we would've just seen; or when one is writing a critique of the same, one would eventually get a DVD copy of it pausing on each and every scene or photogram in order to analyze and criticize what one views at a 'conscious' level.

\subsection{The Unconscious as an Active Agent}

The role of the unconscious as an active agent would be best illustrated by the example of someone who is learning a new language. There is one moment after which one is able to say that one has grabbed the 'spirit' of the language and that things start making sense. To learn a language can thus be divided into two levels parallel to each other but which are reciprocal at the same time. On the one hand, there is a conscious intake of the language whereby one is learning grammar, listening skills and comprehension. The first level is intentional comprising a conscious subject who learns and is introduced to a whole new set of a language's paradigm. The subject knows she is learning a new language and has to think for a while before being able to compose a meaningful, intelligible sentence. The second level is an unintentional, unconscious one whereby the subject is acquiring and aggregating her knowledge in a crescendo. The latter level is much more important

\footnotetext{
${ }^{39}$ Berman, Morris, The Reenchantment of the World, Cornell University Press, 1981, pp. 137-140.
} 
than the first one insofar as the language is stored, along with all that which sounds logical and illogical to the consciously perceiving subject, until a certain threshold has been reached and the language smoothly and gently overflows from the person - one now has a good command of it. It suffices to observe someone who is learning a new language when he has had several alcoholic drinks to know how important the unconscious agent is. A 'tipsy' person would have lost all the social and conscious barriers which prevent him from seamlessly conversing in a language which is not his native tongue before being able to freely express himself; at this level, the importance of 'tacit knowledge' attributed to the unconscious is demonstrated.

Morris Berman, in his book The Re-enchantment of the World refers to this as mimesis ${ }^{40}$ - not in the banally re-productive sense, but through genuine involvement of oneself in the activity in order to 'grab on' and have a deeper 'conscious' state and meaning of what one is doing. Mere intellectual activity would thus not serve an economist without seeing the models applied in real life and experiencing them for herself in a concrete case. Hence the Schellingian focus on both will and experience in the overall dialectical process. This act of mimesis is a creative one for the person who is positively and actively engaging herself in each and every activity she is doing. It is an act of mimesis of the dialectical process by which everything in nature is governed, but the process itself is one's own way to authenticity. In a certain sense, each and every single person is authentic once he understands and embraces a new subject that he is learning or participating in. Authenticity is therefore configured in someone

\footnotetext{
${ }^{40}$ Berman, Morris, Op. Cit., p. 139.
} 
who is 'alive'. To be 'alive' requires one to avoid the trap of falling into a monotonous lifestyle insofar as it requires not take the outside world (nature, society, life) for granted; this entails one to be able to stretch one's positive engagement in all the fields of one's life. One form of such a livelihood is corroborated through the act of artistic creation carried out by the artist through a creative movement which starts as an intentional and conscious decision on behalf of the artist but which is carried out through, and ends by, an unconscious creative movement, the result of which is a synthesis between the real and the ideal in an objective work of art.

Schelling himself elucidates in the very beginning of Ages of the World the necessity of re-presenting one's knowledge externally in order to acquire understanding and control over ones thoughts. ${ }^{41} \mathrm{He}$, for once, alludes to the importance of contemplation as means of engulfing nature in order to grasp one's object of contemplation internally. The contemplative presence entails the intuitive apprehension of that which is external to the observer which is subsequently internalized into one's innermost depths, in the soul which for Schelling has coknowledge of the beginning of creation. To contemplate means to 'let-go' off oneself in order to embrace a wider scope of vision than one is normally accustomed to observe when one perceives intentionally. Such an activity therefore can only be carried out in an oneiric state of unconsciousness, the like of which I described earlier.

\footnotetext{
${ }^{41}$ Schelling, Friedrich, The Ages of the World, trans. Wirth, Jason M., State University of New York Press, 2000, p. 89.
} 
Nevertheless, it does not suffice to have a vision without a mediating organ. ${ }^{42}$ That's the differential, according to Schelling, between theosophy and philosophy or art. It is essential of philosophy and art to express one's visions, intuitions, ideas and perceptions externally. To externalize them allows one to reflect upon the represented work in order to gain clear and conceptual understanding of that which one was able to know immediately.

Michael Polanyi, in his book Personal-Knowledge: Towards a Post-critical Philosophy gives one example of contemplation. He talks of a student of radiology who is at first not able to identify more than the shades of ribs and the lungs on the $x-$ ray photo. The key to be 'initiated' in the world of x-rays interpretation depends on the immersion of the student in that world until after a certain amount of time one has been able to internalize and acquire all the necessary tools and expertise in order to externalize one's own knowledge all by oneself. Polanyi describes at first how the student would not be able to distinguish a rib-rupture or identify whether or not what he is seeing is actually an infection. However, by the passing of time the student is able to internalize mental images of the x-rays through the help of the professional doctors by contemplating the $\mathrm{x}$-rays, acquiring tacit knowledge, forming a whole repertoire of x-ray nuances, slowly identifying and being able to interpret the same. The externalization and thereby understanding of one's own knowledge need not only be a literal creation of literary writing for example; when the med student finally reaches the stage where he can take full responsibility of interpreting $x$-rays, this

\footnotetext{
42 Ibid., p. 89.
} 
stage means one is able to externalize one's acquired knowledge in an act of extrapolation of the same onto a unique x-ray photo present in front of him. This variance is what usually drives us to say one doctor is better than the other, insofar as the 'better' doctor is able to creatively confront an x-ray because of her continuous development and understanding of her own thoughts in relation to what he acquires intuitively through contemplation. The difference is that he has mastered her own thoughts by projecting them externally and, more importantly, by reflecting upon the myriad x-rays he was exposed to during her career.

\subsection{On the Dynamics of Artistic Creation}

In a similar manner the process of artistic creation, according to Schelling, is governed by the following dialectic:

1) Inward apprehension of the proper experience of the artist.

2) The externalization of the artist's vision.

3) The reflection upon the object of art in order to understand one's own thoughts.

"Rationality as it turns out, begins to play a role only after the knowledge has been obtained viscerally. Once the terrain is familiar, we reflect on how we got the facts and establish the methodological categories. But these categories emerge from a 
tacit network, a process of gradual comprehension so basic that they are not recognized as categories. $43^{\prime \prime}$

In other words, Morris Berman's conclusion lies in the same stream of thought as that of Schelling's most important idea: rationality can only be grounded in something different from itself, hence the important role of knowledge acquired tacitly and unconsciously, which is thereafter comprehended viscerally before being reflected upon rationally and categorized in a systematic manner. At the end of it, the process of understanding moves from concrete experience to abstract categories in an intertwining movement between form and matter, between the ideal and the real, the synthesis of which is only completed when they both are synthesized externally. The grounding of the ground in a groundless ground is Schelling's point of departure; the ground of Being is not Being itself but rather a contingent No-thingness. Schelling's insight lies at the very origin of all that there is. At all levels of creation, there is always dialectic between the existence of what is for itself (in actu) and what is potential. Both of them depend on each other, and neither of them is before the other. It is one of the most interesting insights into what is and what is not, or rather into Being and Nothingness, for nothingness is not insofar as it does not exist, but rather insofar as it is only potential. Nothingness is that which is in Being but is not being. In the same manner, the grounding of rationality cannot be anything else other than non-rationality insofar as non-rationality is that which cannot be discerned straightforwardly in a systematic manner. Non-rationality comprises a wider

\footnotetext{
${ }^{43}$ Berman, Morris, Op. cit., p. 139.
} 
panorama than that of mere rational thinking, precisely because its base is knowledge attained viscerally in a non-intentional, unconscious manner.

We encounter such an interesting example in the novel Night Train to Lisbon ${ }^{44}$ written by the philosophy professor Peter Bieri under the pseudonym Pascal Mercier. At the very beginning the protagonist of the story (Raimund Gregorius - referred to as Mundus), a teacher of classics at a grammar school in the city of Bern, Switzerland, has an encounter which will forever change his life. Mundus meets a lady in a red coat standing on the Kirchenfeld Bridge while on his way to the grammar school. As banal and mundane this happenstance might seem, this minute detail was sufficient to turn Mundus' life upside down in a way he wouldn't have imagined. The experience itself might have had nothing to do with his ensuing decisions, but more likely than not has it served as an indirect stimulator for the eventual abrupt decision to leave everything behind and embark on an odyssey of self-discovery and transformation. These kinds of experiences which instigate one to brusquely but intentionally decide to change one's life course are more often than not the result of what would have been already unconsciously sedimenting but what would eventually shine through in an external outburst paving the way for a whole new spectrum of Reality perception. The set of events line themselves up forming a wider picture in which the dots being connected would not make sense until one has connected all of them together. This fatum-like circumstance caught grips of Mundus on a day like any other. He knew it the second he met the lady in the red coat

\footnotetext{
${ }^{44}$ Mercier, Pascal, Night Train to Lisbon, trans. Barbara Harshav, Grove Press, 2008.
} 
standing on the bridge reading a paper under the rain. Later on, on the break between his classes, he decides to walk away from the grammar school leaving his stuff behind - he walked straight out without looking backwards. After ordering breakfast which he ended up not eating - at a hotel's restaurant, where Mundus had never been before, he enters a Spanish library which he frequented every now and then. The unchained reaction of events was still cascading when he approached a book recently left behind by a previous customer to find out that it was written in Portuguese. The compass of Mundus' journey was pointing in the right direction when the first paragraph, which he made the owner of the library read and translate for him, said the following - which I shall here quote at length:

"Of thousand experiences we have, we find language for one at most and even this one merely by chance and without the care it deserves. Buried under all the mute experiences are those unseen ones that give our life its form, its color, and its melody. Then, when we turn to these treasures, as archeologists of the soul, we discover how confusing they are. The subject of contemplation refuses to stand still, the words bounce off the experience and in the end, pure contradictions stand on the paper. For a long time, I thought it was a defect, something to be overcome. Today I think it's different: that recognition of the confusion is the ideal path to understanding these intimate yet enigmatic experiences. That sounds strange, even 
bizarre, I know. But ever since I have seen the issue in this light, I have the feeling of being really awake and alive for the first time. $45^{\prime \prime}$

Mundus knew at that moment that what he was passing through was similar to what the writer had written. Therefrom he decides to take a night train to Lisbon to trace the roots of the writer of this above book, A Goldsmith of Words - Amadeu de Prado. Del Prado, as Mundus later figures out, was a doctor who had helped treat one of the important figures of the Salazar regime and had decided thereafter to become part of the resistance in penitence for the decision to help the patient he had at his hands - a decision which he would forever regret. In a sense, Mundus was on the road discovering himself in this journey which in principle was intended to know more about the story of Amadeu de Prado. During his search, he had the time to contemplate and internally reflect upon his self by remembering important episodes of his past when he had to take crucial decisions and considered the possibilities of what the outcomes would have been whether he had taken a different choice. Guided by the text, he would eventually come to authentically know himself. Two things scared Mundus: falling unconscious because of dizziness, which hit him every once in a while, after which he would wake up having lost his memory, and seeing any doctor whom he didn't know because of fear the doctor would make him lose himself. This latter was precisely his preoccupation before entering a clinic recommended to him by his ophthalmologist to undergo some diagnostic examinations. "What if they find something bad? Something that would make me lose myself?" Mundus asks his

\footnotetext{
${ }^{45}$ Mercier, Pascal, Ibid., p. 17.
} 
doctor, in what might be a sign that he has finally been able to hear the music of the spheres of his soul and was finally feeling alive as though he was resurrected from the ashes of his past life. On the other hand, in one of the flashbacks into Amadeu del Prado's book, which are numerous in the novel, del Prado writes about the detachment of language from thought as he reads the newspaper, hears people talk or even as he himself talks. The conclusion he reaches is clearly a call to return to the origin and mythologize in a new language which would clearly and simply express the concreteness of the experience of oneself. The result would be an unblemished, laconic text; a language which although not totally new, but rather (still in del Prado's case) the Portuguese, is radically novel and beautiful but considered bizarre to the rest of the people. What does this mean? This call for a language which expresses one's own thoughts anew is the key idea behind the works of Schelling - the idea that mythology is a grounding ground for our perception of Reality (more on this idea later). The rationale behind it is the following: from their inception until the current time, words, at first so attached to their meaning, lose it and become empty concepts which serve for our daily life communication. Schelling points out how the concept of father and the philosophical concept of the patriarchal are derived in Hebrew from a verb which is to desire and to long for and therefore, the concept is tied to a concrete verb, a state of desire which would later on be reflected upon and would result in the derivation of the concept of father. ${ }^{46}$ It is for that reason that Schelling could almost affirm that language was itself a faded mythology. ${ }^{47}$ So whereas at first words were in

\footnotetext{
${ }^{46}$ Schelling, Friedrich, Op. Cit., 2007, p. 39.

${ }^{47}$ Ibid., p. 39.
} 
a sense existential statements of people to express their status quo, whether internally or externally, they would eventually transform into dead words that can't grasp the essence of one's own state. Hence, this need to continuously renew oneself like within a chrysalis entails the continuous search for a genuine way of creation which captures one's reality.

This idea lurks at the very core of consumer based societies which are everlastingly looking for new cell-phone models or the latest laptop or tablet to buy. The consumer would feel the necessity to dispense with a recently bought mobile for a new one not only because of the upgrades and the newly added features of the same, but also because of this tendency of people to feel the satisfaction of change in hopes that the new bought cell phone gratifies their social status inasmuch as they are trying to express an unconscious desire of revitalization. Only this time the creation is as easily bought as by going to the cell-phone store to buy one. But I diverge; the central idea is that this constant urge to reinvent oneself in hopes of being able to make a statement which clearly reflects one's status means that we are continuously creating myths which reflect our direct experience through a genuine discourse rather than by alluding to a language long dead. In the same manner, Amadeu de Prado correctly reaches the conclusion that if one is reinventing oneself through a new discourse, even though this discourse is using the same language as the previous, it would at first seem unintelligible. One such discourse which grounded a whole new Reality of our perception and formed a discourse of its own is that of cinema. The quantum leap in the domain was achieved at the premiere of Lumiere's Arrival of the 
Train which caused havoc among the spectators, for they thought that the train was going to run them over; they were stunned at the fact that the train was a moving image, and not a real one. People were thus introduced to a whole new space comprised of the motion pictures. Whereas they couldn't conceive of such a thing before, they soon after assimilated such an astonishing form of expression which captured reality and re-presented it on the projection screen. Early film directors, on their part, felt that what could best capture their inner state was this new field which was on the rise - cinema. So we can establish a point of reference before which people couldn't conceive of the cinematic space and after which they were finally able to conceive it. This novel introduction of cinematic space is denominated by Margaret Wertheim as the pearly gates of cinematic space.

In her book The Pearly Gates of Cyberspace Wertheim outstandingly recounts the historical evolution of the conception of Space from the middle ages to the invention of cyber space. Her thesis is that Reality is always more abundant than how we view it to be, and that the mere fact that after the Scientific Revolution people leaned to a more physical conception of space does not necessarily point to an absolute truth about the nature of Reality. In doing so she explains how in the middle ages people had a dualistic conception of space, the spiritual and the physical one, and that this dualistic view was consistent with the contemporary scientific theories back then. However, the events took a course different to the one Cartesianism would have liked them to take, and instead of keeping both the res cogitans and the res extensa as the basis of scientific and philosophic studies, the res extensa came to 
dominate the scientific field by the time scientists were able to explain the beginning of the universe through the theory of the big bang; hence the conception of space radically shifted from being a dualistic one to becoming a monistic one insofar as space was reduced to a mere physical notion.

Nevertheless, Wertheim introduces cyberspace as a domain which was created out of nothing as a reaction against the purely physical conception of space which was deeply rooted in the societies. At the end of the day, she argues, people became aware that something was missing, a conception of space which would not be as reductionist as the scientists would have them think, and so the inevitable outcome was the invention of cyberspace. What interests me in all this is the following: it is true that reality cannot be reduced to any one notion, because nature itself is a natura naturans. So if science gives us its own version of reality through mesmerizing details of how our bodies function, and provides us with a detailed account of the universe, this doesn't in fact prevent the existence of other spaces of conceptions which reflect a different dimension of Reality. It was in the same manner that mythology was viewed as superstition after the Enlightenment. It was indeed rendered superstitious from the point of view of (Cartesian) science itself which cannot conceive of any reality which cannot be methodically measured and explained. This notwithstanding, mythology, as I have explained, is not the result of an intentionally fabricated doctrine, but rather it reflects a way of life. In a similar way, Cartesian science has become our way of life for the past five hundred years, and in the same manner, the future generations might contemptuously consider our science superstitious, ignoring 
the fact that it is and has been our way of life. But science is not the only form through which we perceive or explain or found our Reality, and as Wertheim indicates, it would not be contradictory to have a different conception of space not because what science tells us is dubitable, but because of the abundance of Reality. Not only this, but she also points out how, more often than not, precisely artists were the driving force of scientific discoveries: "for long before men of science accepted the new vision of space, it was artists who found a way to give coherent meaning to the idea of an extended physical void.48" So what do we have at hand now? We have a space which re-presents reality and captures it in its motion. This space has widely spread in a way that it has been grounded in our collective unconscious, and has become a way of life. Cinema and film have been incorporated into our lives and have therefore become an integral part of it; hence becoming a contemporary form of myth creation for it contains all the necessary elements which have been discussed so far. But one cannot approach cinema without a philosophy of mythology.

\subsection{A Closer Look at the Schellingian Dialectic}

Philosophy, according to Schelling, is not empty, nor does it revolve around itself in a vicious circle. Philosophical activity comprises a double reflective movement; the first reflective movement is upon itself, where the subject splits itself in two (subject and object) in such a way that the subject relates to its self as an object

\footnotetext{
${ }^{48}$ Wertheim, Margaret, Op. cit., p. 105.
} 
and vice-versa. Nevertheless, the primary reflective act which the subject endures is not one tautological in nature, but rather a 'purifying' one in which the subject delimits itself and establishes the basis apart from which it will open up to a newly generated fecundity in front of it. The movement, thereby, is a critical one, where any subject posits and thinks itself, not creatively, but rather critically in order to determine its own limits and confines as the maximum diameter which belongs to itself, and to which it itself belongs. Kant set the ground of negative philosophy understood as such, as he renewably established the ground of philosophy as a reflective act on itself. He was therefore able to set the limits for a philosophy of reason which revolved around establishing the grounds of how, what and to what extent we could know. The overall Kantian scheme sufficed to revolutionize the philosophical world, and thereby radically change our views and perceptions of things. Notwithstanding, Kant got stuck at the primary reflective philosophical act, and no matter how hard he tried to leap to the consequent reflective one, his attempts failed. The failed attempts are due to the problematic which Schelling so insightfully recognized, and that is that the subject finds itself before the secondary reflective act as a part of a universal cosmic process. The subject of reflection is immanent to the overall necessary process through which the Absolute moves away from and gets back to itself. 
Creation, at the end of the day, returns to the origin - itself. 49 This process of returning to the origin is the unconscious acting through the creation of myths in the ultimate form of artistic creation. The myth itself therefore forms the object at the periphery off which humans bounce back to the center. Each myth, in its particularity, contributes to the overall process of the return of the Absolute back to itself. Taken alone, a myth could be true or false, but taken globally the overall process is always true. This means that the mythological discourse of people could be equivocated in that which it creates. The discrepancy is due to the imperfection of all that is contingent and does not exist for itself. Being is impure not in its absoluteness, but insofar as that which is characteristic of the non-being dependent on Being. This impurity is due to the identity between good and evil, and creation's ultimate goal, Schelling argues, is the separation of good from evil. Hence falseness will persist throughout human's progress until evil has been finally torn from good, and nonbeing has gone back to the center in complete harmony with Being. "One can admit that the particular in mythology is false, but that does not mean that the whole is considered in its final sense, that is, in the process. $50^{\prime \prime}$

Truth, according to Schelling, lies in the overall process of mythological creation throughout the ages. Once a mythology is taken as a form of religion in a static sense it is then converted to a false mythology.

\footnotetext{
${ }^{49}$ Schelling, Friedrich, Op. cit., 1978, p. 12.
}

${ }^{50}$ Schelling, Friedrich, Op. cit., 2007, p. 146. 
"Now, after that which has been already earlier suggested, one has to see in reality the various mythologies of the peoples only as moments, as moments of a process extending through the whole mankind. To this extent every polytheistic religion that has fixed itself in a people and has remained unchanged is, as such, a false one; that is, every polytheistic religion is indeed a false one, insofar as it is a moment exclusively positioned at that present time. But we are considering mythology precisely not in these singular moments; we are considering it in toto, in the uninterrupted interrelation, connection, coherence of its continual movement through all moments. ${ }^{51 "}$

Schelling makes a clear distinction between looking at things in their absolute movement - in toto - and looking at them in their particular moments of manifestation and development. He gives a similar example in Ages of the World explaining that both a peasant and a scholar cannot know a plant from merely seeing it because they are unable to look at the momentarily parts of its process. Therefore, there is a discontinuity between the overall process and its parts which is completed in the observer; hence the incompleteness of the dialectic until one is able to support it historically through experience. There is always a non-interrupted interaction between the Absolute and the particular. The breaking through the Absolute which results in an ecstatic moment for the philosopher or the artist is not everlasting because it forms only one moment in the process of the evolutional process of human beings. What the artist does, therefore, is re-present this ecstatic moment attained

\footnotetext{
${ }^{51}$ Ibid., p. 147.
} 
contemplatively (demarking) as precisely one moment in the in toto movement of human beings, and that is because to know the Absolute, one has to stop and reflect upon one's breakthrough thereby acquiring mastery over ones thoughts. It is precisely because of this dynamic that Reality is non-exhaustive, because to re-present Reality whether in Literature, Poetry or Film is to re-present one particular moment of the overall flow of Being. The complexity of human thought attained by reflecting over such re-presentations implies that one cannot eventually "step twice in the same river."

Volition is at the center of Being; it is volition that distinguishes the Schellingian dialectic from that of Hegel's purely conceptual one. ${ }^{52}$ The will-to is essential in the process of carrying out a creative act. It is a willing which cannot be explained, a constant yearning to a better state. Within the person, there is a split between a constant yearning for knowledge, and a constant yearning for free selfexpression and a desire to return to the origin not knowing that it has the knowledge within itself, being a co-knower from the beginning of creation. Because of this intercourse, as Schelling refers to it, the result of this dialectical system is one that it is circuitrically vortexed in a progressive manner returning each time to a state of homeostasis just like in cybernetics. The key factor to this movement is that it is dynamic in nature and once it reaches a static monotonous state it putrefies and starts to self-destruct violently. The reason behind that could be explained through an analogy: one is not able to exceed the limit capacity of a certain box to hold things in;

\footnotetext{
${ }^{52}$ Beach, Eduard Allen, Op. cit., p. 84.
} 
once the limit is achieved, and in the case of needing more space to add more things to the box, one has to get a bigger box or else the one at hand will be destroyed. Therefore, both matter and form has to constantly cope and adapt to each other because at the bottom of it both are identical.

Mythology has no beginning for it is the beginning. ${ }^{53}$ It cannot be traced down to a unique origin for it abounds in all the ancient societies such as the Nordics, Greeks, Mesopotamians, etc. To mythologize is to delve into the depth of Reality in hopes to know one's surroundings and one's place in the universe. In fact, to know one's place in the universe has been one important recurrent mythological theme all along. It is consequently, as Károly Kerényi denominates it the activity of begründen. Mythology acts as a grounding ground for Reality. It is neither intended as an explanation tool nor as a pedagogical instrument. It is the basis apart from which human beings edify their perceptions and worldview. It is therefore a way of expression triggered through an inner transformation at the individual level which therefrom spreads out to encompass the connivance of the society as a whole in a harmonious process of social transformation. What would be denominated as mythopoesis, therefore, is an intent to externalize an awareness and reflect upon this knowledge to have a proper understanding of it. It is not to our surprise that someone like Parmenides opened his poem On Nature with a mythological scene whereby he was carried by the mares on a chariot to meet the goddess. Nowadays what most

\footnotetext{
${ }^{53}$ See Jung, C.G. and Kerényi, The Science of Mythology. Essays on the Myth of the Divine Child and the Mysteries of Eleusis, trans. R.F.C. Hull, Routledge Classics, 2002.
} 
interests many of the philosophers is just the more 'important' part of the poem that deals with Being and Thought, what is and what is not. What we tend to forget, however, is that what Parmenides was trying to establish was to inform us that the goddess is speaking through him, and that he is merely a mediating agent communicating to us the message delivered by the goddess. In other words, Parmenides had been aware of Truth which he felt the compulsion to externalize and communicate. His knowledge did not sprout from a detailed analysis at the periphery of concepts; instead it sprang out from the center of Being, from the origin of the abundance which turned out to be a crucial step for a grounding ground of a new perceptual worldview for his contemporaries. As a result, were we to read Schelling's essay on freedom, we would definitely find out that what Schelling is trying to deliver is an internal awareness of how really everything came to be. Schelling is neither trying to prove anything nor argue in this particular essay, but rather it feels as though he had really seen and caught grips of what really happened at the center of all that there is; as though he was there in the groundless ground and witnessed the unfolding of the absolute through all its stages until he reached his internal self. Hence one could denominate this particular work of Schelling as his own mythology, for it expresses and delivers a world view which has been definitely fortuitous because of an unconscious outflow which emanated through Schelling himself. This work, in turn, acted as grounding ground for many a philosophical view to come.

What I have been doing so far is the following: introduce some of Schelling's most important themes which figure in his late writings in order to establish a solid 
ground for the philosophy of mythology. The conclusion which I have reached to during this process is as follows: Mythopoesis, as the ultimate form of artistic creation, is a way of expression to externalize an internal awareness of the myth creator. The creative process comprises an intercourse between a conscious intentional decision to create and an unconscious unintentional emanation which reflects a deeper individual awareness. The result of this development is an externalized mythological corpus which acts as an object of reflection for both the individual and the society. This object of art, hence, forms the organ of contemplation and reflection for the people in order to better understand itself and its reality.

The dialectic as the dynamic for the evolution of human thought entails us, as previously said, thinking and reflecting about the bountiful work of art created. This is undertaken through the contemplation of the produced object of art. For as Schelling said, philosophy is an inquiry beyond the mere-fact-of, which means that to philosophize is to inquire about the nature of the subject one is trying to reflect upon. The subject matter of this thesis is an inquiry into the nature of film as a generator of mythology. But before delving into film proper, I would like to highlight in the coming chapter the important role which imagination plays as a mediator and as the space of the intercourse between the unconscious and consciousness. 


\section{Imagination as a Mediator between the Infinite and}

\section{the Finite}

The gods, according to Schelling, that are constituted within the human consciousness are not modifications or permutations of the Absolute, but rather potencies that represent ideas in the human unconscious. ${ }^{54}$ They are posited in the human consciousness after being objectified, represented in the respective mythologies (as the ultimate form of artistic creation). These ideas are infinite by nature, and as soon as they are represented they allude to no other thing than themselves; i.e., they are tautegorical, as Schelling calls them. Moreover, Schelling maintains that there is a universal force of the unconscious which acts through the

\footnotetext{
${ }^{54}$ See for example Schelling, Friedrich, On the Deities of Samothrace, Op. cit.
} 
particular unconscious of the individuals, and therefrom it manifests itself objectively in the work of art. But how would the Unconscious force manifest itself consciously?

I contend that the mediating faculty between the Unconscious and consciousness, between the Noumenal and the Phenomenal is creative imagination. Hence, in this chapter, I will tackle the subject of creative imagination in order to demonstrate how it is that the artist is able to break through to the Noumenal and thereby express that which he is aware of in an externalized work of art. In order to achieve said objective, I will at first discuss the active role of the observer in the creation of the phenomenal world as indicated by quantum physics. Then I will discuss Schelling's dynamics of synthesizing the Real and the Ideal through the artist in the work of art; in the last section of the chapter I will give one example for the importance of creative imagination in the Steppenwolf of Hermann Hesse.

\subsection{The Subject of Cognizance Re-Introduced}

In The Tarner Lectures delivered at Trinity College, Cambridge, in October 1956, under the title of Mind and Matter, Erwin Schrödinger argues that the crucial mistake that science committed since the scientific revolution was that it excluded the 
Subject of Cognizance without being aware of it. ${ }^{55}$ What this entailed for the scientific domain was the following two antinomies:

1) Through this conception we obtained an insipid worldview insofar as the ' $\mathrm{I}$ ' is disregarded.

2) The puzzling problem of the 'mind' is raised but cannot be tackled directly for now everything is only and merely reduced to the neural activity of the brain. The ' $\mathrm{I}$ ' which perceives is left out of the frame.

This simple conception of the 'I perceive' is mind-blowing because at first hand the ultimate goal of neuro-biology nowadays is to find consciousness inside the brain. However, neither Schrödinger nor quantum science in general would agree with such a contention. Schrödinger points this out clearly when in the chapter on The Oneness of the Mind he affirms that the antinomy of the mind surges precisely because the ' $\mathrm{I}$ ' is the world picture. The 'ego' as he denominates it is identical with the whole, and therefore it cannot be contained as part of it, which is why the famous paradox arises: that of how the One can become many and vice-versa, and whether or not my perceptions are identical to those of other people, and whether or not what we perceive is merely an object of our representation or it is the thing in itself. Notwithstanding, these questions are rendered useless according to Schrödinger because they arise out of the arithmetical paradox - "the many conscious egos from

\footnotetext{
${ }^{55}$ Schrödinger, Erwin, What is Life? The Physical Aspect of the Living Cell; Mind and Matter, Cambridge University Press, 2012, p. 118.
} 
whose mental experiences the one world is constituted.56" He goes on to add that the solution to the arithmetical paradox would resolve once and for all such kind of questions.

The solution to which Schrödinger hints is the oneness of the mind. In doing so he refers to Aldous Huxley's Perennial Philosophy in which the latter recollects quotes from different philosophers and mystics from both the east and the west showing the similarity that reverberates throughout the different schools of thought and traditions. Hence, Schrödinger calls for abolishment of the Principle of Objectivation (whereby the Subject of Cognizance is excluded from the scientific worldview) by widening the western perspective through a cautious and deliberate integration of some important eastern philosophical concepts into it.

Were we to scrutinize Schrödinger's call for dismantling of the Principle of Objectivation, by hinting for the unity of the mind, we would find a striking similarity between his thought and that of Schelling. For the Oneness of mind is what Schelling refers to as the Absolute which is One. In Philosophical Investigations into the Essence of Human Freedom Schelling puts forth his account of the beginning first by emphasizing that God (Absolute) has the ground of his existence within himself (see the previous chapter), and how the eternal entities, which have always been in the groundless unground (ungrund), come to be what they always have been in their eternal nature through the unfolding of the universe into two sides of one coin: the

\footnotetext{
${ }^{56}$ Ibid., p. 128.
} 
Ideal and the Real (spirit/mind, and nature). The evolution is circuitrical because this system, at the end of the day, returns to itself in order to be complete. However, through the unfolding of the Absolute, each and every entity which is granted Being comes to be what it has always been since eternity; and through this process evil is separated from goodness as the Absolute comes to full awareness of itself as it returns back to itself again. The distinction of this dialectic from the Hegelian one is that Schelling maintains the personal-God in contrast to the conceptual God in the Hegelian system. In the very same manner, Schrödinger explains that in a worldview where the Subject of Cognizance is excluded, no matter how immediate one's experience of God is, it will never be granted reality due to the physical conception of reality prompted by science. Hence anything outside the domain of space-time is avoided.

To think within these terms might, however, be erroneous because what is left out is a crucial step in how we tend to perceive the outer world. The Principle of Objectivation hints towards the existence of a passively perceiving subject and a perceived object. This, Schrödinger affirms, create an impasse for from this strict dichotomy arises the famous onto-epistemic problem. Nonetheless, and ironically so, the quantum theory of measurement points towards the active participation of the conscious 'subject'. In his book Nature Loves to Hide, Shimon Malin highlights the problem of western science with respect to the Principle of Objectivation, and attempts throughout the book to provide what could be the basis of a new paradigm shift which would pave the way for the embracement of the Subject of Cognizance in 
the overall scheme of the interpretation of Reality. Malin explains how after the introduction of quantum science, absolute realism disintegrates automatically, because what we perceive is not the object which is out there, but our mental construct of it. This mental construct is, moreover, not passive, but rather it is first and foremost a creative one. Hence, the role of the perceiving subject is primary in the perception of the 'outer-world'. Malin gives the example of how the Swiss psychologist Jean Piaget demonstrated that during the first three years of their lives, children actually acquire and develop the sense of three-dimensions, whereas before fully acquiring this ability they would perceive reality in two dimensions only. Therefore, Malin concludes that perception is actually a creative mental construct whereby the individual is constantly and actively participating in the creation of the phenomenal world. However, from the abovementioned examples, we realize how important the role of the ' $\mathrm{I}$ ' in the active construction of the phenomenal from the noumenal stance. The creative faculty which allows for such a mental construct, I contend is that of creative imagination.

The puzzling nature of quantum science, whether be it Heisenberg's uncertainty principle or the wave-particle dual nature of light (or electrons) led Niels Bohr to adhere to what he called the complementarity principle. ${ }^{57}$ The effect of such a conception is that it establishes a complementary relationship between two apparently contradictory descriptions of natural phenomena. In other words, whether light is perceived as a wave or a particle depends on the perspective, situation and

\footnotetext{
${ }^{57}$ Malin, Shimon, Nature Loves to Hide, World Scientific Publishing, 2012, pp. 25-40.
} 
circumstance from which we attribute to it one characteristic or another. Consequently such a complementarity view confirms Wertheim's thesis which I mentioned in the previous chapter: it is not contradictory to have different perceptions of Reality for Reality is not exhaustive nor is it reducible to any one view. Hence, this step generates space for more than one conception of Reality including that of science - the important issue at hand is that Reality is not reducible to merely scientific knowledge, but is available to more than one conception including that of literature, art, philosophy, etc...

In a different context, Pierre Hadot outstandingly exposes this problem in his book The Veil of Isis ${ }^{58}$ where he distinguishes between the Orphic (contemplative) and the Promethean (scientific) approach to Reality. So before moving on to Schelling, I will explain the difference between the Orphic and the Promethean approach in order to establish one crucial difference which Schelling emphasizes: that of aesthetic vs. intellectual intuition whereby the former could be related to the Orphic approach and the latter to the Promethean approach; the synthesis of which is, as I will explain towards the end of this chapter, attained through the creative imagination of the ' $\mathrm{I}$ '.

\footnotetext{
${ }^{58}$ Hadot, Pierre, The Veil of Isis: An Essay on the History of the Idea of Nature, trans. Michael Chase, Belknap Press, 2008.
} 


\subsection{On the Orphic and Promethean approaches to Knowledge}

Pierre Hadot, in his book The Veil of Isis, traces the evolution of the human approach to knowledge throughout the centuries within the different schools of thought. He explains how it was possible to leave out the 'spiritual' side of nature and human beings after Plato's strict distinction between the world of Ideas and physical reality. Therefrom, and after the Church adopted this strict dichotomy, it wasn't far away from being easily implemented making thereby what is related to the mind a matter for the religions to study, and the physical reality that of scientists to explore. It was however not until Descarte's cogito that this dichotomy cemented the breach and gave a real value to only what was possible to measure. Moreover, Hadot draws the distinction between what he denominates as the Orphic approach to nature, which comprises contemplation and the immersion of oneself in nature to intuitively unveil its mysteries through a direct form of 'visceral' knowledge. This form of knowledge could be compared to the tacit knowledge discussed in the previous chapter. On the other hand, the other approach to nature is what Hadot refers to as the Promethean one whereby the secrets of nature are 'violently' excavated from within the depths of nature through experimentation - for example Francis Bacon's conviction that one has to actively extract knowledge from nature by manipulating it. The difference between the two kinds of approaches lies in the nature of knowledge each ultimately seeks. For example, the contemplative approach 
to nature, in order to experience the 'ineffable' by breaking through to the Noumenal, seeks a knowledge which is beyond the space-time framework (i.e. Universal) - it is directly related to the Subject of Cognizance after which the individual is certain of the experience one would have just had. Therefore, what this approach seeks is to break through to the infinite and subsequently to represent the infinite in the finite. On the other hand, the Promethean approach moves the other way around from the finite to the infinite through experimentation, logical reasoning and analysis in order to intuit the meaning behind the corpus that one would be contemplating. Alas, not only did most scientists and philosophers get stuck in the Promethean approach rendering the Orphic approach to knowledge useless, they also left aside the quantum leap which one has to do in order to make sense of the results one obtains from one's available research. In other words, more often than not, these scientists and philosophers are not able to make the quantum leap from the available results (finite) to the Absolute (infinite) in order to make sense of what they have before them, but are rather stuck in detailed analysis which would thereby branch into yet further detailed and minute analysis of the same subject. This problem arises because, as said in the previous section, the Subject of Cognizance is left out of the whole framework.

Likewise, Morris Berman in The Re-enchantment of the World stresses the difference which Gregory Bateson establishes between Analogue and Digital knowledge insofar as the former is associated with a holistic knowledge which cannot be understood rationally, while the latter form of knowledge is the result of 
discursive reasoning, which can only be understood logically. Both forms of knowledge include clichés which are consolidated in the activities of our everyday life. The making of the quotidian life clichés ensues from the very fact that original experiences at the center of being are stripped off their meaning and are converted into insipid concepts dis-imbued from any deep or creative meaning (see the example given in the previous chapter in relation to Schelling's idea of how the original verb is subsequently converted into mere concept); this is what everyday language consists of. We are able to relate to each other and communicate in our quotidian life because of the notion of 'redundancy' on which cybernetic theory is based.59 Clichés acquired at the Digital level would include the understanding we infer from gestures or tones of voices of those around us. We would directly know that even if someone says 'What a great idea' in an ironic tone of voice that what he actually meant was that the idea was not great at all. However, we are able to enjoy an authentic music performance or a literary work because the redundancy is broken in communication; for there will always be parts of our tacit knowledge that could not be made conscious or reduced to a mere cliché. Thus the experience of the ineffable is the result of deep unconscious interaction of tacit knowledge which could never be made explicit nor expressed insipidly in a well-organized rational discourse. Berman compares this 'uncertainty' in what to expect to the uncertainty principle in quantum science. And precisely because our knowledge could never be reduced to a merely redundant form of communication that we are able to continuously creatively create and propel ourselves to a deeper sense of awareness of ourselves and of the universe

\footnotetext{
${ }^{59}$ Morris Berman, Op. cit., p. 249.
} 
around us. This in turn does not mean that the mysteries around us are solved once and for all, quite the contrary; it means that we are able to achieve a more complicated system (or paradigm) out of which surge more mysteries to be contemplated, reflected upon, experienced - the knowledge of which we would later on externalize in the different forms of expression available: science, art, philosophy. Thus no matter how evolved we think we are, there will always be room to express Reality in a deeper sense because of the uncertainty of what it is that we are able to unveil at the Noumenal level!

Consequently, the gap which is established between the Digital and the Analogue forms of knowledge could be compared to the gap between the Orphic and the Promethean approaches to Reality. To resolve this gap, as said in the previous section, we have to re-introduce the Subject of Cognizance in the overall framework of our paradigm; not only this, but to accept Bohr's complementarity view insofar as both approaches do not contradict each other but are rather indeed complementary and according to Schelling they are all the more so reciprocal in that at the bottom of it they inevitably depend on each other in the overall progress of any system. Consequently, upon accepting the re-introduction of the Subject of Cognizance in the overall picture, then the synthesis of both approaches can only be sustained in the ego, in the agent of the ' $\mathrm{I}$ '. It is, thus, thanks to the creative imagination that the ' $\mathrm{I}$ ' is able to transcend the finite into the infinite and to move freely from the infinite to the finite making the quantum leap from one side to the other, in both directions, through the creative faculty of imagination (more on the topic later). 
Let's take the example of Michaelangelo Antonioni's Blow-up. Throughout the movie, the protagonist (played by David Hemmings), a photographer trying to capture an authentic photograph, is obviously stuck in what could be understood as the 'photographer's block'. He roams the streets in search of something authentic which would add meaning to it all. We see him once taking pictures of a park, and eventually of two lovers that are kissing - the girl takes notice of him and follows him in order to get the negative roll but he ends up giving her a different one. The episodes in the movie slowly pave the way to the key moment in which the photographer, while developing the photos he had taken in the afternoon, sees what could be a dead body lying on the floor, and what could be a gun pointed at the body protruding from within the bushes. He proceeds by developing more than one zoomed copy of the different pictures in hopes of being able to finally have an evidence of the factuality of the crime and the dead body. Later at night, he visits the same park and to his surprise, he encounters a corpse lying by the bushes; not having his camera on him and scarified of the whole situation, he is forced to leave the park and subsequently attends a drug party where he meets his agent whom he wants to accompany him as a witness to the existence of the corpse in the park. However, unexpectedly, the protagonist finds himself waking up in the same house where the party was held. He revisits the park to find the body gone. In the closing sequence of the film, the photographer watches a mimed tennis match between two players before the eyes of the rest of the mime group who are actively interacting with the events of the mimed match. Dazzled, unable to comprehend how the group is able to 
actively participate in the mime, he accidentally finds himself in an awkward situation whereby the 'imaginary tennis ball' drops right next to him. In a sudden transformation, though, he finds himself 'absorbed' into the match, picks up the 'imaginary' ball and throws it back into the tennis field; thereafter, we hear the sounds of the ball bouncing off the tennis raquette, as the image fades away towards the end of the movie.

We can look at what the photographer experiences in view of the abovementioned distinction between Digital and Analogue knowledge. It is clear from the beginning on that the photographer is unable to 'latch onto' a creative experience in order to 'produce' an authentic work of art; which is why, at the antique store, he is fascinated by the propeller which he eventually ends up buying and subsequently hangs on the wall in his studio. He is looking for an event that would 'propel' him into the future by breaking out of the 'block' in which he encounters himself to be. For a second, he thinks that this experience will be prompted to him merely through a detailed analysis of the photographs of the park hanging on his wall - where, he ends up suspecting, that a crime took place. To 'grab-on' the real value of the event, he ends up zooming the available pictures, and is eventually trapped in the minute details to the extent that reality becomes very blurry making him unable to distinguish between what is and what is not real. Not only this, but he also doubts his senses when, at night, he encounters the dead body lying on the grass of the park. He is quite sure that no one is going to attribute any value to his knowledge had he not a 'proof'. Thus he ends up doubting his personal experience as 
well. It is not until towards the end of the movie that he is able to break free when he is finally able to break to the Noumenal and participate with the mime group in the 'imaginary' tennis match being played to the extent that he now is able to hear the sound of the bouncing of the ball! The movie can be perfectly interpreted from within the boundaries of quantum science. For what we perceive is not the thing in itself but rather our mental construction of it. Thus it was not until the photographer was finally able to include himself in the overall picture that he could not doubt his experiences anymore. The apparent three distinct levels of experience (analytical, perceptual, noumenal) are not contradictory but rather complementary, for each takes occasion at a different levels, all of which, however, are creatively synthesized by the creative imagination of the ego, and in expressing them one is eventually using different kinds of symbolism and metaphor - in the very same sense, thus, the artist, according to Schelling, is able to Unconsciously re-present the Infinite (Noumenal) in the finite work of art.

\subsection{Corollary: From Space and Time to Atemporality}

According to Kant, Space and Time are both necessary conditions for the very possibility of human experience. That is to say, transcendental time and space allow us to intuit objects since we have apriori forms of space and time through which we can actually have any experience at all. 
Rather than only being forms of perception, it might be helpful instead to think of space and time in terms of yet other categories in the Kantian sense. For otherwise we wouldn't have been able to identify that this experience is in fact in space and time. The existence of apriori forms of perception would not allow us to reflect upon them in order to intuit and thereby understand these forms. In other words, and to give another example, I cannot know that I am without some form of self-reflexivity, or by the help of an 'other.' Here we can digress into the psychoanalytical theories of the formation of the self (see Lacan's mirror stage for example). Nevertheless, I will stick to the main argument, which is that in order to know or have even the vaguest idea about what could be called time or space, there actually has to exist some sort of, according to Kant's system, conceptual representation of space and time to which we can therefore refer as such. Our experiences are in space and time, but had there not been the categories of space and time, we wouldn't have been able to understand what space and time mean.

That is to say, the form of space and time is not a cognitive experience but rather a positive re-affirmative experience. For example, when we talk about different kinds of time: internal, external, biological, social and psychological; what we are doing is re-affirming the category of time through our experience. 
The outside world in its absolute is beyond our perception, and therefore it's beyond space and time. ${ }^{60}$ We can only perceive according to our sensory organs, by mapping these sensorial data in the brain and then understanding and interpreting what we have perceived. Hence, this interpretation, by the very fact that space and time are categories, would allow us to understand that this sensorial data was intuited in space and time.

Kant's stance, nevertheless, was contrary to the possibility of knowing the thing in itself. Since our perception is delimited or determined by space and time as the conditions of possibility, we cannot consequently break-through to the 'outer world'. This means that we cannot know or speculate about the thing in itself, which is outside, beyond space and time. Notwithstanding, when we assent to the proposition that space and time are in fact categories of the understanding rather than forms of perception, we might actually be paving the way for another form of expression - or, rather, revival of another form of expression - by breaking into the outer world through aesthetic intuition as proposed by Schelling. This means that only an atemporal language could actually be used to talk about the outer world, through metaphor and symbolism. ${ }^{61}$ This is, at its core, what Schelling's positive philosophy was proposing. The Romantics' call for a new mythology could be very well seen in that respect, because the domain of mythology is the infinite and the eternal. It allows one to speculate - not superstitiously, but rather according to

\footnotetext{
${ }^{60}$ Rainer E. Zimmerman, Beyond the Physics of Logic: Aspects of Transcendental Materialism or URAM in a Modern View, 2001.

${ }^{61}$ See Zimmermann, Rainer, Op. cit., 2001.
} 
scientific, philosophical and historical accounts - in order to reformulate, create and re-present the world in forms of metaphors and symbolisms which allow the human being to have a grasp of and thereby be able to embrace the absolute.

The consequences of this would then be migration of the domain of jeux (understood according to the French definition of games, which integrates a perspective wider than that of the mere entertaining ones) from pure logical games within the limitation, into an infinite series of possibilities and interpretations in the field of the absolute, into re-presenting it in the finite through the diverse forms of expression: philosophy, art, literature, film, etc.

\subsection{Creative Imagination: A Synthesis of Intellectual and Aesthetic Intuition}

Throughout this chapter I have traced a common line of thought between quantum science and philosophy. We have seen how both agree, from the given examples of Schrödinger, Bohr, Malin, Pierre Hadot and Morris Berman on the necessity of looking at the different conceptions of Reality as complementary to rather than opposing each other. How does all this relate to Schelling's synthesis of the Real and the Ideal; Intellectual and Aesthetic Intuition? 
In the System of Transcendental Idealism we see how Schelling is able to explain the movement of philosophy from the activity of the ' $\mathrm{I}$ ' through the intellectual intuition to construct the objective world outside, although only subjectively. Philosophy is able to achieve such unity through the activity of the ' $\mathrm{I}$ ' as a reflective agent, but all that the philosophy is able to produce is what could be referred to as 'discursive' reasoning inasmuch as the philosopher expresses his awareness through argumentation and logical reasoning using language; nevertheless, Schelling affirms time and again, that such discursive reasoning will always be subjective for it will always be the result of a subjective awareness on the philosopher's part. So what philosophy does, at the end of the day, is give a subjective account of the respective philosophers insofar as they are able to transcend the mechanism of knowing and the concept of knowing as an act and continuously create while perpetually self-intuiting this action. ${ }^{62}$ On the other hand, what the philosopher is able to achieve subjectively, the artist is able to achieve objectively through the externalized work of art, which is universal, through the aesthetic intuition. ${ }^{63}$

Moreover, Schelling highlights the importance of the object of art as the organon of philosophy. Thus, were we to hierarchize the dynamics of the Schellingian dialectic, the diagram would be as follows: The Absolute $\rightarrow$ Aesthetic intuition $\rightarrow$ Object of Art $\rightarrow$ Intellectual Intuition $\rightarrow$ Philosophical Corpus (discursive reasoning.) This diagram, however, is not linear, but rather comprises a parallel and retrospective

${ }^{62}$ Schelling Friedrich, Op. Cit., 1978, p. 14.

${ }^{63}$ See Ibid. 
movement between both intuitions at the same time, for both of them are present in the artist and the philosopher, with each having the ability to better express their knowledge through the one or the other. On the one hand, through aesthetic intuition one is able to break through the Noumenal, and on the other hand, through the intellectual intuition one is able to perceive and thereby build up the phenomenal. The synthesis of both is very fine, and would be achieved in the ego's creative imagination. The facile ability we have to freely move from the Absolute (One) to the many and vice versa could not be achieved otherwise than in the synthesis of the creative (productive) faculty through which we are able to perceive the phenomenal. To put it in Schelling's words: “Thus philosophy depends as much as art does on the productive capacity, and the difference between them rests merely on the different direction taken by the productive force. For whereas in art the production is directed outwards, so as to reflect the unknown by means of products, philosophical production is directed immediately inwards, so as to reflect it in intellectual intuition. ${ }^{64 \prime}$

Similarly, we are able to grasp the ontological work of art through the aesthetic intuition, and the logical work of philosophy or science through the intellectual intuition. The former would be identified as a Universal knowledge insofar as people are able to relate to it through the collective unconscious precisely because the work of art is propelled to completion through the unconscious driving force of nature; and through the latter people are able to relate to it subjectively

\footnotetext{
${ }^{64}$ Ibid., p. 14.
} 
through an inner awareness, self-reflection and intuition of that which is prompted through the discursive language. Immersed in both activities, as concluded above, is the faculty of creative imagination which allows the seamless movement from the Noumenal (infinite and eternal, lying beyond space-time) and the Phenomenal (finite, perceived in space-time). Also, as indicated previously, since the experience of the Noumenal is one outside the frame of space-time, the expression of such knowledge can only be achieved through an atemporal language, which time and again, Schelling maintains, is a creation artistic in nature, which in its ultimate poetic form is mythology - the investigation of which later on will be dedicated to the ambit of film and cinema. One literary example which could be symptomatic to what Schelling is referring to is the novel Steppenwolf by Hermann Hesse. The reason why I have chosen this novel is because it encompasses more than one subject I have approached in this and the previous chapter (Jungian residues, creative imagination, discursive reasoning, the experience of the noumenal/phenomenal), and it beautifully demonstrates how Hesse created a mythology of his own (whether consciously or unconsciously). It also serves as a bridge between this chapter and the next one the subject of which will be the presence of mythology in our quotidian life. 


\subsection{Steppenwolf: Mythology and the Creative Imagination}

In the last section of this chapter, I will exclusively limit myself to delineate the emergence of mythology in the Steppenwolf.65 To start with, the division of the novel into more than one account is indicative of the different levels of Reality at which things take place and these are:

1) The preface: An 'objective' account of the Steppenwolf

2) The treatise on the Steppenwolf: a discursive account of the Steppenwolf

3) The personal experience of the Steppenwolf related in a mythological sense

In search of the absolute, one faces the duality that is the outcome of apperception of the mind involved in understanding the different phenomena of the world. The individual is then dragged into deep analysis in order to fully comprehend what there is around him: objects of perception, experience. The conscious mind of the individual perceives the outer world and analyzes it to build up his point of view - a subjective point of view maintained in his identity. The

\footnotetext{
${ }^{65}$ Hesse, Hermann, Steppenwolf, trans. Basil Creighton, Penguin Books, 2001.
} 
"multiplicity-unity" 66 of time of Bergson's An Introduction to Metaphysics thus plays an important role in the individual's life, because when one becomes conscious of himself, as a result of an existential state, for example, where one starts pondering questions about life and how one should be living, one starts to think about and have a unique understanding of the different concepts and build them up to form his unique identity. These concepts are in a single moment founded as the ground concept that is the base of all that there is in the individual's inner self. The first idea to appear after the first shock, first realization of the moment that flashes within the self, allows the individual to recall his past in a single moment after which he realizes that he is conscious of himself and forms the first ground concept related to his individuality. Harry Haller's (the protagonist of the novel) existential crisis very much concurs with the abovementioned. He is not only existentially alienated from the society, having a convoluted love/hate relation with its bourgeois counterpart, but he is also alienated from himself in a forever complicated intercourse between his inner desires of which he is not fully conscious (the part which he refers to as the Steppenwolf), and his outer self, his human consciousness (the 'human' part of him).

In the Treatise on the Steppenwolf Hesse hints that all the characters in the novel are merely manifold of the spirit of the same character - mainly Harry Haller. Because what the self-transformation of Haller throughout the novel will lead to is the full acceptance of himself as a multitude of spirits all to be found in one body - his

\footnotetext{
${ }^{66}$ Bergson, Henry, An Introduction to Metaphysics, trans. T.E. Hulme, Palgrave McMillan, 2007, p.
} 34. 
body. "And in modern times there are poetic creations, in which, behind the veil of a concern with individuality and character that is scarcely, indeed, in the author's mind, the motive is to present a manifold activity of the soul. Whoever wishes to recognize this must resolve once and for all not to regard the characters of such creation as separate beings, but as the various facets and aspects of a higher unity, in my opinion, of the poet's soul. ${ }^{67 "}$

At the beginning of the novel Harry Haller in search for an epiphany, or in other words, in search to break to the Noumenal, which in the novel is represented by the world of the Immortals 'governed' by Mozart. The search is stimulated, as previously explained, by the sense of revival and renewal to go back to the center of being and start anew. This crisis, no wonder, arose in Hermann Hesse in times of turmoil whether at the personal level, or at the social level (the World War I, the rising sense of nationalism, and then the political tumult during the Weimar Republic); but these instigations to look for change resulted in a universal poetic mythological fabric, which can be extrapolated to all the epochs of human life; not only this but could also be extrapolated to the evolutional dialectic of humanity in its entirety. Therefore, the character of Harry Haller transcends all the boundaries of space-time to depict a universal dialectic not attached to any one experience at all and here lies the difference between the subjectivity of philosophy in opposition to the universal objectivity of the art.

\footnotetext{
${ }^{67}$ Hesse, Hermann, Op. cit., pp. 72-73.
} 
Haller explains his moments of joy, the experience of the Noumenal as follows: "It was a concert of lovely music. After two or three notes of the piano the door was opened all of a sudden to the other world. I sped through heaven and saw God at work. I suffered holy pains. I dropped all my defenses and was afraid of nothing in the world. I accepted all things and to all things I gave up my heart [...] Sometimes for a minute or two I saw it clearly, threading my life like a divine and golden track." Notwithstanding, it was a while before he was able to see the walls dropped before him so that he would be enabled to see God at work. But it will not be too long before he was going to enter the magical theatre, which is not for anybody, but for madmen only. What Haller tries to explain is that one has no control over when or where such ineffable experience clutches the person. The main key towards it is nevertheless known: it is contemplation, be it of objects of art, literary texts, nature, etc. Thus, while wandering down the streets at night Haller sees what appears to be a sign of an old wall between a church and a hospital. He is unable to discern the letters of the sign at first, but after a while it becomes clear to him that it says: Magic Theatre, Entrance not for everybody. Then after a while he could also read the rest of the sign through the reflections of the scattered letters on the asphalt in front of him saying: For mad men only. This incident was enough to shock him and make him realize that it was similar to previous joyous experiences he had undergone. Then, not giving this happenstance any importance, he moves to sit in the corner of a bar, to later on go back to the old side of town where he finds the old wall again, only this time a strange vendor shows up and hands him a book titled Treatise on the Steppenwolf. Therefrom, different episodes in the novel take place as new characters 
beautifully pop-up in order to 'help' the Steppenwolf acquire deeper self-knowledge in a double sided movement intertwining between the dichotomies of the body and spirit, subject and object. Among these characters are Hermine (the prostitute), Maria, and the saxophonist Pablo. Haller meets Hermine at first at a dance, and thereafter Hermine introduces Haller to her friends Maria and Pablo. Many are the papers and analyses which have been written on the relation of Hermine to Haller, explaining how in the Jungian psychology, Hermine would be Harry Haller's anima whom he mirrors and who slowly drives the repressed emotions of the Steppenwolf, of which he is unconscious, to the surface. ${ }^{68}$ For this reason I will not delve into a detailed analysis of the characters; it is beyond the scope of this thesis.

Towards the end of the novel, when Haller is unable to break free from the strict human/Steppenwolf duality by failing to embrace Hermine and in contrast tries to kill her, he is confronted with Mozart who enters the room in the Magic Theater wearing a modern dress in order to inform him of his failure: that he couldn't realize how important it was to listen to the music of life or the importance of laughter:

"So, you see, you will have to learn to listen to more of the radio of the music of life. It'll do you good. You are uncommonly poor in gifts, a poor blockhead, but by degrees you will come to grasp what is required for you. You have got to learn to laugh. That will be required for you. You must apprehend the humor of life, its gallows-humor. ${ }^{69^{\prime \prime}}$

\footnotetext{
${ }^{68}$ See for example Rookwood, Heidi M., The Function of Pablo in Hesse's "Steppenwolf", South Atlantic Review, Vol. 59, No. 4 (Nov., 1994), pp. 47-61.

${ }^{69}$ Hesse, Hermann, Op. cit., p. 250.
} 
So does Mozart advert him as his figure changes into that of Pablo who offers him another cigarette to smoke; Haller, however refuses to do so, but is then at the same time confident that he has learned his lesson, and that he could now assemble the various pieces of life's game. "I knew that all the hundred thousand pieces of life's game were in my pocket. A glimpse of its meaning had stirred my reason and I was determined to begin afresh. I would sample its tortures once more and shudder again at its senselessness. I would traverse not once more, but often the hell of my inner being. One day I would be a better hand at the game. One day I would learn how to laugh. ${ }^{70^{\prime \prime}}$

On the ending Michael Sipiora in a paper titled Hesse's Steppenwolf: A Comic Psychological Interpretation says the following, and I quote him at length:

"When he wakes up, the Steppenwolf will return to the tortures of his inner being, but he is not damned to the hellish existence with which his narrative began. The comic imagination has interceded to transform the lone wolf's fate. The union of magical thinking and laughter has seen through Haller's tragic dilemma in the affirmation of the dance of life over the despair of death. Haller will not be consumed by the desire for suicide. That fate has been averted; tragedy has been foresworn. No, Haller's hell is, at the close of the novel, purgatorial, not infernal. The justice meted out by the Immortals condemns Haller to go on living; time is on the side of life and Fortune. Pablo and Mozart have offered fellowship, and the world of jazz and the

\footnotetext{
${ }^{70}$ Ibid., p. 251.
} 
realm of the Immortals remain opened to the Steppenwolf. There will be other balls and journeys once more through the Magic Theatre. There is hope that the Steppenwolf's destructive split between spirit and matter will give way to the joys of the embodied imagination and that he will, in time, learn to laugh.71"

The key word which Harry Haller writes in his manuscript is that he will be able to start afresh. Even though he fails to appreciate the importance of the 'comic imagination' and laughter, he, nonetheless, is able to transcend the previous status quo and open up himself for new life experiences. He is not going to be suicidal anymore, but rather he will be able to cope with the crisis of his existence, with the banality of life where everything seems dull and insipid, but what does this mean? It means that Haller is aware of the evolutionary dialectic. It is inevitable that one has to constantly renew oneself to avoid stagnation. The result of this awareness at the level of Harry Haller was externalized through the manuscript which he ends up writing; and the overall novel is, without a doubt, the result of Hermann Hesse's inner experience at the center of being which he materializes through this beautiful mythological corpus. That the ending is left open is crucial, because even though the dialectic system turns back to itself it is never selfsame, nor is it close-ended. There will always be a fresh start, another ground on which to edify a whole new complicated edifice of information, knowledge and complicated texture of poetical and philosophical texts. And as Spiora affirms, there is hope that eventually Haller is able to dilute the strict

\footnotetext{
${ }^{71}$ Spiora, Michael P., Hesse's Steppenwold: A Comic-Psychological Interpretation, Janus Head, 12(1), Triuvium Publications, Pittsburgh, PA, 2011. http://www.janushead.org/12-1/sipiora.pdf. Link accessed on February 14, 2013.
} 
difference between spirit and matter, in order 'to give way to the joys of the embodied imagination' and therefrom to be able to laugh. Here again, we see the importance of the imagination at the level of synthesis of the duality of spirit and mind. It is thus, a crucial element, as a creative faculty of the ego, in the jointing of the gap which has sprung ever since the Subject of Cognizance was left out from the overall picture.

So to come back to the observation with which I started this chapter, we see how the gods which are posited in the consciousness have taken the form of the different characters which the novel comprises; the dynamic which Harry Haller went through on the way to self-transformation was precisely the positing of the different characters in his consciousness each of which had a specific role to play and which kept impelling him to a further development of his inner self. First by the positing of Hermine whom she taught him how to laugh and dance, then by the positing of Maria whom she taught him how to love and enjoy sexual pleasures, and after that Pablo whom he taught him how to listen to the music of life. At the bottom of it we see how these unconscious forces are pushed to the surface and subsequently posited in Harry Haller's consciousness consecutively, until he finally was able to enter the Magic Theatre and join the Immortals (break through to the Noumenal). The interaction of both the Unconscious and the conscious is thus facilitated through the mediating faculty of Haller's creative imagination. 


\subsection{Closing Remarks and Conclusion}

"However, as man intends to retain his central position and the intuition bound up therewith-while he already is in another place-there emerges that middle world, which we name a world of the gods, out of the striving and fighting to hang on to the original divine unity in that which is already disturbed and diverged, that world of the gods that is as it were the dream of a higher existence, a dream that man continues to dream for a certain time, after he has sunk from that higher existence.

It is not at all the things with which man deals in the mythological process by which consciousness is moved, but rather it is the powers arising in the interior of consciousness itself. The theogonic process, through which mythology emerges, is a subjective one insofar as it takes place in consciousness and shows itself through the generating of representations: but the causes and thus also the objects of these representations are the actually and in themselves theogonic powers, just those powers through which consciousness is originally the God-positing consciousness. The content of the process are not merely imagined potencies but rather the potencies themselves - which create consciousness and which create nature (because consciousness is only the end of nature) and for this reason are also actual powers. The mythological process does not have to do with natural objects, but rather with the pure creating potencies whose original product is consciousness itself. ${ }^{2 \prime \prime}$

What Schelling is saying in the paragraph above is that mythology is the necessary outcome of the human's struggle to hang on to the original divine unity; because of the distortion of this unity creation was possible at all. Hence the inevitable outcome is a polytheistic independent world of gods which merely represent the product of the potencies of the unconscious creation of nature which ends up with consciousness as Schelling says. So the theogonic process is not the result of human hallucinations but is rather the result of the unity of the Mind according to Schrödinger, or the collective Unconscious, which is a universal process of the Ideal

\footnotetext{
${ }^{72}$ Schelling, Friedrich, Historical-Critical Introduction, Op. cit. p. 144.
} 
side of the Absolute coming to consciousness of itself and which manifests, as explained earlier, through the artist in the objective work of art, according to Jung. The consciousness of the human being is, therefore, seen as the ultimate product of these forces which are not 'imagined potencies but rather the potencies themselves'. So for example, when Harry Haller is coming to consciousness of the driving forces which lurk at the bottom of his self, this is done through the potencies themselves represented by the different characters of the novel. These potencies are the archetypes in the Jungian sense, most significantly represented by Hermine as the anima (this topic will be explored in depth in chapter 5). It is through this overall theogonic process, and according to the Schellingian dialectic that mythology necessarily emerges as the Unconscious force, is externalized and therefrom posited in the consciousness of people. The production of all this results in a mythological corpus and the apprehension of its possibility because of the faculty of creative imagination which makes the intercourse between the intellectual intuition and the aesthetic intuition, and the eventual transcendence of both of them, possible. And in the words of Schelling:

"The ideas through whose succession the formal polytheism immediately emerges, but also through which material (simultaneous) polytheism mediately emerges, produce themselves for consciousness without its cooperation, indeed against its will and-so that we definitely articulate the correct word, which brings to an end all earlier explanations that somehow assume invention in mythology, and that actually first gives us that which is independent of all invention, indeed that which is opposed to all invention, which we were already occasioned earlier to demandmythology emerges into being through a (in view of consciousness) necessary process, whose origin is lost in the supra-historical and is concealed from it itself, a 
necessary process against which consciousness perhaps can resist in isolated moments, but which it cannot stop on the whole and can revoke and undo still less. ${ }^{73}$ "

Thus far we have seen the significant role of creative imagination as a mediator between the infinite and the finite (noumenal and phenomenal) in the externalization of the awareness of the artist in mythopoesis. The process of externalization, though it starts consciously, ends up in the actualization of the potencies the product of which, through the theogonic process, is consciousness. What we have seen on the one hand, is how this synthesis is possible by looking at Schelling's System of Transcendental Idealism and in a concrete example of Hesse's Steppenwolf, not only have we seen an application of this synthesis in the creative imagination, but also how it is that a mythological corpus would inevitably be created from this dialectic. We will furthermore see in the coming chapter how this continuous desire to self-renewal and to start afresh is productive of mythologies which we might not be aware of but which are, as Roland Barthes would agree, present in our daily life.

Through the first and the second chapters the first facet of the present dissertation would have come to conclusion. These two chapters have dealt with Schelling's philosophy of mythology in order to ground the ontology on which the subsequent chapters will be based upon. What has been said until now could as well be related to what Schelling denominates as 'negative' philosophy; the second step would, therefore, be the exposition of a 'positive' philosophy. In the subsequent

\footnotetext{
${ }^{73}$ Schelling, Friedrich, Op. cit., 2007, p. 134.
} 
chapters of this research, thus, I shall try to focus on 'positive' philosophy insofar as I hope to show that contemporary cinema could be one form of contemporary mythology. What is ought to be done is an analysis of the cinematography of one of the acclaimed cinematic directors of all time: Andrei Tarkovsky. Therefore the core of the research will revolve around the abovementioned thesis by considering three of Tarkovsky's movies, more specifically Ivan's Childhood, Andrei Rublev and Stalker in order to argue in what way cinema could be a form of contemporary mythology and the relation of this field to the people as spectators. The concepts which will be referred to throughout the research are based on the first and second chapters and these in a summary are:

1) Mythology is a necessary process in the restoration of the original unity - insofar as the system, at the end of it, returns to itself.

2) Mythology is a theogonic process which emerges because of the movement of the positing of the Unconscious potencies in consciousness.

3) Particular mythologies as such might or might not be false, but the overall process is true.

4) The origin is transcendent with respect to what has originated. The originated has its ground in an 'indifferent' groundless ground. It is not, however, an origin of causal relation, but rather a necessary one. The beginning, at all levels is 'indifferent' from the outcome. That is to say, the ground of thinking is not thinking, thinking itself. Thinking is grounded transcendentally on a ground which is indifferent to itself. 
5) The role of the ' $\mathrm{I}$ ' as the Subject of Cognizance is crucial in the active perception and thereby creation of the phenomenal world.

6) The faculty of imagination is the mediator between the Infinite and the finite, and is responsible for the seamless synthesis between the aesthetic and the intellectual intuition. 


\section{Contemporary Mythology}

In this chapter, I will argue that the ethical is grounded in the aesthetic by medium of reason. There is a transcendental philosophy insofar as reason is grounded in the aesthetic by medium of our cognitive domain which comprises consciousness, in the sense of Humberto Maturana. The result of such conception is, therefore, an inversion of the Kantian system whereby the point of departure would be the Critique of Judgment and not that of reason. In other words, the faculty of judgment is the condition of possibility of the faculty of reason. The foundation of the proposed argument will be substantiated by tracing a line of thought which includes 
Schelling, Jung, Cassirer, Blumenberg and Barthes. The goal of this chapter will be threefold. First, to argue, as already mentioned, that the aesthetic activity is the condition of possibility of rationalization. Second, to provide a systematic approach to the theories of mythology of the above mentioned philosophers; this approach will, accordingly, allow us to conclude that far from having been overcome, mythologies are reverberant and are well grounded in our everyday lives.

\subsection{On Aesthetics}

Rainer E. Zimmermann writes in Deriving kalokagathía from Schelling's Grounding of Nature: "If the concept of "unground" leads into a region of thinking that tends to escape clear conceptualization rather than becoming part of established theory, then this region is probably the adequate field on which the categories of aesthetics and ethics may unfold." And he goes on to add a few lines later: "So it is the cognitive framework of some suitable meta-theory which is at stake here: in order to eventually learn how to actually utilize the meaning implicit in any type of information gained." To conceptualize the 'unsayable' and thereby that which cannot be communicated through abstract discourse is a tedious process; that is because concepts elude discourse. One cannot pinpoint them as such in their pure nakedness. The solution, thus, is not what Bacon thought it might be: it is not that the only way to extract nature's secrets - to unveil Isis - would be through gaining control over it in

an act of violence. Since the 'unground' cannot be clearly conceptualized because of 
its continuous eluding of logical discourse, at the bottom of it, therefore, one can be able to access this abundant region - which is non-exhaustive at the end of the day through the aesthetic sensibility - as Zimmermann has argued, subsequently unfolding an aesthetic object that would be taken as an object of reflection amongst the subjects. These subjects, in turn, as agents of society, are able to conceptualize that which has been accessed-through aesthetically, forming as such a collective system which would allow them to take a qualitative leap on the evolutional line. This process of emergence of complexity from chaos is facilitated through mythopoesis as the ultimate form of artistic creation, which is, moreover, governed by the Schellingian dialectic, in a system which always comes back to itself but is never self-same. The stress here would be on the process of emergence as mentioned from chaos to complexity, and not as is usually commonly thought amongst the different philosophical traditions as an emergence from chaos to logos. This is precisely due to the circularity of the system which comes back to itself. In other words, chaos and logos are in a continuous intercourse whereby both depend on each other throughout the different stages of the system; it is not, therefore, a linear process such that once logos has emerged from chaos, the latter is totally overcome. We will get back to this idea later in relation to Humberto Maturana's explication of autopoesis and the circularity of systems. The ideas that will be examined throughout the chapter will focus on the following:

1) Schelling's On the Deities of Samothrace

2) Cassirer's conception of the metaphor. 
3) Jung's conception of the collective unconscious and the archetypes.

4) Blumenberg's Absolutism of Reality.

5) Roland Barthes' Mythologies

\subsection{Schelling's On the Deities of Samothrace}

Schelling's philological investigation on the names of the deities of the ancient Cabiri cult which lived on the island of Samothrace is an intent to bring forth to light an example of a primordial system of humanity. ${ }^{74}$ The importance of such a research, Schelling argues, is to excavate the mysteries left by ancient people in order to have a better understanding of "what once united human beings intrinsically." Accordingly, he draws on the interpretation and the significance of the Cabiri gods' names Axieros, Axiorkersa and Axiokersos and shows their close link with the Greek gods Demeter, Persephone and Hades respectively. These gods are usually linked in an ascending chain such that each one of the gods' essences is actualized. The beginning of the cosmos is thus attributed to Axieros' essence of hunger and malaise from which being as such emerges, followed by Axiorkersa from whose essence that being is extended into nature, after which comes Axiokersos by whose essence the world of spirit emerges. All three of them are potencies of the cosmos "through whose preeminent efficacy and government the totality of the world exists, - clear, therefore, that they are

\footnotetext{
74 “das Würzigste, was einst Menschen innerlich vereint." Ueber die Gottheiten von Samothrace, Stuttgart, J.G. Cotta'schen Verlang, 1815, p. 41. The English translation is an unpublished translation done by David Farrell Krell which was distributed to the participants at the Philosophy Summer School of Contemporary Philosophy at Duquesne University, August 2013.
} 
worldly, cosmic deities." It is clear therefore, that these deities are worldly deities, forces through which the universe comes to be and by medium of which it eventually evolves. The fourth deity, Kadmilos, in this sequence is, on the other hand, not a worldly one, prevailing thereby over both Axiorkersa and Axiokersos, and whose essence is to establish a connection between the worldly gods and the demiurge. This demiurge is not a determined deity, though. It is the coming god; the god to be revealed, its revelation in the world is possible because of the mediation of Kadmilos between the meta-worldly god and the world. If we scrutinize closely Schelling's conception of the Cabiri gods, and refer to the deities as our access point into the primordial system of humanities, then it is to be understood that the gods are the natural potencies which occur in the world which would eventually be grounded harmoniously in the coming god who would close the previous system of the society and pave the way to a renewed flow of ideas into the society's panorama. The names attributed would allow us to have a glimpse into the Cabirian system and understand how they made sense of reality. Notwithstanding, these names, which are eventually recompiled into a mythological system are not to be understood allegorically, because they do not intend to represent a natural phenomenon; they are, however, the potencies of nature recapitulated into the linguistic system of societies. ${ }^{75}$ By recapitulating itself in the linguistic system, nature is doing nothing but selfrecapitulating itself in God. ${ }^{76}$

\footnotetext{
75 "Language after Philosophy of Nature: Schelling's Geology of Divine Names" in Anthony Paul Smith and Daniel Whistler (eds.), After the Postsecular and the Postmodern: New Essays in Continental Philosophy of Religion (Newcastle: CSP, 2010), pp. 335-59.

${ }^{76}$ Ibid., pp. 335-59.
} 
What does this mean, and what implications does it have on the understanding of the different systems of different societies during different epochs? It means that, as Schelling clearly contended in the Philosophy of Mythology, the gods are posited in the consciousness of people by emerging from an unconscious state to consciousness by medium of art. God as such, therefore, is a chain of emerging forces of nature which are grounded in the basic physical forces of nature and paving the way to the emergence of the meta-worldly god which is the ultimate realization of freedom in human consciousness through the mediating god: the faculty of imagination. We will see furthermore how this idea perseveres in the philosophical tradition and a concrete example will be given based on Maturana's conception of autopoesis. Thus, there is a continuous and parallel movement between the naturing of nature (natura naturans) and the evolution of human beings as creative agents (being both products of nature and active agents within it). Understood in that sense, the Schellingian conception of revelation would signify the end of an era, the closing of one system of a certain society, realizing a new leap of self-consciousness impregnated with new ideas and insights: this creative leap is in a continuous selfrenewal because it is grounded in nature; consequently, there is a close link between nature and the respective linguistic system of human beings whereby the names given to the gods are nothing but nature self-recapitulating itself in them. ${ }^{77}$ Accordingly, these gods are tautegorical because they are not explaining nature, but they are the potencies which they represent, potencies which are posited in the human

\footnotetext{
${ }^{77}$ See Wirth, Jason, Op. cit., 2013.
} 
consciousness as Ideal, but are actualized to become Real potencies in mythology where both the Ideal and the Real become reconciled and identical. Mythology, hence, could be understood as a form of expression through which human beings tend to make sense of reality. Mythology, understood as such, is a form of expression, the dynamics of which include an intercourse between the unconscious as nature coming to consciousness of itself and the consciousness of human beings as active agents within nature. The nature of this form of expression is aesthetic, which depends on the aesthetic sensibility of human beings by accessing Reality, because the latter, as Natura Naturans is constantly eluding abstract discourse. The first step, thus, would allow one to access the dynamicity of nature through an act of mimesis of the dynamics of creation of nature. This movement cannot be abstract or logical in essence; it has to be a concrete one by medium of, as argued in the previous chapter, creative imagination.

Through the proposed conception of mythopoesis we would have gone back to the Greek root of the word mythos which is understood as a kind of narrative; the narrative as such is poetic in nature insofar as it is not an explicative logical discourse. This is due to the fact that, as argued in the first chapter, the events of nature or human activity are understood only post facto because of the contingency of nature, such that the world-system is not determined and is open to the actualization of different potencies (the perpetual revelation of the coming God). Emergence, therefore, comprises a movement from a simple to a more complex network within the system such that the emergent becomes a theme around which variations are 
constructed in a manner similar to a symphony whereby the newly construed themes are new symphonies and the variations recur throughout the musical piece. Accordingly, "The potencies, in short, are not so much categories or laws as they are metacategories, metalaws on the basis of which all subsidiary objects and all forms of experience have been built up. ${ }^{78}$ " Hence Schelling's excavation into the roots of the Cabirian deities with the hopes of encountering one such a primordial, simple metasystem, which underlies the collective system of the different epochs forming the backbone of the different cultures around the world. The simple harmony which once existed amidst the human race is a simple one from which different cultures emerged in time forming a more complex texture among themselves. In discussing the Cabiri Schelling provides the best example that shows both the contingency of natural events (cataclysms, catastrophes, etc.) and the proto-type of the dynamics of the actualization of the potencies within a certain system that end with the revelation of the coming god.

To recapitulate what has been said in this section: we have reached the conclusion based on the previous chapters and by analysing Schelling's On the Deities of Samothrace, that mythology is a form of expression, a narrative and poetical by nature, through which humans make sense of their Reality. This is due to the fact that nature is both a Natura Naturans and a Natura Naturata, which means that existence is contingent insofar as the consequent is not grounded in the antecedent, but rather the

\footnotetext{
${ }^{78}$ Beach, Eduard Allen, Op. cit., p. 181.
} 
antecedent is grounded in the consequent. ${ }^{79}$ In other words, the course of history is not determined and cannot be explained through a causal chain (Newtonian Universe). Thus, the world-system is always open to whole new possibilities which might not be causally related, hence the grounding of the antecedent in the consequent and not vice-versa. The narrative discourse is the first step into the construction of a corpus which would act as a condition of possibility for the possible interpretations: logical, rational and abstract understanding of the different phenomena. Therefore, the rational is grounded in the aesthetic whereby the aesthetic is understood in the general sense and not in relation to any particular art. The example of the Cabiri cult served to show that the gods are neither an allegorical explanation of nature nor a superstitious belief in superpowers that governed the world from without. Rather, the gods are an ascending chain rooted in the physical potencies of the universe, their names are self-recapitulations of nature, and they pave the way for the revelation of that which is beyond the world, a transcendence, which is represented by the coming God. Said God is merely the culmination of the system in the cyclical movement throughout the epochs. Thus, the actualization of the ultimate potency, Schelling hints, supposes the end of one era and the beginning of a new one.

\footnotetext{
${ }^{79}$ On the topic of the antecedent and the consequent see: Schelling, Friedrich, Philosophical Investigations into the Essence of Human Freedom, trans. Love, Jeff and Schmitt, Johannes, State University of New York Press, 2007; Grant, lain Hamilton, How Nature Came to be Thought. Schelling's paradox and the problem of location. Journal of the British Society for Phenomenology, 44 (1), 2013 pp. 24-43; and Grant, lain Hamilton, The Universe in the Universe. German Idealism and the natural history of mind. Royal Institute of Philosophy Supplement, 72, 2013. pp. 297-316.
} 
In what follows, different theories of mythology will be closely examined in order to support the central argument of this section by first highlighting the confusion which usually takes place upon distinguishing between myth and language as two distinct and parallel realms, then by examining Jung's theory of the collective unconscious and the archetypes in order to shed light on the dynamics of the positing of the unconscious in consciousness and the reverberation of the archetypes in our times, followed by an examination of Blumenberg's conception of the absolutism of reality: that human beings always tend to make sense of Reality. This activity is similar to Schelling's conception of mythology in the sense that humans have always been expressing reality through different kinds of narratives; and Barthes conception of mythology as a system of communication. The theories of the authors to be examined will gradually allow us to reach the second part of the present thesis where it will be argued that cinema is one of the contemporary forms of mythology and how is it that we can make sense of reality through film by using the concrete example of Andrei Tarkovsky's cinematography.

\subsection{A Critique of Cassirer's Language and Myth}

In Language and Myth Ernst Cassirer writes the following: "And this common center really seems to be demonstrable; for, no matter how widely the contents of myth and language may differ, yet the same form of mental conception is operative in 
both. It is the form which one may denote as metaphorical thinking; the nature and meaning of metaphor is what we must start with if we want to find, on the one hand, the unity of the verbal and the mythical worlds and, on the other, their difference. ${ }^{80}$

The affinity between myth and language for Cassirer is due to the 'same mental conception' that is operative in both: what we denote as metaphorical thinking. Moreover, Cassirer saw in myth, as with many of the philosophers, a primordial step into the emergence of logos under which language could be categorized. However, I will argue in this section that Cassirer's view falls short precisely because, as mentioned previously, mythos is not eliminated once logos has emerged. Cassirer does not oppose mythos and logos; however, he sees in mythos an obsolete activity once the logos has been posited into human's consciousness. The argument displayed here will be founded on the one hand on Schelling's understanding of language, and on the other hand, on the conception of language as described by Humberto Maturana.

Schelling's understanding of language as faded mythology has been briefly treated in the first chapter: the evolution of the word father in Hebrew was rooted in the verb desire which, in turn, was rooted in desire as a concrete experience rather than an abstract idea. ${ }^{81}$ On this matter Tyler Tritten says the following:

\footnotetext{
${ }^{80}$ Cassirer, Ernst, Language and Myth, trans. Susanne L. Langer, Dover Publications Inc. New York, 1953, p. 84.

${ }^{81}$ Note that traditionally, at the time of Schelling, Hebrew was thought to be a reference to the earliest language available. Obviously, there are examples that refer to a much earlier time: e.g. the Egyptian language, to name only one.
} 
"The thing itself, i.e. the father, could not have been the representation of the abstract, i.e. pure, meaning under Schelling's view because the meaning only arises with the manifestation of the phenomenon, the thing itself. Language, just as mythology and the formation of peoples, is not something invented and enacted by consciousness but points to a pre-reflective and pre-conscious inception. Consciousness presupposes language and so language itself could not have emerged consciously. In other words, the origination of language cannot be conceptual but only inceptive. Abstract and formal conceptuality, like philosophy, can only appear as a later sedimentation of language but not at its inception. Language, as faded mythology, must be the product of aesthesis, emerging from primal, mythological experiences. ${ }^{82^{\prime \prime}}$

In other words, consciousness is not the condition of possibility of language, but rather its origination is 'inceptive' rooted in concrete experience and is the product of aesthesis: a pre-reflective origination rooted in narrative rather than logical discourse. Accordingly, Hans Blumenberg sees in the Homo Pictor not only an artist who paints on the cave walls for magic and rite purposes related to hunting, but because by projecting these images the early human was trying to delimit and make sense of reality, which appeared to be fickle and unreliable. ${ }^{83}$ Such images were, thus, not merely teleological, but also expressive and inceptive: they narrated peoples' fears and allowed them therefore to present for themselves a reality that they could

\footnotetext{
${ }^{82}$ Tritten, Tyler, Beyond Presence. The Late F.W.J. Schelling's Late Criticism of Metaphysics, Walter de Gruyter, 2012, p. 300.

${ }^{83}$ Blumenberg, Work on Myth, trans. Robert M. Wallace, MIT Press, 1985, p. 8.
} 
actually make sense of. These images, as the outcome of mythopoesis are to be viewed not as allegories, but rather as symbols in the Schellingian sense, and are to be understood not metaphorically, but tautegorically because in them the content and the form are actually identical.

The act of painting these images supposes, therefore, a 'symbolization' rather than a 'metaphorization' of a reality that people are trying to make sense of. In that sense, it would not be that difficult to understand that the Greeks did not view their myths and gods as dead figures or fictitious characters; to them they were alive and were integrated in their daily life because that's how they made sense of reality prereflectively. Accordingly, the aesthetic activity, insofar as it is understood as a prereflective narrative of images based in concrete experience in order to delimit and make sense of one's reality, becomes the organ of the logical discourse of the people. This process entails the separation of the content from the form and the abstraction of the content in order to conceptualize it projecting it under the scrutiny of reason and logic, etc.

We can now venture on to understand what Schelling really meant when he referred to language as faded mythology, and consequently pinpoint out where Cassirer's argument falls short: what has come to be known as language: the collective corpus of concepts and lexicon through which we are able to communicate with each other is nothing but the result of the severance of the form and the content of that which once comprised a mythical narrative. The former allows one to generate 
different kinds of narratives: lyrical, epical, which would include different figures of speech. They can form the bases of all sorts of language games within a predefined form whereby form and content are not identical. There will, thus, continuously be a gap between the form and the content, between appearance and reality, without one being able to accommodate to either view due to the lack of proper 'expression' as facilitated by the act of 'symbolization.' Hence, on the one hand, language is a faded myth insofar as it has gained autonomy as a logos, as a corpus which is first and foremost an abstract, conceptual domain - in that sense we can agree with Cassirer's understanding of the relationship of myth to language. On the other hand, however, insofar as language is a corpus which is continuously evolving and developing is grounded in aesthesis, new concepts and words are generated and developed and similarly acquire new meaning with the passage of time.

\subsection{On the Archetypes and the Collective Unconscious}

We have seen so far, on the one hand, the importance of the prioritization that Schelling attributes to nature as a naturing subject the self-recapitulation of which results in theogony, as well as the importance of understanding the gods posited in consciousness as symbols to be tautegorically interpreted; and on the other hand, that language is grounded first and foremost in a pre-conceptual experience. Human beings, it has been shown, are continuously making sense of Reality through images 
which subsequently and eventually are abstracted and conceptualized forming the lexicon of the language. The proposed view can be further supported by Jung's theory of the archetypes and the collective unconscious.

According to Jung, the concept of the archetype "indicates the existence of definite forms in the psyche which seem to be present always and everywhere. ${ }^{84}$ These archetypes are symbolic images full of meaning, and their meaning is inexhaustible; moreover, these images always have historical antecedents and they are always inherited by generations throughout time. ${ }^{85}$ Jung stresses on the concreteness of these images for they are not thought but are rather the result of experience whereby one tries to make sense of reality.

The inherited archetypal images, for example the gods of a certain epoch, Jung argues, are sometimes pronounced dead due to the sudden awareness that people would have acquired with respect to the uselessness of these images. ${ }^{86}$ When such an event takes place, it is because said people would have started questioning the meaning of these images and the relation that they have to them. In other words, when they start reflecting upon the archetypal images they would have inherited from the ancestors they are acquiring a rational dimension. Nevertheless, the uselessness of these images, Jung stresses, is only insofar as people cannot relate to them concretely. Accordingly, the solution would be in the creation of new symbolic

\footnotetext{
${ }^{84}$ Jung, Carl Gustav, The Archetypes and the Collective Unconscious, trans. R.F.C. Hull, Pantheon Books, 1959, p. 42.

${ }^{85}$ Ibid., p. 33.

${ }^{86}$ Ibid., p. 13.
} 
images grounded in concrete experience - what we have previously referred to as aesthesis - this process is achieved by another class of archetypes which Jung denominates as the archetypes of transformation. This process of transformation can only take place when that which is unconscious is posited in consciousness. According to Jung, consciousness is a safe place for human beings because it is the domain where we can be in control of our fears and the situations which we find ourselves confronting. Nevertheless, conflicts arise when the unconscious is not posited into consciousness. Notwithstanding, the unconscious which Jung mentions and deals with is not the individual unconscious, but rather the collective unconscious which he defines as:

"In addition to our immediate consciousness, which is of a thoroughly personal nature and which we believe to be the only empirical psyche (even if we tack on the personal unconscious as an appendix), there exists a second psychic system of a collective, universal, and impersonal nature which is identical in all individuals. This collective unconscious does not develop individually but is inherited. It consists of pre-existent forms, the archetypes, which can become conscious secondarily and which give definite form to certain psychic contents. ${ }^{87}$

The unconscious, therefore, is comprised of archetypes which Jung compares to biological instincts and which human beings inherit from their predecessors. As such we can conclude that the collective unconscious is rooted on the one hand in the physical nature, in the genes, and is passed on to posterity, and on the other hand it is rooted in the human psyche which is comprised of the collective mythologies, religions, arts and literature of the respective societies.

${ }^{87}$ Ibid., p. 43. 
This view leads us back to Schelling's examination of the Deities of Samothrace where he argued that the gods are posited into consciousness from the unconscious as a result of nature naturing through us. The unconscious in that case is that which nature is creating within human beings. Nevertheless, human beings are a cornerstone in this process because they complete the whole circle by projecting these images externally through, according to Schelling, mythopoesis. Jung calls this process of externalization a symbolic process whereby humans experience the archetypes consciously as symbolic images. This process is an "experience in images and of images."

\subsection{Blumenberg's Absolutism of Reality}

Because nature is always naturing, we are always stepping into the unknown, hence the collective unconscious also contains our fears. To have a sense of control over these fears, human beings are determined to constantly cope with the continuous change which is constitutive of the nature of nature. This is done by the positing into consciousness the images which form the collective experience of human beings as they collectively try to give order to, and thereby make sense of their reality. This was the conclusion that we have reached reading through Jung's theories of the archetypes and the collective unconscious. This very same process is 
what Hans Blumenberg denominated, as briefly mentioned previously, the absolutism of reality.

Blumenberg affirms that the generation of myth is made possible by two antithetical ideas: these are poetry and terror. 88 The overcoming of this fear is mediated through the poetical generation of images by medium of active imagination. Blumenberg emphasizes the embedded need within human beings to name the unnameable and to give explanations to that which is incomprehensible ${ }^{89}$; consequently, the perpetual generation of myth is rooted within the collective unconscious of people, be it the Greek or Roman gods, or even naming the basic elements in nature within the scientific domain.

Based on Blumenberg's view, there is a certain dynamic which underlies the development of human beings whereby mankind is in an interminable process of rationalizing its fears when confronting the unfamiliar that is perpetually being generated within nature which is, in turn, generative of myth. The generated myths, Blumenberg argues furthermore, are narratives, stories, which are told in order to kill time and to kill fear. 90 These narratives are a way "of expressing the fact that the world and the powers that hold sway in it are not abandoned to pure arbitrariness. ${ }^{91 "}$

\footnotetext{
${ }^{88}$ Blumenberg, Hans, Op. cit., p. 59.

${ }^{89}$ Ibid., p. 5.

${ }^{90}$ Ibid., p. 33.

${ }^{91}$ Ibid., p. 42
} 
They are stories that recount the origin of the names "from night, from earth, from chaos. ${ }^{92 "}$

Once the mythical narrative has been externalized within a certain domain, as a result of the collective unconscious/conscious collaboration of the society in the process, it eventually acquires what Blumenberg denotes as significance. To equip a certain mythical narrative with significance is not something that we can choose to do. Moreover, the concept of significance - not an easily defined concept, Blumenberg stresses - bears a contradiction, for the concept is "related to finitude", to the fact that objects are finite and would someday disappear and it is also related to the renouncement of the concept 'Vogliano tutto' which is the main reason for one's drive towards the impossible ${ }^{93}$, on the one hand; and on the other hand, it is related to the fact that objects that are pregnant with significance are those that resist the factor which tend to efface them, like the passage of time for example. Also, Blumenberg understands the concept of significance as "with the aesthetic object, part of the definition of significance is the way it emerges from the diffuse surrounding field of probabilities.94" It is therefore, directly related with the significance that the newly emerging narratives when making sense of reality has for the society.

The produced images are, nonetheless, not restricted to any single domain, for the underlying dynamic of the generation of these images is how human beings in

\footnotetext{
92 Ibid., p. 38.

93 Ibid., p. 67.

94 lbid., pp. 68-69.
} 
general relate to their respective reality. Therefore, I contend, we can conclude that aesthesis, as a pre-conceptual 'symbolization' of reality underlies the different fields that have constantly been emerging throughout time from the early Homo Pictor to the contemporary science, art and literature.

\subsection{Roland Barthes: On Mythopoesis and the Mythicization of the}

\section{Narratives}

In this section, a difference will be highlighted between what has been so far denominated as mythopoesis and what is known as the mythicization of narratives, i.e., the formation of a systemic corpus of myths just like in Hesiod and Homer. The difference is essential in order to be able to distinguish between how humans make sense of reality on the one hand, and how eventually the stories that they have been telling throughout ages eventually become mythicized by time.

Mythopoesis as we have already shown is related to aesthesis, it is, therefore, the first activity of mankind when making sense of reality, before the generation of language as logos. Aesthesis as the condition of possibility of the evolution of the $\log o s$, thus, means that the first order 'symbolization' of reality is done through the creation of images whereby these images act as tautegories. The generated narrative is thereafter dissected and examined, to be later on abstracted, forming as such a semiological corpus. Roland Barthes' Mythologies does not, however, take that into 
consideration because he deals with the mythology pervasive nowadays only as a mythicization of discourse and not as a mythopoesis. What Barthes proposes is that myth is a form of speech. This is true only insofar as the understanding of myth is understood in the Barthesian sense as a second-order of semiological system. The semiological system is comprised of a signifier, a signified and the sign. ${ }^{95}$ Myth takes as its signifier, Barthes argues, the sign of the first semiological system (for example language, paintings, photography) are appropriated by myth and taken to be only as signifiers which is correlated with the signified to form a second-order sign which Barthes refers to as signification.

The example that Barthes gives refers to the phrase from Valéry's 'quia ego nominor leo' (because my name is lion). One can conclude, Barthes affirms, that this phrase hints that there is more to it than merely what it signifies, but that there is a second-order of signification which acts as a grammatical example which shows a certain agreement of the predicate. He concludes, thus, that the signifier is formed of the linguistic signs of the phrase because my name is lion, the signified is that this phrase serves as a grammatical example, and the signification is the correlation of the signifier to the signified because both depend on each other in order to form the second-order semiological system.

We can extrapolate the same Barthesian conception of myth as such to the Greek mythology - or to what has come to be known as Greek myth. For example,

\footnotetext{
${ }^{95}$ Barthes, Roland, Mythologies, trans. Sian Reynolds, Vintage Books, 1993, p. 137.
} 
Hesiod's Theogony which relates the origins of the Greek gods in the form of an epic poem. Hesiod, however, provides us with nothing more than a compilation of a systematically harmonized account of the gods' origins. ${ }^{96}$ The compilation, however, becomes the mythical corpus of the Greek society's 'Absolutism of Reality.' That which was the result of the images produced by the Greeks in their attempt to make sense of their reality, the result of which were the gods posited within their consciousness, became mythicized by the introduction of Hesiod's Theogony. Consequently, we can look at Hesiod's poem as a myth of a second-order semiological system whereby the signifier is formed by the constructed signs, the building blocks of the text: i.e. the words and the names of the gods, and the signified would be the different interpretations that has been given to what the gods meant to ancient Greek society, and the signification is the correlation of the signifier and the signified.

It is in that sense that Barthes argues that every discourse could eventually be a myth and he proceeds accordingly in Mythologies to analyze different contemporary phenomena in media and art to prove that potentially any discourse can be mythicized. Because myth is a form, he stresses, irrespective of its substance.

It is opportune here to note that mythopoesis as an aesthetic activity is not myth per se, insofar as myth is to be understood as a finished oeuvre. That is because "[m]yth does not tell its own history. It does not exhibit the toil by which it converted

\footnotetext{
${ }^{96}$ Blumenberg, Hans, Op. cit., p. 611.
} 
itself from the ritual to the rhapsodic form and worked its way all the way through to a frivolous fluency. ${ }^{97 \prime}$ Accordingly, aesthetic activity, at its core, is not an ideological activity, but rather an activity whereby the ethical and critical activities are grounded. The first activity through which the society is making sense of reality is, therefore, dogma-free and not intended as an ideological agenda but rather an attempt to delimit reality in order to come over the society's fear. (Concrete examples will be given further in relation to the films of Andrei Tarkovsky). This is precisely because as Iain Hamilton Grant notes in Philosophies of Nature after Schelling:

"Therefore, to eliminate one ideation (that has its electrochemical grounds) in favour of another cannot be grounded in physics. Hence Schelling's late definition of myth as still 'a kind of philosophy', only 'unconscious, naturalistic, autophusis philosophia' (XI, 258), or 'nature itself philosophizing'. Myth is of course preconceptual, but precisely in the sense that the potentiation of the autophusis generates concepts. Forces, as we shall see, subject the concept to other tests. ${ }^{8 \prime \prime}$

That is to say, the symbolization of reality, at the end of the day, is in a sense, nature philosophizing through us, but this philosophizing is unconscious and is dependent on the conscious and intentional determination of mankind to 'create.' Consequently, mythopoesis and what is generated therewith and only afterward referred to as a mythical text cannot be the same as what Barthes called a secondorder semiological system, because this conception would thereby make myth prone to be used in a dogmatic and purely ideological sense. Mythopoesis and the mythopoetical narrative as treated in the present thesis are not the result of an ipso

\footnotetext{
${ }^{97}$ Ibid., p. 611

${ }^{98}$ Grant, lain Hamilton, Philosophies of Nature After Schelling, Continuum International Publishing Group, 2006, p. 188.
} 
facto mythicization of a discourse which depends on the existence of an already formed semiological system, but it is rather the very condition of possibility of the generation of any semiological system at all. It is, as Grant pointed out, a preconceptual creation, but the potentiation of which is generative of concepts. 99

Accordingly, the symbolization of reality produces a system comprised of different images that serve as a foundation for understanding the domain in which humans find themselves. These produced images, as a result of a pre-conceptual activity pave the way for the generation of new concepts; this would result in the generation of a new system. In order to understand this system, it will not suffice to use the same semiological system (metaphors, symbolism, etc.) which has been generated and understood in relation to a previous system. Rainer E. Zimmermann argues that it would be necessary to "carry over" a known meaning from a previous system subjecting it to alterations in order to generate a new meaning that would "correspond to the novelty of the new system. ${ }^{100 "}$ It is in the understanding of the newly generated system that we can therefore use what Zimmermann calls metaphorization: “[i]n principle, metaphorization (substituting one word by another in order to actually produce a new meaning) can then be expressed as a generalized quotient $\left(S^{\prime} / S\right)(S / s)$ indicating the space of free play for new meanings. ${ }^{101}$ This is similar to the second-order semiological system proposed by Barthes, which is only possible after

\footnotetext{
99 Ibid., p. 188.

${ }^{100}$ Zimmermann, Rainer, p. 89

${ }^{101}$ Zimmermann, Rainer, Op. cit., p. 59.
} 
the generation of language by medium of which the "space of free play for new meanings" is made possible.

Notwithstanding, the meaning of any new system, unlike the metaphorization principle suggested by Zimmermann, is to be understood tautegorically through a process of symbolization whereby, as previously mentioned, the content and the form are both important to the understanding of the system. In other words, if the images generated through mythopoesis which is generative of a mythical narrative are to be reflected upon rationally through philosophical discourse, the understanding of these texts can only be read and understood, as Schelling proposes in the Philosophy of Mythology, tautegorically. Tautegoricality applied to the understanding of a philosophical text would, therefore, mean reading a text within its context; however the interpretation, as proposed by Schelling, would be by creating a new discourse and a new meaning based on the context within which the text is being read. In that sense, Schelling's reading of Plato's texts takes into consideration the context that surrounded Plato, but Schelling's use and understanding of them sprang out of the contemporary philosophical problems that he confronted at the time. The difference of such concept of understanding a text with respect to that as proposed by hermeneutics lies in that, as Daniel Whistler argues, the tautegorical understanding of a text is not qualitatively different, but quantitatively. This means that Schelling's 
interpretation of Plato is infinitely potentiated and now qualitatively different because of an alteration in the understanding of the text by time..$^{102}$

The proposed argument could be substantiated by examining Schelling's explication of symbolism and allegory. The difference as we shall see lies in that symbolism is the identity of the indifference between schema and allegory, such that in the schema the universal is the dominant element intuited through the particular and in allegory the particular is the dominant only this time intuited through the universal.103 Symbolism is the identity of indifference of both schematism and allegory, such that the universal and the particular are completely identical in the particular. As a result, Homer's the The Illiad is to be understood symbolically, Schelling argues. One can interpret the poem allegorically or schematically, but the poem itself supposes no other than the absolute identity of schematism and allegory, hence the identity of the real and the ideal, the content and the form, i.e. tautegoricality. Schelling furthermore explains on the one hand that language is schematical, whereas he views philosophy to be symbolical; it is not surprising, therefore, that it is important to understand the philosophical text, as previously mentioned, for what it is, and even more so to interpret it not allegorically but tautegorically.

\footnotetext{
${ }^{102}$ Whistler, Daniel, The New Literalism: Reading after Grant's Schelling, paper presented at the Second North American Schelling Society Conference at Western University, Ontario, Canada, August 29-31, 2013.

${ }^{103}$ Schelling, Friedrich, Op. cit., 1989, p. 49.
} 


\subsection{From Naturphilosophie to the Philosophy of Mythology}

In the present chapter, we have so far been tracing a line of thought in order to show how it is that the mythopoetical narrative, which is a pre-conceptual act of aesthesis, is generated. This view has been in part based on Schelling's On the Deities of Samothrace, followed by a survey of some of the important theories which has been proposed on the generation of myths. From the previous sections we can thus far conclude that the aesthetic activity is grounded in nature along with the emergence of consciousness in human beings. The system is concluded by coming back to itself, to the absolute where by the identity of the infinite and the finite would have taken place through the object of art, according to Schelling. In Schellingian terms, the coming of the system back to itself indicates the revelation of the coming god which, as explained previously, indicates the end of one epoch and the emergence of a new one.

"Instead, Schelling constructs a continuum of nature filled out by a plurality of reciprocally interacting forces that stretches from the initial conditions of creation's absolute involution to the ever more complex phenomena of nature, eventually attaining to organic life and its most complex manifestation, human consciousness. ${ }^{104^{\prime \prime}}$

There is always an emergence from a simpler to a more complex system according to Schelling. This emergence is due to the interaction of the potencies of the world which underlie the different systems of the universe, until the most complex

\footnotetext{
${ }^{104}$ Mathews, Bruce, Schelling's Organic Form of Philosophy. Life as the Schema of Freedom, SUNY Press, 2011, p. 179.
} 
manifestation has been posited, and that is human consciousness. It is through human consciousness that freedom is finally achieved whereby freedom is the absolute identity of freedom and necessity manifested in the artistic creation according to Schelling.

The unity of the universe means that the whole universe becomes a living organism. The mere telos of this living organism is to achieve freedom. It is for that reason that the consequent cannot be predicted, but rather the antecedent is grounded in the consequent. That is to say, the movement within nature from the simple to the more complex necessitates that the consequent is grounded in the antecedent insofar as the antecedent comprises the matter and condition of possibility of the consequent. Nevertheless, the movement is free insofar as the outcome is unpredictable and, therefore, it can only be grounded as such after the consequent has been actualized.

"Humanity is incontrovertibly from the lowest of creations, i.e. from the material, from the part of matter in which the innermost root of selfhood - the wanting to be for itself (without the higher potency) of B - is overcome, but it is not therefore necessary that it is partial or parochial essence, it is the universal essence. Because it is the existent, all the potencies of the universe all these separate moments, are determined to be compacted into humanity as the final unity... Humanity is the starting point of a new process. ${ }^{105^{\prime \prime}}$

\footnotetext{
105 "Der Mensch ist unstreitig aus dem tiefsten Geschöpflichen, d.h. aus dem Stoff, dem Theil der Materie, in welchem die innere Wurzel der Selbstheit - des für sich (ohne die höheren Potenzen) seyn Wollens des $B$ - überwunden ist, aber darum ist es nicht notwendig ein partielles oder locales Wesen, es ist das universales Wesen. Weil er das Existirende ist, so waren alle Potenzen des Universums, alle diese getrennten Momente bestimmt, in ihm als in der letzten Einheit zusammenzugehen. Der Mensch soll als die innigste Zusammenfassung, alle Momente der Welt in sich vereinigen. [...D]er Mensch Anfangspunkt eines neuen Processes ist." SW X, Stuttgart, J.F. Cotta'scher Verlag 1861, p. 389-390. The English translation is an unpublished translation done by lain Hamilton Grant which was distributed to the participants at the Philosophy Summer School of Contemporary Philosophy at Duquesne University, August 2013.
} 
Schelling's Naturphilosophie, which deals with the real side of the Idea being actualized, paves the way for a philosophy which would deal with the ideal side of the actualization of the Idea - hence the need to develop a philosophy of freedom, art and mythology. The reason for this is, Schelling argues, that humanity is the limit of nature, which is why philosophies like the philosophy of art, freedom and mythology would be the key to conceptualizing, and thereby understanding, how the absolute comes to consciousness of itself through nature as 'natura naturans'. This leap - from the real to the ideal side of creation-, even though is emergent, and through it a whole new level of complexity is established on the evolutional line, has its foundation, nevertheless, in the 'lowest of creations.' Examined more closely, Schelling's concept of matter, which is not reduced to what is purely physical, becomes the building block for a unified, complex system by medium of which consciousness in nature finally emerges in human beings. Therefrom, the role of human beings as social agents who are moreover aesthetically sensible as to intentionally engage in artistic activity is to create, imitating the dynamics of naturing of nature. The aesthetic activity is grounded in nothing other than matter, through which the Absolute returns back to unity by returning back to itself.

In a similar line of thought, Humberto Maturana discusses autopoesis and the generation of order within a living system. In his book Autopoesis and Cognition he explains the importance of the circularity of the living system (for example the cell's metabolism) and how is it that through this circularity there is a margin for evolution 
insofar as the circularity itself is maintained. ${ }^{106}$ Moreover, the main characteristic of the living organism is autopoesis, the capacity to generate and maintain itself, with an open possibility to evolve and develop, maintaining throughout its autonomy and identity along with the capacity for variation. He moreover stresses the importance of the circularity of the system:

"It is the circularity of its organization that makes a living system a unit of interactions, and it is this circularity that it must maintain in order to remain a living system and to retain its identity through different interactions. All the peculiar aspects of the different kinds of organisms are superimposed on this basic circularity and are subservient to it, securing its continuance through successive interactions in an always changing environment. ${ }^{107 "}$

In a similar manner, human beings are comprised of the building blocks which are the result of millions of years of evolution, until organic life has finally emerged. Human beings are rational animals who are able to observe and symbolize nature, generating therefore a language of their own by medium of which they are able to reflect upon themselves and thereby become self-conscious. As a rational animal, and part of the overall evolution process within nature, Maturana argues that human beings construct their own rational systems which serve as a reference for their system of values. ${ }^{108}$ Maturana suggests that " $[\mathrm{m}] \mathrm{an}$ is a rational animal that

\footnotetext{
${ }^{106}$ Maturana, Humberto and Varela, Francisco, Autopoesis and Cognition. The Realization of Living, D. Reidel Publishing, 1972, p. 9.

107 Ibid., p. 9.

108 lbid., pp. 57-58.
} 
constructs his rational systems as all rational systems are constructed, that is, based on arbitrarily accepted truths (premises). 109

Maturana's scientific research consolidates Schelling's philosophical views as to regarding the whole universe as a living organism which is autonomous, and capable of self-generation, reproduction and evolution. Moreover, the fact that rational systems are a construction of human beings as rational animals is similar to the concept of the mythopoetical narrative through which human beings establish and make sense of their reality by creating a new system of their own insofar as the system of their ancestors would have become obsolete. This in turn is similar to Blumenberg's theory of the absolutism of reality through which human beings try to gain control over their fears. Accordingly, the system of values is generated based on the rational construction of the system within a society. Consequently, truth becomes, as mentioned at the beginning of the chapter relative to the system of value underlying a specific rational system of a specific society. Therefore, truth as an absolute category is not an apriori one, but rather something to be achieved in the future through the collective system of values that would have been emerging within the different societies - it is similar to how Schelling argued that particular mythologies might be false but the overall movement of them is constitutive of truth. Maturana, similarly suggests that:

${ }^{109}$ Ibid., p. 57. 
"The ultimate truth on which a man bases his rational conduct is necessarily subordinate to his personal experience and appears as an act of choice expressing a preference that cannot be transferred rationally; accordingly, the alternative to reason, as a universal system of values, is aesthetic seduction in favor of a frame of reference specifically designed to comply with his desires (and not his needs) and defining the functions to be satisfied by the world (culture and material) in which he wants to live. ${ }^{110^{\prime \prime}}$

In other words, Maturana points out that the arbitrariness underlying the choice of human beings in favor of a certain rational construct to make sense of the world and not another, which cannot be transferred or explained rationally, might alternatively be resolved by grounding such decision in what he calls aesthetic seduction. This entails that the frames of references according to which certain systems could gain priority over others in a certain society are related to the people's desires and not their needs, and therefrom the people would accordingly proceed to find the best ways or functions in order to satisfy these desires. If however, the first step in the construct of a rational system is grounded in an aesthetic activity, along with such a construction comes ethical responsibility. ${ }^{111}$ Through the present exposition, it would have been shown, therefore, how is it that the ethical is grounded in the aesthetic by medium of reason.

\subsection{Film as an Aesthetic Activity}

\footnotetext{
${ }^{110}$ Maturana, Humberto, Op. cit., p. 58.

${ }^{111}$ Prigogine, I. \& I. Stengers, Order Out of Chaos: Man's New Dialogue with Nature, Bantam, 1984, p. 312.
} 
We have thus far argued that the pre-conceptual activity through which human beings make sense of their reality is aesthetic in nature. Moreover, we have argued that this type of activity is inceptive in nature, grounded in experience and, as a pre-conceptual activity, is generative of new concepts. Also, we have reached the conclusion that this type of activity is an act of symbolization of reality insofar as what is understood by symbol is the identity of the form and the content in the artistic image. The product of such activity is a narrative poetical in nature; we have in that sense argued that this narrative is similar to the original meaning of the Greek word mythos. Thereafter, we have seen how is it that the dynamics of such an activity is grounded first and foremost in naturing nature, according to Schelling.

This section will serve as an introduction for the following chapters of the present thesis. By taking into consideration the conclusions that have been reached so far, I contend that ever since the introduction of cinema, we have been making sense of reality through film insofar as it is understood as an aesthetic activity. The most interesting feature about the cinematic image, I will argue, is that it could be understood as a tautegory in the sense of Schelling. By viewing the cinematic image as such, this would, therefore, act as a symbol in the sense of Schelling. In other words, the cinematic image becomes the contemporary form of the ultimate artistic creation - which for Schelling is mythopoesis - in which the infinite and the finite are identical in the object of art, i.e. cinematic image. 
Accordingly, the line of thought which will be followed will comprise a close examination of Andrei Tarkovsky's conception of film. Understood from the Tarkovskian perspective, an image that best captures the artist's thoughts and alludes to infinity, depicting the world in its absolute, hints towards a 'metaphysics of emergence' (a concept proposed and explained by Rainer E. Zimmermann). Moreover, film images, as Tarkovsky stresses on more than one occasion, do not symbolize anything specific; they are and represent what they are. This reminds us of Schelling's comment on the Greek gods of mythology: that they are not allegorical but rather tautegorical, i.e. they are and represent what they are. Understood from that perspective, a similar line of thought could be traced from Schelling's Philosophy of Art and the Historical-Critical Introduction to the Philosophy of Mythology, and Tarkovsky's conception of the film image. A film image is what best embodies the artist's striving for making sense of reality in its absolute sense. Furthermore, Tarkovsky emphasizes that '[...i]nfinity is germane, inherent in the very structure of the image,' hinting at a transcendence which is generated in and out of the film image, similar to Schelling's conception of the dynamics of artistic creation. The condition of possibility of this emergence is mythopoesis: the attempt to represent poetically the abundance of reality which, at the end of the day, is not reducible to pure logical discourse. Mythopoesis, thereby, entails a kind of revival of transcendentality which is autogenerated by the film itself, giving cinema a metaphysical dimension; notwithstanding, this transcendentality is not imposed from without, but is rather generated out of the cinematic production. The film serves as the basis of the 'return to the Absolute' not through intellectual intuition, in the sense of Schelling, but rather 
through his conception of aesthetical intuition. The Russian director Andrei Tarkovsky intended to create one such example of a poetical cinema that, in turn, would engage the spectator at a deeper level of apprehension of the film, to actively establish its continuity beyond the screen: this view is best presented to us in Tarkovsky's concept of the film image which he treated in depth in his book Sculpting in Time. Tarkovsky says of the film image: "The true artistic image is always based on the organic unity of idea and form. Indeed, any imbalance between form and concept will preclude the creation of an artistic image, for the work will remain outside the realm of art. ${ }^{112 "}$ Conceiving of the cinematic image as the organic unity of idea and form can only remind us of the Schellingian conception of the symbol. Thus viewed, film as an aesthetic activity becomes one of the contemporary forms of mythopoesis, comprising cinematic images which are conceived as tautegories meaning and representing what they mean. But what implications do the proposed argument and concepts have? We shall examine that extensively in the remaining chapters of the thesis.

\footnotetext{
${ }^{112}$ Tarkovsky, Andrei, Sculpting in time, tr. Kitty Hunter-Blair, Austin: University of Texas Press, 1989, p. 26.
} 


\section{Transcendental Dimension of Cinema}

In the Metaphysics of Emergence, Rainer E. Zimmermann tackles closely and lays a foundational outlook on the emergence of complexity within systems. He moreover stresses the importance of aesthetics as a ground for an adequate form of harmony within societies. This, in turn, acts as a ground for the emergence of ethics based in the model/design which social agents might have constructed within a certain period. Accordingly, the two Stoic notions which would be revived are: Kátà physin and Kalokagathía, whereby the former is the concept of finding the adequate 
form to live according to nature, and the latter is the idea of living in harmony in order to achieve an identity of the good and the beautiful in one's life.113

The aesthetic, however, has come to be acquainted with politics such that the political and ideological are inherent in the concept of the aesthetic. Different philosophers and writers such as Barthes, Ranciere, Zizek and Eagleton, consequently, have been concerned with the ideological use of the aesthetic and the employment of such a field as another tool to foment the hegemony of the dominating political power. Ideology, which at its inception was concerned with the science of ideas, has come a long way acquiring different meanings and significations the value of which has been neutral, positive and negative depending on the different ideological theory proposed. The path that the evolution of the concept of ideology has taken ever since Destutt de Tracy coined the term, saw many thinkers and schools of thought (e.g. Frankfurt School) struggling to break out of this 'prison' in search of a social theory which favored a more democratic egalitarian approach as opposed to hegemonies based in false consciousness and class segregation.

At first glance, the aesthetic domain is prone to be imbued with ideology. It is sufficient to read Roland Barthes' Mythologies and Zizek's The Sublime Object of Ideology to realize how it is that different social domains such as advertising, media and arts are used to promote the capitalist ideology within which we are nowadays living. However, the verity of such observation is precisely due to the theory of

\footnotetext{
${ }^{113}$ Zimmermann, Rainer, A Metaphysics of Emergence, College Publications London, 2015, Forthcoming.
} 
ideology as a false consciousness; that is, that the real intention or meaning of a certain conception is always masked for the social agent. This problem is rooted in the Platonic concept of the Idea: the remoteness of the meaning of a certain domain which is to be found in its ideological substrate. This conception would suppose a limitation for the aesthetic domain insofar as it limits it to what has been thought and not to the potentiality of the emergence of meaning in and out of it - which is also contingent. In these terms, Lacan's Big Other is none other than the collective superstructure of the state throughout history forming the sole looking-glass through which people are to interpret a certain image. Eventually, the outcome would hardly be none other than the interpretation grounded in the remote meaning (conspiratorial in nature) reinforcing preconceived ideas which would have become thing-ed rather than undergoing a dynamical process of production.

The goal of the following chapters, starting with the present one, is to elaborate Schelling's concept of tautegory, which he borrowed from S. T. Coleridge, in order to show how is it that this concept responds to the aesthetico-ideological problematic. Schelling discusses the concept of tautegory both in The Philosophy of Art and The Philosophy of Mythology. The word literally means that which expresses itself, which Schelling proposes as another way to understanding mythology and art - as a production of poetry. This notion entails an apprehension of the work of art not merely as an allegory but rather as that which signifies and means itself only (therefrom, such work can be interpreted allegorically or schematically whereby the former would suppose an ideal interpretation of it and the latter its real side of the 
interpretation.) It, moreover, entails a utopian conception of the aesthetic in Bloch's sense; in other words, the object at hand is no longer limited to a historical interpretation, disregarding as such the present and the future, but it rather widens its limits to include the present and the future, which is based in real possibilities of becoming actualized. By shifting our apprehension of the aesthetic domain from merely an allegorical one (or any conception which might imply a remoteness of meaning of the domain) to a tautegorical apprehension, this will suppose an amplification of the aesthetic scope to include a concept with which Schelling dealt time and again throughout his ample corpus: the coming of the gods and the advent of the Unvordenkliche or the Ungrund (which in the Deities of the Samothrace is attributed to the god Kadmilos - as we have seen in the previous chapter.) Thus, a tautegorical conception of the aesthetic would pave the way for the emergence of meaning - and not an imposition of it - within a certain system (hence the transcendental dimension of cinema). A specific example will be applied in order to support the proposed argument by analyzing both Andrei Tarkovsky's conception of the cinematic images as figures in his book Sculpting in Time and his movies Andrei Rublev, Stalker, Nostalgia, and The Sacrifice. The emergence of meaning of the not-yetthought or the not-yet-being would entail an evolving ethical theory which would be grounded in the aesthetic a posteriori whereby the social agents are continuously adapting to the evolving complexity of the yet-to-come, in a perpetual action, to live according to kalokagathía which is not an ultimate state to be achieved, but rather an ongoing dynamic process. This underlying concept of the novum, as Ernst Bloch points out, has not been given much attention in the philosophical tradition, 
overshadowed by the ultimum. Through the introduction of the tautegorical, the aesthetic is thus liberated from the ideological substratum which might be attributed to a certain aesthetic domain, but which calls for an ethical responsibility therefrom (Tarkovsky himself conceives of an ethical role of art); therefore, the emergence of meaning would entail nothing else than a dynamic theory of ethics which would be an approximation to the Stoic notion of kalokagathía. The proposed dynamic theory of ethics would have to cope with the constantly developing scientific, cultural and social panorama. This is made possible, nonetheless, through aesthetic activity which is perennially in search of the adequate form whereby both form and content are identical and indifferent or, in other words, tautegorical.

This chapter will comprise reflections on Andrei Takovsky's conception of artistic creation and the cinematic image by examining closely his book Sculpting in Time and by examining concrete examples from his cinematography. Tarkovsky's reflections on cinema evoke Schelling's conception of Tautegory in relation to the artistic object. Viewing the cinematic image as such would allow us to argue in favor of an aesthetic dimension of cinema such that the meaning would be emergent rather than imposed dogmatically from without. That is not to say, however, that what cinema is today in its totality is free from any dogmatically or ideologically imbued movies. On the contrary, this chapter and the ones that follow will comprise of an examination of a certain kind cinematic activity, which is mostly based in the cinéma de auteur like that of Andrei Tarkovsky, Werner Herzog and Wim Wenders. These 
directors, and many others, insist that cinema be viewed not as a tool but as an end in itself and as an autonomous domain.

\subsection{Takovsky's Sculpting in Time: Art as a Longing for the Ideal}

"When I speak of the aspiration towards the beautiful, of the ideal as the ultimate aim of art, which grows from a yearning for that ideal, I am not for a moment suggesting that art should shun the 'dirt' of the world. On the contrary! The artistic image is always a metonym, where one thing is substituted for another, the smaller for the greater. To tell of what is living, the artist uses something dead; to speak of the infinite, he shows the finite. Substitution ... the infinite cannot be made into matter, but it is possible to create an illusion of the infinite: the image. ${ }^{114 "}$

"The purity of cinema, its inherent strength, is revealed not in the symbolic aptness of images (however bold these may be) but in the capacity of those images to express a specific, unique, actual fact. ${ }^{115}{ }^{\prime \prime}$

\subsubsection{Film and the Evolving Idea}

Andrei Tarkovsky (1932-1986), a true icon of Soviet cinema, has left a distinguished legacy admired by directors and film critics alike. In the course of the Soviet era, Tarkosvky positioned himself as one of the most influential and important directors on the Russian and international cinematographic stage. For the entirety of his short career, which spanned only seven major feature films (Ivan's Childhood (1962), Andrei Rublev (1966), Solaris (1972), The Mirror (1975), Stalker (1979), Nostalgia (1983) and The Sacrifice (1986)), he set up a framework of ideas and a line of thought which are captured both in his films and in his theoretical conceptions of cinema. Thus, one can consider him an art theoretician (a theoretician of cinema as art) as much as an artist. He himself chose to take upon himself the task of trying to establish

\footnotetext{
114 Tarkovsky, Andrei, Op. cit., p. 38.

115 Ibid., p. 78.
} 
a solid conceptual base for this nascent artistic discipline even in his first years as a film director - this endeavor witnessed the development of his intellectual and creative facets.

Tarkosvky thought that cinema should be conceived as an autonomous art that must be distinguished from literature. For him, the distinction that should be given to cinema as opposed to literature is based on the fact that each of these two fields has its own characteristic features which single it out and define it.

To quote Tarkovsky himself: “My professional biography has been none too happy; the intervals between films were long and painful enough to leave me free to consider - for want of anything better to do-exactly what my own aims were; what are the factors that distinguish cinema from the other arts; what I saw as its unique potential; and how my own experience compared with the experience and achievements of my colleagues. Reading and rereading books on the history of cinema, I came to the conclusion that these did not satisfy me, but made me want to argue and put forward my own view of the problems and the objectives of filmmaking. I realised that I generally came to recognise my own working principles through questioning established theory, through the urge to express my own understanding of the fundamental laws of this art form. ${ }^{116^{\prime \prime}}$

We can see, therefore, that Tarkovsky held a vision of cinema rather different than that of his contemporaries - since he considered it another autonomous art field, he saw the necessity to articulate his own ideas about its essence before being able to apply it to his own work.

${ }^{116}$ Tarkovsky, Andrei, Sculpting in time, Op. cit., p. 7. 
However, the formation and maturation of the conception of the field of cinema which moved Tarkovsky was evolutionary and retrospective. That is to say, even as he created his films, he was drawing, abstracting and developing his own cinematographic conceptions or, to be precise - his particular understanding of what cinema should be. On the basis of his own work, one can reflect on and unravel both his theoretical capacities, laid out in his book Sculpting in Time, as well as his practical and creative ones, captured in his films. To paraphrase Schelling, Tarkovsky's films form the "organ of his reflections". There arises, then, an interplay between the theoretical and practical aspects of the work in the author himself, who then becomes the origin of a dialectical process taking place between the abstract conceptions of cinema as art and the concretion of his cinematographic oeuvre, throughout which a constant evolution of both aspects manifests.

In line with the above, the objective of the following sections is attending to both theory and practice of the filmmaker under study. I will begin by investigating Tarkovsky's conception of art based on his book Sculpting in Time, simultaneously analyzing screenshots and scenes of his films in order to highlight the similarity of his conception of art to that of Schelling's, more specifically to the concept of tautegory.

The conclusion towards the end of the chapter will lie in the reaffirmation that the kind of cinema Tarkovsky aspired for could be an alternative to the ideological cinema per se. This will be based on the concept of the cinematic image as tautegory which would pave the way for an emergence of meaning rather than an imposition of 
it prior to the commencement of the creative process. We will see therefore, that upon such considerations, art would eventually have an ethical role - this role would only be a dynamic one similar to the line of thought as proposed by Stoic philosophy at the beginning of this chapter. Accordingly, the core of this investigation consists of two parallel tasks: first, analysing and describing the conception of artistic creation in Tarkovsky and second, synthesizing Schelling's conception of art with that of Tarkovsky in order to establish the thesis proposed in this chapter.

To carry out my study, I shall formulate and try to answer questions such as the following: what is the conception of art in Tarkovsky? - or, in other words: what does Tarkovsky refer to, when he speaks of art as "yearning for the ideal"? How does he capture this idea in his work? What are the most prominent themes he addresses? How does he arrive to configure them and to what aesthetic categories could they be related?

For Tarkovsky, being an artist requires certain conditions that allow completing the creation of a work. These conditions are yearning for the ideal, love and sacrifice. The last, sacrifice, is realised by the artist through creating a work which would acquire autonomy for itself; that is to say, becomes somehow foreign to the autonomy of its creator. The autonomy I am speaking of in these terms is not an aesthetic category, but rather that of an event - in other words, the principal character of creation is not the artist, but the work in itself. Therefore, the humility of the artist and his sacrifice manifest themselves in the act of his concealment behind his work 
and consequently, in contributing, through such an act, to an immediate connection between the work and the spectator.

The concept of yearning for the ideal refers itself, fundamentally, to an existential state (existential insofar as it refers to the inquietude in the artist's life, which is the awareness of the essence of the human being as "spiritual being"117, as Tarkovsky puts it). This yearning is a figure, as we shall see later on, similar to that of the coming god in Schellingian terms. It is not an ideal insofar as a spiritual/nonmaterial one, but rather that which is not-yet-is, and so a potentiality which would be actualized as the work of art is being created. This ideal is, therefore, as Bloch would agree a utopian state in search of the novum; in other words, that which has not yet been actualized, the novel and creative. Consequently, the term "existential" should not be interpreted in line with the eponymous philosophical tradition and should not be construed as some sort of predicament that makes the artist "uneasy" and, ultimately alienated from himself, society and the world. On the contrary, this existential state does not bring about the separation of the artist from the world, i.e, does not make him somewhat of a hermit, but rather fuels the yearning for an ideal, for the spiritual - it impels the artist to go on a quest. At a first glance, this can seem like a contradictory approach, but one should note the following: the artist holds the

\footnotetext{
${ }^{117}$ Tarkovsky's use of the word spiritual is not that of a religious one, even though he considered himself to be a Christian. His view of the human being as a spiritual being was, in a sense, a reaction to the radical materialistic view which has been dominating, most effectively, in the scientific domain. Therefore, by spiritual, Tarkovsky is looking for an expression which would shake the readers and point out that the worldview could not only be reduced to a purely materialistic view in that sense, but to such a view which, as I will argue later, could be denominated, as Rainer E. Zimmermann argues, a transcendental materialism.
} 
capacity both to observe and to express reality, and thus is aware of the problems which humanity faces; this awareness in turn incites the emergence of the state of inquietude in which the artist strives towards the ideal. This striving, however, would have no sense for Tarkovsky precisely if the artist distances himself from society through and in which he notes the lack of touch with the ideal. Consequently, in one form or another, he has to dedicate himself to artistic creation molding reality in the work. The alienation of the artist from the society is not a physical escape, but a purely transcendental leap, in which, abhorring the banalities of society, he tries to find an ideal, a utopian state similar to the one anticipated by the aesthetic ideals of first-generation romanticism. ${ }^{118}$ The journey undertaken by the artist does not consist in a search or aesthetic experimentation per se, something of which Tarkovsky is vehemently critical, but rather in that the artist should embark on an auto-reflexive movement which makes way for a contemplative, meditative and active path leading to a search for the spiritual. Under these presuppositions, the path itself cannot but be directed by the impulse to build, although created with a distinct goal: that of presenting the spectators with a work that would stimulate them to undertake a movement similar to that of the artist, or - if not - at least to stir intense and profound feelings which come to move them emotionally and sensitize them to the sacred, in both nature and the work of art. That is why, for Tarkovsky, the artist does not hold a didactic role, but a role that is fundamentally "rousing", that is, one which could inspire and stir the emotions of the viewer.

${ }^{118}$ Pontara, Tobias, Romantic and Existentialist Utopia in Andrei Tarkovsky's Stalker, $19^{\text {th }}$-Century Music, Vol. 34, No. 3, Spring 2011, p. 313. 


\subsubsection{Poetic Cinema}

As has already been pointed out, the condition of possibility of being an artist, according to Tarkovsky, is the yearning for the ideal, for the spiritual. The artist acquires awareness of himself as suffering from a state of existential inquietude in which and from which he tries to satisfy his yearning for the ideal, wandering down a path of searching that integrates contemplation, reflection and self-reflection simultaneously.

The search in itself is not the object of art, but it is the quest for the proper "self" of an artist who is thrown into the world. The search itself brings the artist knowledge forged in this "self" so that this, over time, will develop and construct an essentially subjective aspect to the world - that, which would serve as a point of departure for artistic creation.

The self-awareness which the artist acquires is a leap beyond a mere creation of the self. What is seen here is a conscious leap, a meta-creation of self which not only constructs itself and the world, but is the very movement and activity that allow for creating a work of art that would become autonomous by itself. The metaphysical leap of the artist that takes place when he gets beset by the yearning for the ideal, without which there would be no possibility for artistic creation. All this Tarkovsky puts into practice when he decides to write his reflections on cinema as a field and on his work as a cinema director. The self-reflection in his work gives him an 
increasingly more complex and deeper awareness, for it is always immersed in a process of evolution and development, both personal and professional.

The artist, according to Tarkovsky, is capable of bringing together people who, in turn, experience a yearning for the spiritual but are neither able to make this same leap in order to create an object of art, nor to sacrifice for the people. ${ }^{119}$ The artist does not choose this outcome, he has no choice, but is rather involved in a quasioverwhelming situation, in which, on one hand, he decides to create consciously; while on the other, he is creating unconsciously, under the necessity imposed on him by the work itself.

In this situation, which would appear to take a tragic form, there is a tension between freedom and necessity. The total freedom of the artist lies in that he assumes his role as creator, and this role determines an activity which becomes redemptive as a result. On the other hand, necessity is linked to the artist's destiny, because he is confronted with the requirement of the created piece itself to reach a certain level of completeness as a whole, absolute and autonomous work.

The artist is always in motion, on his way to an "encounter" with the absolute which never comes to pass, or - in case it does, comes to pass only ephemerally.

\footnotetext{
${ }^{119}$ The word "people" in this current investigation is void of any political connotation. The term recurs in Sculpting in Time, and thereby is used as an alternative to the expression "human being". When using 'people', therefore, I have in mind an entity constituted by human beings as such and not a political entity.
} 
Therefore, the artist is always on a middle path, defined by the search and the encounter at the same time. Tarkovsky's Stalker reflects this scenario of the artist well, portraying him as a stalker who goes in search for the absolute to satisfy and calm the tension that builds up within, and burdens his soul.

The search, as has been mentioned before, is not the artistic creation, but it is the acquisition of knowledge for which the human being yearns since it acquired selfawareness. Knowledge, for Tarkovsky, grants sense to human life. And given that the individual is bound to seek that knowledge, to seek the truth, there is no other solution than to wander out, try and discover where truth lies, because there also lies happiness.

Absolute truth, says Tarkovsky, is the object of inquiry of both science and art. ${ }^{120}$ Absolute truth is related to the human being's appropriation of reality such that the appropriation of reality rests on the knowledge that the human being acquires having undertaken a voyage in search of it.

Takrovsky divides knowledge into two kinds: scientific and artistic. The difference between the two stems from the way in which each is attained. While the first has a relative nature, the other has a subjective one. Scientific knowledge is, moreover, of an evolutionary character: new discoveries take place of older ones permitting human beings to acquire a more advanced knowledge of nature and

${ }^{120}$ Tarkovsky, Andrei, Op. cit., p. 37. 
themselves as well as to go on an infinite path to an open future, without boundaries, and most importantly, without certainty.

Artistic knowledge, on the contrary, "occurs each time as a new and unique image of the world, a hieroglyphic of absolute truth. ${ }^{121 "}$ The image of which Tarkovsky speaks here and which forms a part of artistic knowledge "appears as a revelation, as a momentary, passionate wish to grasp intuitively and in a single stroke all the laws of this world-its beauty and ugliness, its compassion and cruelty, its infinity and its limitations. ${ }^{122 "}$ Takovsky refers to the art object as an image which contains a unique vision of the real world. This would be the result of the subjective aspect of the artist: "this goal necessarily passes through the subjective moment of the creator: every artist integrates in his work the vision he has of a better world. ${ }^{123 "}$

However, artistic truth does not have a pedagogical purpose as such, but it rather targets the sensibility of people in order to shake them emotionally, hence the "stirring" nature of art. Tarkovsky is interested that the viewer, from the very first moment, be struck, moved by the artistic object, even before he is able to reflect upon it. "Art addresses everybody, in the hope of making an impression, above all of being felt, of being the cause of an emotional trauma and being accepted, of winning people

\footnotetext{
${ }^{121}$ Ibid., p. 37.

122 lbid., p. 37.

${ }^{123}$ Tarkovski, Andrei, Esculpir en el tiempo, trad. Enrique Banús Irusta, Ediciones RIALP, Madrid, 2008, prólogo, p. 10. (I have cited the prologue from the Spanish translation. The translation is mine.)
} 
not by incontrovertible rational argument but through the spiritual energy with which the artist has charged the work. ${ }^{124 "}$

Tarkovsky does not strive for rational arguments, or for arguments that "make sense to the viewer". Life might as well be conceived as meaningless - in fact, quotidian events occur without having any absolute sense, to the extent that one can begin to believe that they are something dreamlike and will dissipate as soon as one wakes.

The artist is the one capable to heed and be fully aware of quotidian events, of social norms and of people's psychological conducts, all of which permit him to form a clear vision of the world which are then reflected in an object of art that, in turn, will come to emotionally stir the viewer.

There is a link, a very special relation between the material and the ideal in Tarkovskian thought. The ideal can be referred to as a utopian state that the human being effectively craves for - such as, for instance, a yearning for the "indigenous" state of Adam and Eve before the fall of mankind. But this yearning, paradoxically, cannot be sated through a separation from and subsequent rejection of the bodily, but rather comes to be "calmed" through the material. Recall that the role of the artist is

\footnotetext{
${ }^{124}$ Tarkovsky, Andrei, Sculpting in Time, Op. cit., p. 62.
} 
the creation of a work of that moves the spectator, and that the work necessarily alludes to the infinite through the finite, to the spiritual through the material. ${ }^{125}$

When we speak about a manner of non-rational argumentation which does not make direct sense to the spectator, we have in mind the "poetic reasoning" that Tarkovsky adopts in his films. This "poetic reasoning" - a special "logic of poetics" opposes itself in the field of cinematography to the logic of linear narration. The latter usually provides a meticulously maintained connection between events which, for Tarkovsky, inevitably leads to the trivialization of reality. ${ }^{126}$ Poetic reasoning, meanwhile, is "closer to the laws by which thought develops, and thus to life itself, than is the logic of traditional drama. ${ }^{127^{\prime \prime}}$

Tarkovsky considered this poetic reasoning fruitful because first, it is able to move the spectator emotionally, secondly, because it makes him participate positively in the film, in the process of acquiring knowledge, and thirdly because it lets him construct the unity of the film as well as add something more, something which contributes to understanding and the formation of the spectator's own perspective on the work which ultimately leads him to forge an original conclusion of the film. Consequently, when non-rational arguments are discussed here, what is alluded to is a poetic sequence in which Tarkovsky displays images - a sequence which surpasses any linear logic and which follows a process according to "the birth and development of

\footnotetext{
${ }^{125}$ Tarkovsky, Andrei, Ibid., p. 37.

${ }^{126}$ Tarkovsky, Andrei, Ibid., pp. 34-35.

${ }^{127}$ Tarkovsky, Andrei, Ibid., p. 20.
} 
someone's thoughts and this includes dreams, memories, fantasies, desires, thoughts and remorse. ${ }^{128 "}$ Hence, the viewer does not hold a merely passive role, but quite the contrary - he must associatively synthesize images so that, at the end, he is emotionally moved in catharsis, and so can attain the knowledge and truth present in a work of cinematography. Thus, understanding a poetic work involves an effort similar to the one needed to enjoy and understand the arguments of Tarkovsky's films.

We can distinguish between two levels of perceiving the same work. On one hand, one can enjoy the beauty and simplicity of Tarkosvky's images that, throughout his entire oeuvre, never failed to fascinate the spectator. Moreover, perhaps thanks to the abundance of silence in Tarkovsky's films, it is not at all strange that the spectator "loses himself" in the image and is mesmerized by whatever is captured on film. But there is some more than mere visual appearance presented by the image - the positive co-implication of the spectator in an intellectual process of reflection so that he not only does take pleasure in the apparent beauty, but also in the harmonious multiplicity depicted in the work, a multiplicity that demands an intellectual effort on behalf of the spectator so that he is able to "piece it together", since the style of narration Tarkovsky adapts is quite poetic. ${ }^{129}$

\footnotetext{
${ }^{128}$ Vacariu, Mihai, Tarkovsky and the Function of Art, Analele Universtitatii Bucuresti, Filosofie, 2002, p. 120.

${ }^{129}$ A classic text which treats the themes of enjoyment of beauty and of perfection and the difference between the two, unity in multiplicity, as well as the perfection of each element in multiplicity, which is based on another element and therefore arises perfectly would be Mendelssohn, Moses, Sobre los sentimientos, en Belleza y verdad, Sobre la estética entre la
} 
The cinema image, for Tarkovsky, is an expression of the infinite through limitation. Tarkovsky chooses to be preoccupied with spirituality linked to the material world, and therefore the absolute with which the artist aims to be reunited with is not an absolute-alien-other, detached from the world, but rather an absolute which is in and through nature. For Tarkovsky, therefore, the modern world has not made the wrong choice because it chose the material over the spiritual (which are always presented as two opposing options), but because it has forgotten the identity of the human as spiritual being. ${ }^{130}$ The human being, by definition has imbalanced himself, having forgotten the spiritual side of his own existence and that of nature.

\subsubsection{Cinema as an Autonomous Artistic Domain}

Tarkovsky equated art with a 'confession', as the work created was redemptive to humanity. Alberto Ciria also speaks of this redemptive function of art, expressing it as follows: "Artistic creation is elevation, the work is elevated - once elevated - and the earth is that to which the effort of elevation is directed, before elevation. No deed is redemptive except creation. ${ }^{131 "}$

\footnotetext{
Ilustración y el Romanticismo, trad. Vicente Jarque Soriano y Catalina Terrasa Montaner, Alba Editorial, 1999, fifth and second letters.

${ }^{130}$ Tarkovsky, Andrei, Op. cit. p. 47.

131 “La creación artística es la elevación, la obra es lo elevado - una vez elevado -, y la tierra es aquello a lo que se dirige el esfuerzo de elevación - antes de elevar -. No la obra es redentora, sino la creación." - Ciria, Alberto, Op. cit. p. 189.
} 
Thus the act of sacrifice, the act of creation, is a redemptive act. To create a work of art, you have to have hope and humility 132 , for nothing is created without then taking on autonomy for itself. The artist will then be concealed behind it, obscured by the work created, because the work itself exceeds the receptive capacity of the created. That is to say, the work of art comes from an organic necessity, 'required' by the inner tension of the artist and the work itself - thus the work exceeds the receptive capacity of the artist himself. Nevertheless, the object of art in itself is not a thing-per-se; it is autonomous only insofar as it is reflected upon dynamically. In that sense, the cinematic image is not to be observed as a thing-ed object to be perceived dogmatically, but is rather to be apprehended as a form of identity between the form and the content; this identity is, as mentioned earlier, similar to Schelling's conception of the symbol insofar as it is understood as the unity of the infinite and the finite in the finite. Understanding the cinematic image as such would, therefore, mean that the image is open to both allegorical and schematic interpretation, but in its totality it would only comprise the identity of both with view towards the future creating thus a space for the generation of new concepts, ideas, meaning and significance.

The very act of sacrifice is tied to the fate of the artist who chooses to surrender himself in it. As mentioned previously, the tragic character of the artist conveys a cathartic element to the viewer. The situation is reminiscent of the sublime and this sublimity ennobles others - just as in the case of one person who acts to

\footnotetext{
${ }^{132}$ See Ciria, Alberto, Op. cit.
} 
redeem all mankind. As Kant says: “There [in tragedy] love is melancholic, tender, and full of esteem; the misfortune of others stirs sympathetic sentiments in the bosom of the onlooker and allows his magnanimous heart to beat for the need of others. He is gently moved and feels the dignity of his own nature. ${ }^{133 "}$ Ciria also writes on the feeling of the sublime: "The aesthetic sublime, however, is conveyed in an action that, undertaken by one person only, is enough to ennoble mankind.134" This category of the aesthetic sublime is very pronounced in Tarkovsky's films.

There is no need to burn one's own house like Alexander has done, to redeem. The same sacrifice made by Alexander is able to redeem man and save him from an impending catastrophe. Domenico from Nostalgia, on the other hand, immolates himself in an act of self-sacrifice because of the miserable state of society. Here you also do not need everyone to set himself on fire to save mankind because the action taken by Domenico is enough for everyone to be redeemed and welcomed in the aesthetic sublime before this shocking a sacrifice. Tarkovsky points out, when talking about Domenico: "In the eyes of normal people he simply appears mad, but Gorchakov responds to his idea - born of deep suffering - of individual responsibility for all that is going on in the world, of each being guilty before everyone for everything. ${ }^{135^{\prime \prime}}$

\footnotetext{
${ }^{133}$ Kant, Immanuel, Observations on the Feeling of the Beautiful and the Sublime, Cambridge: Cambridge University Press, 2011, p. 19.

${ }^{134}$ Ciria, Alberto, Op. cit., p. 77.

135 Tarkovsky, Andrei, Op. cit., p. 205.
} 
All this culminates in the reflection Tarkovsky makes about art in the epilogue of the book. He concludes that art is more of a weapon in the man's struggle against matter, which threatens to devour his spirit.136 There is in art, therefore, an element of reiteration that repeats itself with the passage of time to 'save' the human from the sea in which he sinks. That is why the artist takes a decision to freely create artistically, an act which requires humility and hope at the same time. As it progresses, the created work itself begins to be more demanding, which leads to a situation where the artist is just unconsciously creating. And since the art has a "reiterative" character, the artist is facing a tragic situation, such as that of Prometheus. In addition, acceptance of and surrender to the artist's own destiny make the work of art gain autonomy; it becomes an image that refers to the infinite.

The very actions of Tarkovsky's sacrificing characters are associated with the sublime aesthetic. The action of sacrifice, redeems humanity, tries to stir it showing a path to the future away from a catastrophic end. To surrender to fate and move forward along this road, however, the artist "supports himself" through faith, a very important factor for Tarkovsky. This is why The Sacrifice begins and ends with a shot of a dead tree, symbol of faith. ${ }^{137}$

Tarkovky asks: "Has man any hope of survival in the face of all the patent signs of impending apocalyptic silence? Perhaps an answer to that question is to be found in the legend of the endurance of the parched tree, deprived of the water of life, on which I based this film, and which has such a crucial place in my artistic

${ }^{136}$ Ibid., pp. 236-237.

137 Ibid., pp. 217-229. 
biography. The monk, step by step and bucket by bucket, carried water up the hill to water the dry tree, believing implicitly that his act was necessary, and never for an instant wavering in his belief in the miraculous power of his own faith in God. He lived to see the Miracle: one morning the tree burst into life, its branches covered with young leaves. And that 'miracle' is surely no more than the truth. ${ }^{138}$ "

According to Tarkovsky, it is this combination, between faith which the artist treasures and the reiterative nature of art (to which I have referred above) that sows seeds of creation the artist will make bloom sooner or later.

"In one form or another all my films have made the point that people are not alone and abandoned in an empty universe, but are linked by countless threads with the past and the future; that as each person lives his life he forges a bond with the whole history of mankind. .. . But the hope that each separate life and every human action has intrinsic meaning makes the responsibility of the individual for the overall course of human life incalculably greater. ${ }^{139 "}$

\subsubsection{On the Relation between Truth and Beauty}

The cinema image is a closed work, just like any other work of art. ${ }^{140}$ Beauty arises, therefore, from the balance between the parts of the image. ${ }^{141}$ As Tarkovsky puts it, "[b]eauty is in the balance of the parts. And the paradox is that the more perfect the work, the more clearly does one feel the absence of any associations generated by it. The perfect is unique. Or perhaps it is able to generate an infinite number of associations - which ultimately means the same thing. ${ }^{142 "}$ The beautiful, for Tarkovsky, arises then from the equilibrium and total harmony of the image, and since the mastery of a work flows from such equilibrium, we can infer that, first of all,

\footnotetext{
${ }^{138}$ Ibid., p. 239.

139 Ibid., p. 205.

${ }^{140}$ Ibid., p. 69.

${ }^{141}$ Ibid., p. 69.

${ }^{142}$ Ibid., p. 69.
} 
beauty forms itself in the image before truth. "And the beautiful and the finished in art-what is proper to the masterpiece-I see wherever it becomes impossible to single out or prefer any one element, either of content or of form, without detriment to the whole.143" Under this premise, Tarkovsky assumes that truth can be communicated through the cinema image, provided that it fulfills the condition of equilibrium between the whole and its parts. In my view, therefore, truth is the consequent that arises from beauty, because if the image does not fulfill the condition of totality, it loses any truth the artist might have wanted to capture. The concept of "truth arising from what is beautiful insofar as it is first of all beautiful144" is clearly a romantic one. One could, in this sense, tie Tarkovsky's ideas on truth and beauty in with some classical theories of romanticism, which hold that "beauty is the fountain of truth. ${ }^{145 "}$ For example, in the "Oldest Program for a System of German Idealism, "beauty is presented as the unifying idea, the idea in which thinking and practical activity converge. ${ }^{146 "}$ Similarly, Schelling, in his Philosophy of Art, affirms the identity of beauty and truth. ${ }^{147}$ It should be added, moreover, that not only did the first- and second-generation of German romanticism present beauty as a source of truth, but the English romaticism - especially the poets Wordsworth and Keats affirmed that truth and beauty coincide ${ }^{148}$. Hence, it can be concluded that Tarkovsky shares the romantic vision of the identity of beauty and truth (to the extent that, first

\footnotetext{
143 Ibid., p. 68.

144 "[V]erdadero surge de lo bello en la medida en que antes de nada es bello" - D'Angelo, Paolo, La estética del romanticismo, trad. de Juan Díaz de Atuari, La Balsa de la Medusa, 1999, p. 83.

145 "[L]a belleza es la fuente de la verdad", Ibid., p. 83.

146 "se presenta la belleza como la idea unificadora, la idea en la que convergen actividad cognoscitiva y actividad práctica" Ibid., p. 79.

${ }^{147}$ See Friedrich Schelling, Op. cit., 1987, §20.

148 D’Angelo, Paolo, Op. cit., p. 81.
} 
of all, truth is beautiful), and perceives beauty as the total unity of the image, starting from which truth is presented.

To understand the cinema image takes, according to Tarkovsky, receiving the beauty of art at an emotional level. The process will be something like the following. First, the spectator has to 'see' the cinema image with his eyes. This forces him to contemplation, and thus is the true emotional impact achieved, that is to say, the spectator is captivated and overwhelmed by what he sees before him, so that he is made to reflect on the existence of the work of art as such. ${ }^{149}$ In order that art acquires a natural communicative aspect, in other words, in order that it be conveyed to the spectator, the latter should question the ontological meaning of the created work. And as soon as it has been perceived that the work of art is an attempt to present a vision of the world - an absolutism of reality in the sense of Blumenberg - as soon as the person is aware of the stimulating and communicative role of art - that is when the beauty of the work will reveal that which is contemplated. In short, the condition for one to discover beauty in the work is to go searching for the truth.

The beauty of art is all of this simultaneously. For example, a cinema image captures an independent world in its totality, reflecting the artists' attempt to present a vision of Reality in order to make sense of it. Beauty, therefore, is inextricably tied to the fact that, upon seeing a cinema image, one cannot divide it up to seek the explanation of this or that element. Moreover, one cannot cut any element out,

\footnotetext{
${ }^{149}$ See Tarkovsky, Andrei, Op. cit.
} 
without making the whole image suffer. ${ }^{150}$ In consequence, the cinema image must be perceived in its integrity without thinking that some element has more value or can stand out more than another one. The cinema image is not to be decomposed because the result would not be fruitful: it would not result in anything save a disarray of previously combined elements which, devoid of their context, lose sense and thus eventually let truth escape them. In consequence, such a conception of the cinematic image is evocative of Schelling's call for the tautegoricality of the interpretation of art. That is to say, what the image presents is an identity between the infinite and the finite in the finite. What is presented in the image, however, is what the image is presenting. The very surging of the cinematic image in the Tarkovskian sense calls for the appreciation of the image for what it is, and not for what the spectator thinks it might signify beyond that which is apparent. In that sense, the interpretation of such an image does not remit to the past but is generative of a deeper dimension into the future where a new space is generated for the surging of new ideas. Accordingly, the context within which and out of which a certain movie is filmed wouldn't serve as the key to the interpretation of the film any more than only providing a ground for the outburst of the novum therefrom.

For Tarkovsky, the cinema image also holds an immediate effect, just as music. That is to say, both reach the spectator immediately and are far from any semiotic character or linguistic framework such as the one that governs philosophy. The

\footnotetext{
${ }^{150}$ See Tarkovsky, Andrei, Op. cit., p. 38.
} 
cinema image, just as Tarkovsky conceived, is moreover not one-sided ${ }^{151}$, that is to say: a real masterpiece should comprise a totality constituted by an amalgamation of different elements. Since, for Tarkovsky, a cinema image is beautiful although it loses meaning when decomposed, it is a manifold image complete in itself without expressing a position or idea that are oriented towards the artist's preference. In other words, insofar as art surges out of the necessity the artist faces, what is presented in the created images are contradictory elements fused together and presented in a total harmony. That is, the expression "multi-sided" is taken to mean that the image is an organic work, so that you cannot extract any element from it without damaging the totality. Those elements, on the other hand, allow for a movement in the image itself that carries the viewer to infinity. They are so interspersed that the very structure of the work alludes to the infinite ${ }^{152}$ and this is due to that the image, as it will be seen later, represents the infinite in the finite.

The contradictory elements are not opposed, because if they were, the result of combining them would be something like combining black and white to get the color gray. The contradictory elements are a combination of differences which, when combined, take on a harmony and are diffused within the whole work without any of the losing their proper features. Therefore when combined, they create simultaneously a harmony and a tension in the whole image, consequently communicating an absolute truth that cannot be decomposed or seen partially, but rather can only be perceived for itself through the totality. Moreover, Tarkovsky

151 Ibid., p. 47.

${ }^{152}$ Tarkovsky, Andrei, Op. cit., p. 38. 
claims that thinking in pictures can substitute any idea which can be expressed in words, and this is since "even what is known as the 'idea' of the image, many dimensional and with many meanings, cannot, in the very nature of things, be put into words. But it does find expression in art. When thought is expressed in an artistic image, it means that its one form has been found, the form that comes nearest to conveying the author's world, to making incarnate his longing for the ideal." 153 Hence the cinema image, due to its manifold nature, represents the truth in its absolute form involving different elements altogether in total harmony.

It is true that Tarkovsky discards any symbolism that can be gleaned from the elements represented in a cinema image, but that is only due to the image being considered a symbol in itself. The finite and material image alludes to the infinite, seeking to stir and incite the spectator so that he is reunited with the absolute represented in the image. The function of this latter is, therefore, to awaken the spectator to a new level of reality. There is an aspiration to make the spectator begin to look at and perceive everyday reality in another distinct form, in a form more alive to the one apparent previously. Tarkovsky defines it in terms of the typical which turns around to take the character of the unique while capturing the more individual aspect of the artist. The example which our Russian director gives is that of a Japanese haiku that reads:

"No, not to my house.

That one, pattering umbrella

${ }^{153}$ Ibid., p. 104. 
Went to my neighbour."

This mundane, typical and quotidian scene acquires a new character that introduces us to the artist as individual. That is to say, the scene gives us an idea about the psychic state of the artist during the gray rain, looking out of the window and observing what is happening outside. The image suddenly acquires a consolidated unity stemming from those features, which typically bring the spectator an absolute vision represented in that image, in which "the entire world is reflected in a drop of water. ${ }^{154 "}$

Tarkovsky explains it thus: "We are faced with a paradox: the character image signifies the fullest possible expression of what is typical, and the more fully it expresses it, the more individual, the more original it becomes. It is an extraordinary thing, this image! In a sense it is far richer than life itself; perhaps precisely because it expresses the idea of absolute truth. ${ }^{155^{\prime \prime}}$

The expression of the typical is tied to the simplicity of the cinema image in Tarkovsky's work. It is for this reason, that he rejects any symbolic interpretation of shots from his films. Tarkovsky's intention is to present reality as it is, coupled with the intention to present this reality in its most "consecrated" form, spirituality and materiality both given in it. It is as if the truth is given right there, where it is most apparent, but swamped by the mundanity of life as we are, we do not see it in itself, in its most spiritual form. The artist is then to represent this truth impregnated by

\footnotetext{
154 Tarkovsky, Andrei, Op. cit., p. 110.

155 Ibid., p. 112.
} 
beauty in a cinema image, converting what is most typical into something unique. The reality as presented has a dreamlike feature, straddling between pure materiality and pure spirituality. A reality more intense and more 'real' than reality itself is discovered there. This is what Tarkovsky alludes to when he says that there is a sense in which the image is richer than life itself.

\subsubsection{On the Ethical Value of Art}

Gorchakov, an exiled poet, goes to Italy to direct a documentary on another poet, Ucranio, who lived in Italy during the Renaissance. Like most of Tarkovsky's characters, and fulfilling the condition of possibility for aesthetic creation, the poet has to be in perpetual tension and internal disquiet that lead to a state of longing for the ideal.

The case of Gorchakov can be taken as an example for mere homesickness, longing for his own country from which he is exiled, but it can also be seen as a longing for the past, for childhood, for infancy, for a state of pure consciousness, a more "indigenous" state, during which one experiences a much stronger relationship to earth, enhanced by that distance which holds children back from any material immersion and by an awareness of the spiritual defined by the state of childhood itself.

During the film, we do not see Gorchakov write a single word. He is a poet who does not write, a poet who is overcome by inner torment and incapable to 
surpass this nostalgia which grabs him by the throat. However, all this is the destiny of the artist. To be able to create, the artist is condemned to this inquietude, to this longing for the past ever present in his memory, because it paves the way towards the ideal.

We see here the relationship between romantic philosophers and Gorchakov. Some romantic philosophers have experienced nostalgia for an ideal past, for example, that of the Greeks, which they considered a more harmonious society, with each individual forming a part of the whole. ${ }^{156}$ We don't need to go too far on this Schiller, in his assessment of the state of modern man, expresses nostalgia and longing for the past based on his point of view on classical antiquity ${ }^{157}$ in his very first poetic compositions, entitled The Gods of Greece.

"It is precisely in this sense that it can be said of his first dramas and first poetic compositions that they are driven by a feeling of nostalgia towards antiquity, which marks the initial reading of Schiller taken within its own present: as the word itself intimates (nostos: return; algos: pain), not only is nostalgia a longing for return, the glance that looks into the distance with the desire to return, but it also is the pain caused by knowing that such a return is impossible, the motherland cannot be

\footnotetext{
${ }^{156}$ I refer to the Spanish edition: Schiller, Friedrich, Sobre Poesía ingenua y Poesía sentimental, trad. Juan Probst y Raimundo Lida, Verbum, 1994.

${ }^{157}$ Véase ACOSTA LOPEZ, María del Rosario. Tragedy and modernity in Friedrich Schiller's theory of the sublime. EPISTEME. [online]. Dec. 2007, vol.27, no.2 [cited 04 May 2012], p.147-168. En el URL: http://www.filosofiaytragedia.com/textos/caracas.html.
} 
recovered, it is lost forever and can only be coveted in memories.158" In the Letters on Aesthetic Education of Man159, Schiller writes of the longing for the ingenuity and simplicity of the Greeks in comparison to modern society: "he Greeks put us to shame not only by their simplicity, which is foreign to our age; they are at the same time our rivals, nay, frequently our models, in those very points of superiority from which we seek comfort when regretting the unnatural character of our manners. We see that remarkable people uniting at once fullness of form and fullness of substance, both philosophising and creating, both tender and energetic, uniting a youthful fancy to the virility of reason in a glorious humanity. ${ }^{160 "}$

Each one, in Greek society, contributed to the whole, so that the mythology which arose was a mythology of the people; all participated in forging it and transmitting it, as if fuelled by the workings of a kind of collective unconscious (which therefore fundamentally involves everyone).

That longing of the romantic philosophers of the past was also a longing for a naive state of human beings, for its infancy, a state of pure consciousness not contaminated by prejudice towards any rigid ideology. It is a state of innocence in

\footnotetext{
${ }^{158}$ Ibid, "Es en este sentido, justamente, que puede afirmarse que sus primeros dramas y sus primeras composiciones poéticas están impulsados por un sentimiento de nostalgia por la Antigüedad, que marcará la lectura inicial de Schiller sobre su propio presente: como la palabra misma lo denota (nostos: retorno, algos, dolor), la nostalgia no es sólo un anhelo de un retorno, la mirada que mira hacia aquello lejano con el deseo de volver, sino el dolor que causa saber que dicho retorno es imposible, la patria materna no puede recuperarse, está perdida para siempre, puede sólo anhelarse en el recuerdo". The translation is mine.

${ }^{159}$ I refer to the Spanish edition: Schiller, Friedrich, Kallias. Cartas sobre la educación estética del hombre, trad. Jaime Feijóo y Jorge Seca, Anthropos, 1990.

${ }^{160}$ See Schiller, Friedrich, Cartas sobre la educación, Op. cit., p. 143.
} 
which the human seeks and acquires knowledge hungrily; he seeks the truth and is always asking for the meaning of everything. This is what children often do: they wander around any and all places, landscape, house, fields, forests...always captivated and in awe of the aura of things around them. Everything fascinates them, and they see reality as it is, without any taint of prejudice. This is precisely how Tarkovsky aspires to have the spectator view his films: as images that present absolute truth referring to the infinite (thus, just as children, incessantly wondering about things, displaying an insatiable desire to know).

The longing and nostalgia for the past, combined with hope, lead one to the terrible, according to Alberto Ciria ${ }^{161}$. However, it is essential that, along with nostalgia, there be a hope that looks on to the future, in the sense of Bloch, towards the ideal and the spiritual. This is because without past, present or future, there is no time, and on the other hand, time is always flowing, elapsing. Time is within nature Tarkovsky demonstrates this through shots of flowing water, trees swaying in gusts of wind and a multitude of other elements that testify to the existence of movement independent of the existence of human beings. This helps achieve an awareness of the passage of time while contemplating nature. In this process the three dimensions of time are united: through memory, one is aware of the past, through awareness of self as a self - of the present, and through hope - of the future.

${ }^{161}$ See, Alberto, Op. cit. 


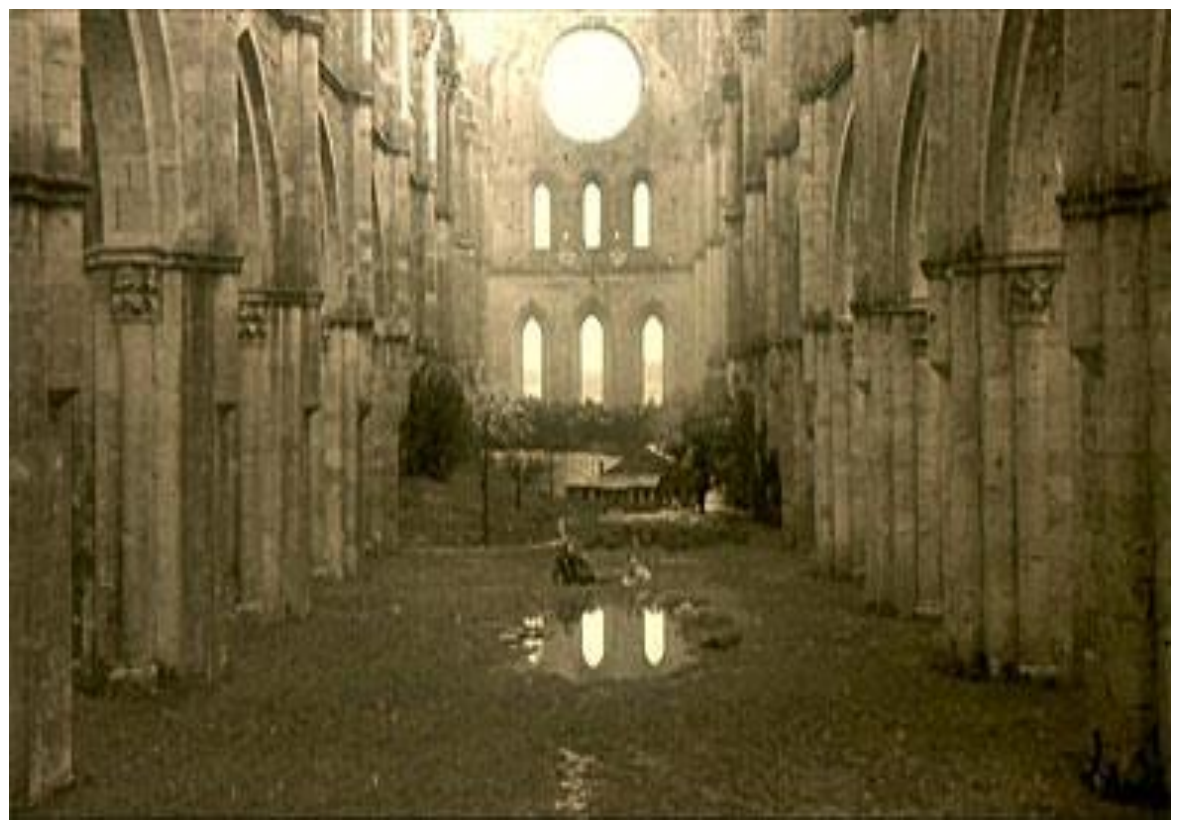

Figure 1: Nostalgia - Andrei Tarkovsky

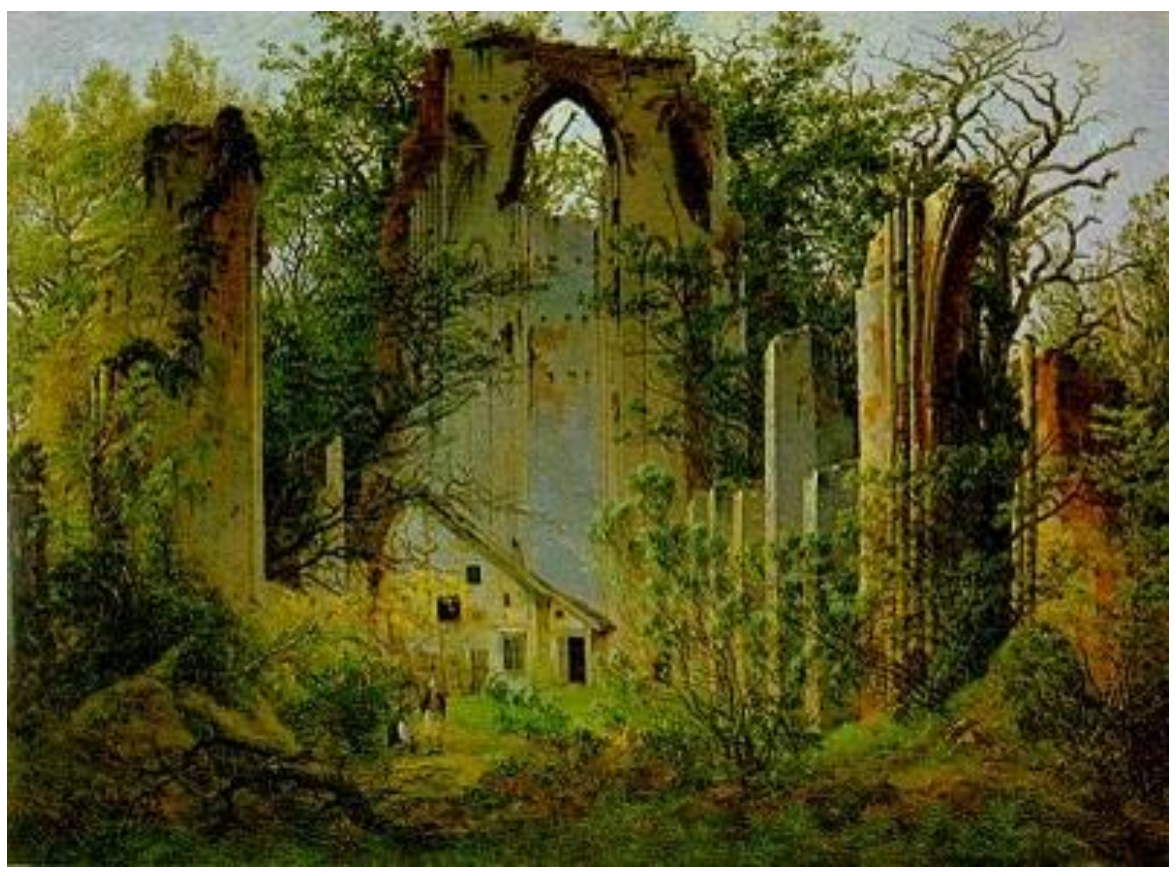

Figure 2: Ruins of Eldena - Caspar David Friedrich 
In the last scene of Nostalgia, Tarkovsky makes a direct reference to Ruins of Eldena, a painting by the romantic painter Caspar David Friedrich, which directly reflects some elements of the romantic tradition of painting. What appears in the shot is a mélange of the ruins of what appears to have been a cathedral and a dacha with trees in the background. Gorchakov sits in front of the dacha, accompanied by a howling dog. Anne Lawton sees in this mélange a harmonisation between past and present, as it is a combination between what is "out of time" (represented by the ruins of the cathedral) and what is "in time" represented by the dacha, Gorchakov and the dog) ${ }^{162}$. The combination entails a transcendence, a union with the absolute outside time. What makes Gorchakov sacrifice himself, carrying the candle through the pond towards the end of the film is therefore this assault at the absolute.

Tarkovsky himself says: “Time and memory merge into each other; they are like the two sides of a medal. It is obvious enough that without Time, memory cannot exist either. ${ }^{163 "}$ He adds "I am interested here in the inner, moral qualities essentially inherent in time itself. $164^{\prime \prime}$

The artist's ability, then, is to "dis-close", reveal (in the literal sense of the word), forge through memory and in suffering from a nostalgia for the past, a future, and attract it to the present.

\footnotetext{
162 Robinson, Jeremy Mark, The Sacred Cinema of Andrei Tarkovski, Crescent Moon, 2006, p. 488.

163 Tarkovsky, Andrei, Op. cit. p. 57.

164 Ibid., p. 58.
} 
In addition to inquietude and yearning for the ideal, the artist is able to give birth to the possibility of the evocation of new ideas out of the cinema image, by the total and harmonious nature of the image. Tarkovsky comments on this aspect: "a new idea, a new organism, has emerged from the ruins. ${ }^{165 "}$ The filmmaker alludes here to the rupture that can occur between the director and the scriptwriter, but his words also introduce us to the idea that one can only move forward, towards the future, taking into account the future (as yearning for the ideal) as well as the past (as memory and nostalgia), while holding them together in the present. An artist guided by such principles is impelled, by necessity, to continue creating and experimenting in a peculiar species of eternal return - with capturing absolute truth in the cinema image. And this force to which the artist yields is as powerful as the one felt in the grandeur and vastness of nature.

The artist is in the middle of a never-ending road, following it thanks to his faith in enlightening people, in providing light, fire - the same fire which Gorchakov tries to move from one side of the pond to another, without the candle going out.

Furthermore, Domenico, another artist who is more like the Stalker ${ }^{166}$, decides to carry out another performance: self-immolation in the centre of the city, all to stir a society that is alienated through everything material, to the extent that it has been

\footnotetext{
165 lbid., p. 98.

${ }^{166}$ See Tejeda, Carlos, Op. cit.
} 
converted into a congregation of 'zombies' who live without perceiving the sacred, without reflecting on truth and without being aware of themselves. This devoted action brings us to the last step of artistic creation, which is the sacrifice realised in the act of immolation (Domenico burning himself in Nostalgia, Alexander setting fire to his home and belongings in The Sacrifice). The sacrifice of the artist himself has to be understood, therefore, in the key of creative action that aims at saving and redeeming the human being.

The ethical value, as mentioned at the beginning of the chapter, is not so much inherent in the cinematic image, or in any aesthetic activity for that matter. Nevertheless, the space generated by the aesthetic activity, in this case cinema, allows for the discovery of the different possibilities precisely because of the organic nature of the cinematic image. Therefore, Stoic concepts such as Kátà physin and Kalokagathía are dependent on the social agents - in the case of cinema, on the spectators. The aesthetic domain, in the general sense, therefore, paves the way for the production of that which would thereafter form the basis on which to speculate ${ }^{167}$ and produce an overflow of new ideas and concepts that would help the respective societies adapt to the state of affairs during a specific period of time. From a wider perspective, this could only be indicative of the importance of interdisciplinary studies which have been on the rise lately (this subject will be dealt with in more detail in the sixth chapter).

\footnotetext{
${ }^{167}$ The subject of the speculative activity and the generation of concepts will be treated in the sixth chapter of the present dissertation.
} 


\subsection{A Schellingian Reading of Tarkovsky's Sculpting in Time}

“The images themselves are like symbols, but unlike accepted symbols they cannot be deciphered. The image is like a clot of life, and even the author may not be able to work out what it means, let alone the audience." - p. 369 (Time within Time)

\subsubsection{On Freedom and Necessity in Aesthetic Creation}

The Tarkovskian artist is subject to the tension between freedom and necessity. The latter arises inside the artist, who creates merely unconsciously - this act takes the place of a conscious decision to create.

For Tarkovsky, the artist himself is a tragic figure, subjected to a destiny which has no respite. The tragedy, then, lies in his inability to escape his fate. His sin, however, is not limited to him as a person, but is also the sin of man. Alexander, the protagonist of The Sacrifice, is faced with the prophecy of possible destruction and disappearance of the Earth, caused by an impending nuclear war. Alexander is aware of it, he knows that people and societies have erred, have committed the sin of shunning their essence as spiritual and material beings. The human being has been preoccupied with technological progress, and this has only led him to the edge of a precipice from which he will either plunge to his demise or be saved by an act of sacrifice. 
In The Sacrifice, Alexander says, aware of the current state of humanity: "All our technical progress has only provided us with comfort, a sort of standard. And instruments of violence for keeping power. We are like savages! We use the microscope like a cudgel!" This is not a view critical of science, but rather of the human being who has forgotten the meaning of his existence in favour of a striving for purely material progress and welfare. Forgetting the meaning of existence, denying the quest for truth, ignoring the path to knowledge of self and world, human being has come to produce tools that were converted into weapons of selfdestruction. Alexander, aware of this, chooses sacrifice to save the world: a prophetic action to open the way into the future for human beings. Thus, first, he seeks help from the witch - and here, faith is revealed as a critical factor in Alexander's decision.

The protagonist chooses consciously and freely to create a work of art that can redeem mankind, but from there, he is confronted by the second dimension of artistic creation: the organic necessity required by the work, which the artist will perform unconsciously and, on the other hand, the complete acceptance of his fate because he has no means of escape.

Alexander is increasingly forced to take another step forward to engage in artistic creation grounded in sacrifice and total submission to fate, all this without concern for whether people appreciate what he does. His enterprise reaches a climax when he burns his house, the home where he belongs, thereby emphasizing the total uprooting of belonging in the world of the artist. Thence, Alexander will be seen as a 
deranged madman who does not know what he has done, and so will end up in an asylum.

Philosophers and poets or even literary characters face the same fate: they succumb to their destiny in hopes of making sense of Reality, presented as an object of art. Such people are often considered insane because they are "beyond" insofar as what they are presenting as a harmonious work which would be total and impartisan, presenting a world picture rather than imposing a one-sided view of Reality: "because of his special awareness of his time and of the world in which he lives, the artist becomes the voice of those who cannot formulate or express their view of reality. In that sense the artist is indeed vox populi. That is why he is called to serve his own talent, which means serving people. I cannot in fact understand the problem of an artist's so-called 'freedom' or 'lack of freedom'. An artist is never free. No group of people lacks freedom more. An artist is bound by his gift, his vocation. On the other hand he is at liberty to choose between realising his talent as fully as he can, or selling his soul for thirty pieces of silver. Was the frenzied search of Tolstoy, Dostoievsky and Gogol not prompted by their awareness of their vocation, of their ordained role?168" The artist, then looks on from the future, sowing seeds and investing in an artistic creation that will need time before coming to fruition.

Tarkovsky notes: "The central character of my latest film, Sacrifice, is also a weak man in the generally accepted sense of the word. He is no hero, but he is a thinker and an honest man, who turns out to be capable of sacrifice in the name of a higher ideal. He rises to the occasion, without attempting to shed his responsibility or trying to foist it onto anyone else. He is in danger of not being understood, for his

${ }^{168}$ Tarkovsky, Andrei, Op. cit., pp. 164-165. 
decisive, just action is such that to those around him it can only appear catastrophically destructive: that is the tragic conflict of his role. He nevertheless takes the crucial step, thereby infringing the rules of normal behaviour and laying himself open to the charge of folly, because he is conscious of his link with ultimate reality, with what could be termed world destiny. In all this he is merely obeying his vocation as he feels it in his heart-he is not master of his fate but its servant; and it may well be that through individual exertions such as his, which nobody notices or understands, world harmony is preserved. ${ }^{169^{\prime \prime}}$

We can see here that Alexander is not merely succumbing to his own fate - as sin is not individual - but is rather subject to the fate of the world, to redeem man through artistic creation. The artist therefore serves his destiny and that of the world and is in some way responsible for this latter. He acts as a unifying factor, someone able to capture reality in an artwork.

\subsubsection{Images as Ciphers of the Infinite}

The artist, in order to make leap towards a union with the absolute, has to touch the infinite in a contact that lasts only a few instants. That infinity with which he is reunited is the perpetual ontological presence represented in the cinema image, ultimately pointing the infinite through the finite. It is for this reason that Tarkovsky's films sometimes tend towards abstraction, the example of which would be the abstract image/painting shown in Andrei Rublev. Abstraction could therefore be the best representation of the absolute, of the infinite through the finite.

169 Tarkovsky, Andrei, Op. cit., p. 209. 
Abstraction refers to the absolute without defining it, because its definition is a task that's difficult, if not unmanageable. Abstraction is a form of mysticism, not the mysticism that aspires to a simple spiritual reunion with the absolute, annihilating itself in the process, but on the contrary, as Botz-Bornstein has it, Tarkovsky's mysticism is more like that of Plotinus in the sense that it is a mysticism that tends to a union with the one from which everything emanates and to which Tarkovsky refers when he speaks of a "simplicity of the image", warning that his images only mean what they are. That is to say, this mysticism is a way of perceiving the reality that is there to know, standing before the human being. When he speaks of spirituality, therefore, he is not referring to another dimension, something that is "beyond", but to another level of awareness. This skips over any ideology that permeates us to instead perceive nature as it is. Thus, sometimes the form of abstraction can be more appropriate than any other form of artistic expression to communicate absolute truth.

So, from my point of view, although Tarkovsky is recognized as a Christian, the sacred and religious in his films refers not as much to a religion, as to a spirituality removed from any kind of dogmatism. He approaches somewhat the grounds of certain Eastern religions such a Buddhism, in which he was himself very interested, ones that emphasize a contemplative vision of the world and oneness with nature, with the absolute, both spiritually and materially. 
One can also trace, in the work of Tarkovsky, a line of romantic sublime traits, making its abstraction comparable to that of abstract expressionism ${ }^{170}$. To highlight this, I will discuss Robert Rosenblum's article "The Abstract Sublime", the main thesis of which is that the origins of abstract expressionism are in nineteenth-century Romanticism.

Rosenblum establishes a common ground between nineteenth-century Romanticism and abstract expressionism. ${ }^{171}$ The link between the two is the evocation of sublime before the formless, boundless and vast. "Indeed, such a breath taking confrontation with a boundless in which we also experience an equally powerful totality is a motif that continually links the painters of the Romantic Sublime with a group of recent American painters who seek what might be called the 'Abstract Sublime'. ${ }^{172^{\prime \prime}}$

Here Rosenblum gives the example of Caspar David Friecrich painting "Monk by the Sea" and that of Mark Rothko, "Light Earth over Blue".

\footnotetext{
${ }^{170}$ See on this topic Reass, Herbert, Breve historia de la pintura moderna, Serbal, 1984, Chapter Seven.

${ }^{171}$ See Rosenblum, Robert, The Abstract Sublime, Artnews 59, no.10, February, 1961. See Also, McEvilley, Thomas, Op. cit. Second Chapter.

${ }^{172}$ Rosenblum, Robert, Op. cit.
} 


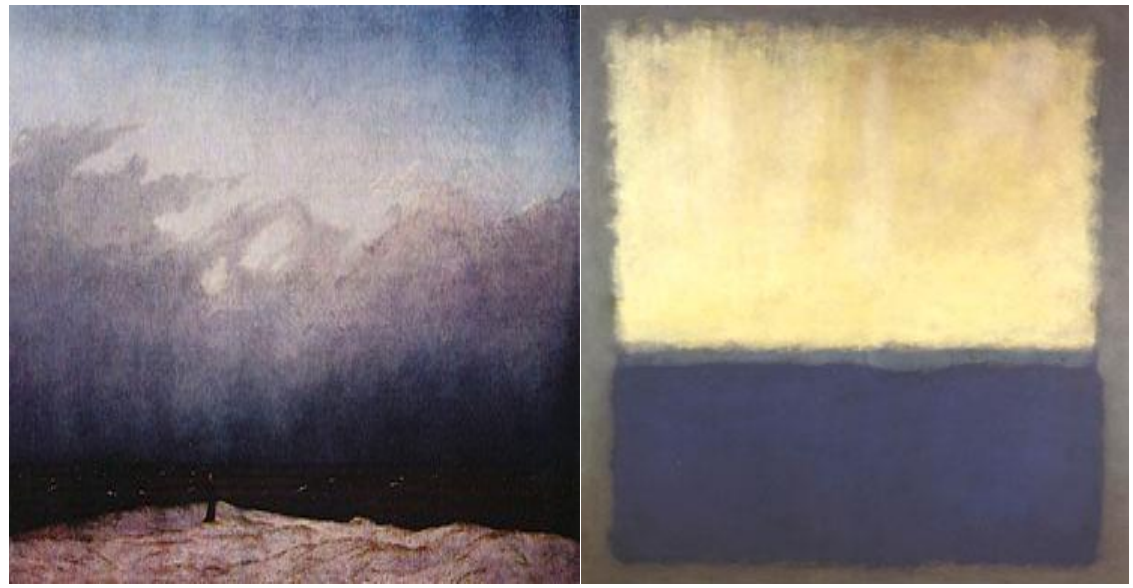

Figure 3: Monk by the Sea - Caspar David Friedrich Figure 4: Light Earth over Blue - Mark Rothko

Both painters manage to capture the formless: an infinite, vast and empty space. In both paintings we see an integration of three elements - in Friedrich, the three elements would be sea, land and sky, while in Rothko the three elements would be expressed abstractly, through a difference between three colors - yellow, gray and blue. However, while in Friedrich, the monk emphasizes the contrast and represents the bridge between the infinite and finite, for Rothko the spectator becomes the monk facing the abstract. ${ }^{173}$ The sublime is immediately evoked in the contemplation of an abstract work, and it transports the spectator to a state beyond reason. ${ }^{174}$ (Note that in case of Rothko, the experience of the sublime is linked to a perception of color). As transcendence is reached, the viewer gets to a state of ecstasies, i.e., the viewer in front of the frame stays there, but he has transcended towards an ontological presence.

\footnotetext{
${ }^{173}$ See Rosenblum, Robert, Op. cit.

${ }^{174}$ See Rosenblum, Op. cit.
} 
"The total extinction of movement results in an experience of quietude into which the observer can feel himself absorbed as the colors are absorbed into the canvas. All sense of conflict or individualized emotions is lost in a pervasive, contemplative experience of light. ${ }^{175^{\prime \prime}}$ This is an experience that inclines and enables one, as stated on many occasions, to establish a link between abstraction and mysticism. The experience of color renders the spectator "absorbed" in the being of the artwork in a transcendent leap towards the metaphysical union with the absolute embodied in the work itself. This is the ontological presence of a work of art to which I referred earlier. As Thomas McEvilley says on this subject: "The ontological aspect of color means that it is not only a quality, but an embodiment of the substrate of pure being, and that it can act as the force of pure being, below and beyond all the other qualities. This is a reformulation of the idea expressed by Malevich, Klein and others: the monochromatic, insofar as it 'eludes infinity', evokes the infinite simultaneously within and outside of itself; it acts as a purifying attraction towards the unity beside the point of view of the ego and represented by the line, the sketch and the figure. The absolute space of pure consciousness a priori to all the images is projected on an uninterrupted monochromatic surface, and this surface is, thus, imbued with the energy of this projection, and is capable of opening a channel

\footnotetext{
175 Levine, Eduard M., Abstract Expressionism: The Mystical Experience, Art Journal, Vol. 31, No. 1, Autumn, 19971, pp.22-25, en el URL: http://www.jstor.org/stable/775629.
} 
that would lead inside the absolute space below the surface or the images formed in the mind of the spectator. ${ }^{176 "}$

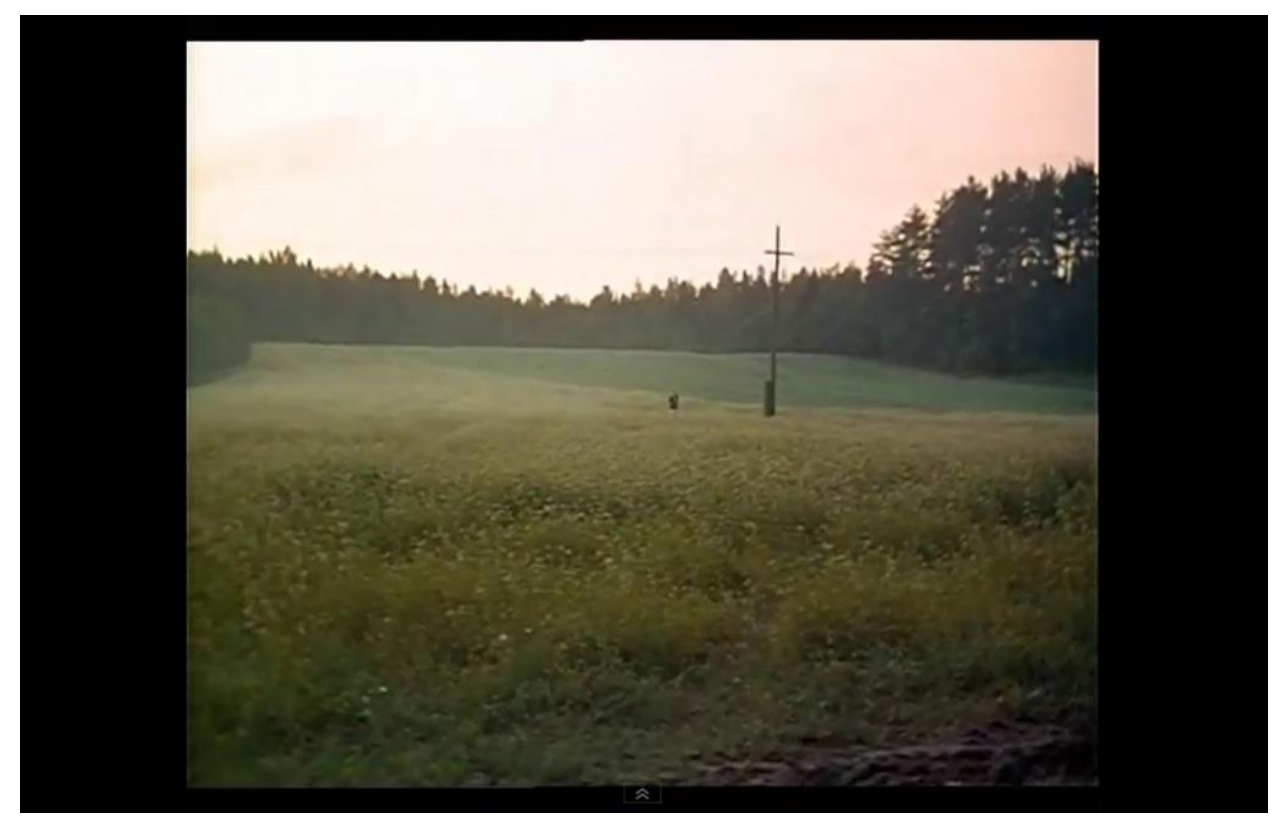

Figure 5: The Mirror - Andrei Tarkovsky

\footnotetext{
${ }^{176}$ I refer to the Spanish edition: McEvilley, Thomas, De la ruptura al "Cul de Sac", trad. Alfredo Brotons Muñoz, AKAL, 2007, p.61: "El aspecto 'ontológico' del color significa que es no sólo una cualidad, sino una encarnación del sustrato del puro ser, y que puede ejercer la fuerza del puro ser, por debajo o más allá de todas las cualidades. Ésta es una reformulación de la idea expresada por Malevich, Klein y otros: el monocromo, en cuanto 'escape a la infinitud', arrastra a uno simultáneamente dentro de él y fuera de sí mismo; ejerce una atracción purificadora hacia la unidad y que aparte del punto de vista separado del ego y representado por la línea, el dibujo y la figura. El espacio absoluto de la consciencia pura anterior a todas la imágenes se proyecta sobre una superficie monocroma ininterrumpida, y esa superficie entonces, cargada por así decir con la energía de esta proyección, es capaz de abrir un canal que lleva al interior del espacio absoluto por debajo de la superficie o la mente formada por imágenes en el espectador." The translation is mine.
} 


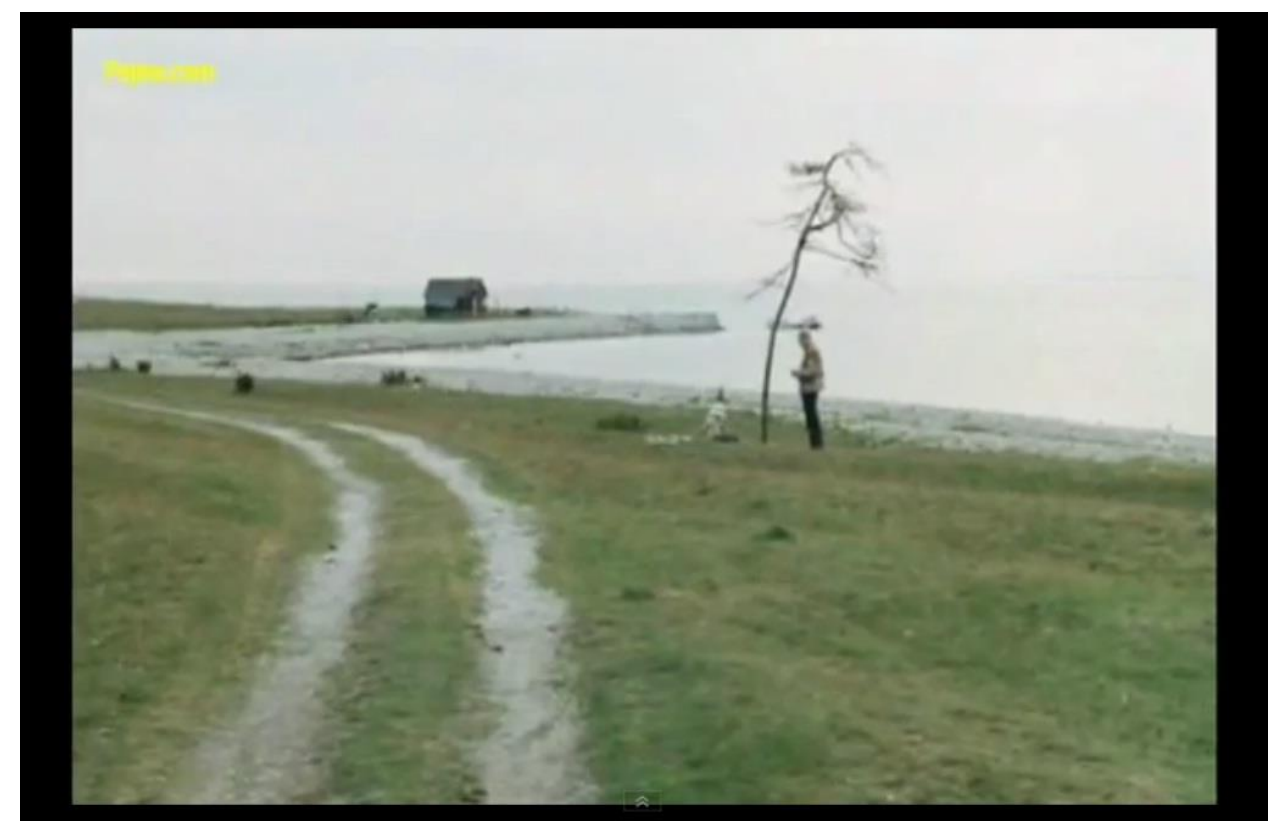

Figure 6: The Sacrifice - Andrei Tarkovsky

I believe these two stills, from The Mirror and The Sacrifice respectively, present some similarity with the aforementioned Friedrich and Rothko paintings. In both three elements exist together. In the first still, the earth, trees and sky are connected by the cross, while in the second frame, the earth, sea and sky are connected by a tree. In both, there is also a person by the cross and the tree.

Contemplating such frames, we approach in thought to a recreation of the sentiment of the romantic sublime or, which is the same thing, attempt to excite intense sentiment amidst the vastness and grandeur of nature as well as the work of art. From this perspective, we can better understand the recurring pictorial 
representation of mountains, cliffs, and seas in the works of romantic painters such as Caspar Friedrich and William Turner. ${ }^{177}$ The representation of the infinite in the finite is what evokes the feeling of the sublime when contemplating a painting or a still. In the words of Schelling: "The first of the two unities, that which constitutes the informing of the infinite into the finite, expresses itself within the work of art primarily as sublimity. ${ }^{178 "} \mathrm{He}$ adds: "The intuition of the sublime enters only when the sensual, concrete intuition is found to be inadequate for the greatness of the concrete object, and then the truly infinite appears for which the merely concretely infinite is the symbol. ${ }^{179^{\prime \prime}}$

The cross, therefore, while "twisting" dimensions to represent infinity, transcendence and eternity in the still above, cannot but stir the spectator, evoking a burning feeling of the sublime.

We see in the previous frames the same contrast between the infinite and the finite as we see in the paintings of Friedrich and Rothko. What unites the three elements in Tarkovsky are the cross and the tree, which tend to twist space to refer to the infinite. The cross symbolises not only the sacrifice, but "also the transition to

\footnotetext{
${ }^{177}$ See Santamaría, Alberto, Sublime, en: Rosa Benéitez Andrés y Claudia Supelano-Gross (eds.), Tipos móviles, Luso-Española, 2011.

${ }^{178}$ Schelling, Friedrich, Op. cit., 1989, p. 85.

179 Ibid., p. 86.
} 
where time and space are absent, to eternity. $180^{\prime \prime}$ Similarly, the tree which represents faith represents eternity, a transcendent leap through faith.

And so, if on the one hand what we contemplate in these stills evokes a feeling of sublime, they also can be compared with abstract paintings. In Tarkovsky, abstraction tends to represent objects as they are - for instance, the Zone in Stalker, or rain and fire, which are recurrent elements in all his films. In that simplicity of looking and contemplating objects as they are, as opposed to a more complex background, i.e., in superficiality derived from a simple contemplation of a frame, there lies a dimension of profundity, which is due to the mystical nature that sometimes - depending on specific works and authors - can be found in abstract art. Here I quote Robert Motherwell: “One of the most striking aspects of abstract's art appearance is her nakedness, and art stripped bare. How many rejections on the part of her artists! Whole worlds - the world of objects, the world of power and propaganda, the world of anecdote, the world of fetishes and ancestor worship.... What kind of mystique is this one might ask. For make no mistake, abstract art is a form of mysticism. ${ }^{181 "}$ Therefore, the nakedness of abstract art Motherwell speaks about is well reflected in the concretization of formlessness and immensity through color.

\footnotetext{
180 "[...] también es el tránsito hacia la ausencia de espacio y de tiempo, la eternidad» - Ciria, Alberto, Op. cit. p. 95.

${ }^{181}$ Motherwell, Robert, Op. cit. p. 12.
} 
If we pause at a still from Tarkovsky's Andrei Rublev, where Andrei blots the wall of the church which he and his crew were working on, we see that the result is something like an abstract painting. This "painting" cannot be seen in color in the black-and-white Andrei Rublev, but it is reflected on the shape of the work as a whole. We have here, just as in the paintings of Friedrich and Rothko, a contrast between the finite and the infinite, a contrast between the surface represented by the shape of the painting as it is on one hand and, on the other hand, the infinite space that opens before the spectator contemplating the painting. The profundity comes from the spectator, and therefore, that dimension that goes beyond the mere surface to penetrate what is deeper and more infinite is also generated while contemplating the cinema-image by the active role of the spectator. Therefore, the spectator must participate in the work contemplatively to reach transcendence pursued not only in a romantic painting or in a painting of abstract expressionists, but in a Tarkosvkian cinema-image.

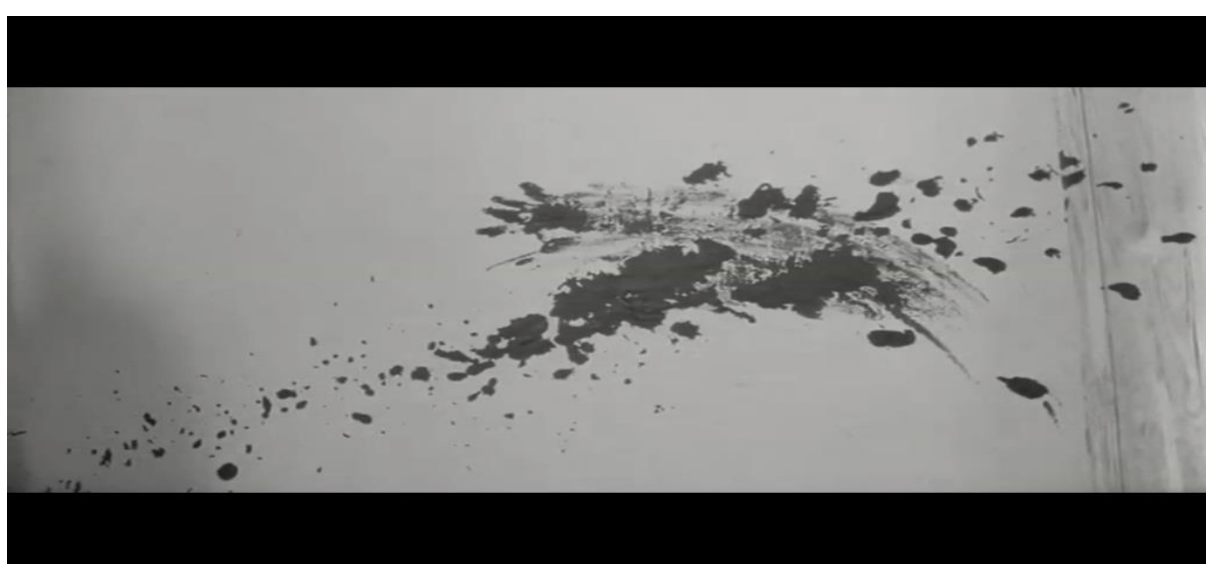

Figure 7: Andrei Rublev - Andrei Tarkovsky 


\subsubsection{On the Tautegoricality of the Cinematic Image}

The active participation of the spectator mentioned in the previous section, however, is hardly a simple one; the spectator needs to engage in a vigorous apprehension of the film in order to articulate a personal view of that which was molded into the cinematic image. Tarkovsky vehemently reiterated and stressed, time and again, that cinema is not a place of entertainment in the pastime sense; cinema is to be viewed as a serious and autonomous domain through which the director and the spectators try to capture and make sense of Reality. Consequently, the reception of the movie among other things, should be met with a critical view, not that proper to connoisseurs, but of a kind of intellectual engagement after having been shaken emotionally (aesthetically) during the movie. Notwithstanding, the kind of cinema Tarkovsky, and other directors, have been calling for, is that which does not strive to enforce or promote any kind of ideological message. The interpretation of such kind of cinema as ideological would, thence, only mean that these interpretations ensue from social agents incapable of confronting the contemplation of the possibility of radically new worldviews.

A similar issue underlies the attribution to the text of a certain kind of transcendence, remote to Reality, following a Platonic tradition in the religious sense. The meaning of such a text would not so much be emergent as it would be imposed from without. Underlying such a view is a radical separation between the content and 
the form insofar as what is Really real is attributed to either the content or the form inevitably leading to a dualistic view of Reality, and attributing importance to one side of Reality over the other. One such approach to cinema, for example, led to the out bursting of too many -isms movements (formalism, expressionism, realism) whereby each and every one of these movements do not only limit their approach to an analysis of the works but also attribute more importance to one aspect of the film creation over the other. This was one of Tarkovsky's main critiques of Eisenstein's theory of montage, and his insistence to take very long shots instead of performing a technical montage in the studio afterwards. This is due to Tarkovsky's organic conception of the cinematic image, and because for Tarkovsky the cinematic image does not mean or signify other than what it means or signifies; in response to what the zone meant, thus, Tarkovsky's reply in Sculpting in Time was: "People have often asked me what the Zone is, and what it symbolizes, and have put forward wild conjectures on the subject. I'm reduced to a state of fury and despair by such questions. The Zone doesn't symbolize anything, any more than anything else does in my films: the zone is a zone, it's life, and as he makes his way across it a man may break down or he may come through. Whether he comes through or not depends on his own self-respect, and his capacity to distinguish between what matters and what is merely passing. ${ }^{182 "}$

We could point out a similarity between the Tarkovskian conception of the interpretation of the cinematic image and the Schellingian conception of the

\footnotetext{
${ }^{182}$ Tarkovsky, Andrei, Op. cit. p. 100.
} 
interpretation of mythology. They both call for a realistic view of the text at hand insofar as by realistic we understand that underlying the text there is no remote meaning or any kind of transcendence which it partakes in and which would remain disguised to us (as spectators, readers, etc.) Tarkovsky's fury at the bizarre conjectures as to what the zone might mean, however, is not so much directed at people's interpretation of the zone, but their attempt to get under the director's skin in hopes of discovering and exposing, to a certain extent, the director's intention which is not obvious and remain hidden, as it were, behind an invisible curtain. We could thence establish a certain parallelism between Schelling and Tarkovsky's view with respect to the interpretation of the cinematic image. Consequently, if as mentioned above, tautegory means that which literally means itself, then Tarkovsky's understanding of the cinematic image could as well be denominated as tautegorical.

The tautegoricality of the cinematic image in the sense of Tarkovsky is similar to the tautegoricality of the myths in the sense of Schelling. For Schelling myths are themselves phenomena, they don't represent an Idea as such, but are the dramatization or the manifestation of Reality itself. 183 This dramatization consists of a continuous repetition or self-recapitulation (as mentioned in the previous chapter) in such a way that the cinematic image is the self-recapitulation of Reality as such only creatively so insofar as it becomes yet another way through which human beings as creative agents tend to make sense of Reality. This repetition "is not a recurrence of the same in allegorical clothing, not a representation of the Ideal, but the repetition of

\footnotetext{
${ }^{183}$ Tritten, Tyler, Op. cit. p. 275.
} 
the Real repeating itself as something, different and novel in every repetition. The myth only acquires an ideality, an inner meaning, by virtue of its actual, historical reality. The analysis again stumbles upon the world law or law of decisiveness. Nothing may remain what it is - or rather is not - accidentally, but all must be decided; to be decided is to accrue a supervenient identity, a supervenience, however, that is essential and not extraneous to the identity of the thing itself. $184^{\prime \prime}$

Such conception invites us to reflect over the surging of the novum and the generation of meaning within the different activities of the societies. The introduction of the tautegorical as a distinct view of how aesthetic activity is to be undertaken, applied more specifically in the present dissertation on film and cinema, might be a possible way out of the pessimistic and closed circle of activities imbued with ideology as Zizek has pointed out time and again. In fact, in one of his lectures, and in response to the problem of ideology, Zizek answered that what we can do is to narrate the facts as are. This could as well be understood in terms of the dramatization and the manifestation of reality through such narrative as called for by Tarkovsky and before him by Schelling.

The supervenience of the identity of the self-same that Tritten discusses hints, therefore, at the emergence of meaning in the future and not as an imposition of that apriori to the beginning of the narrative itself. Thus, meaning and identity of the thing itself are supervenient in such a way that what is to be revealed, in the sense of

\footnotetext{
${ }^{184}$ Ibid., p. 275.
} 
Schelling, is a coming god insofar as this god is none other than the emergence of new meaning (worldview) within a certain system. So the significance which is to be acquired by a certain film or a certain cinematic image is as Blumenberg argues, dependent on the factor of time as it acquires a historical reality. So with view towards the possible historical context of one film, one cannot ask oneself about the intentions of the director but would rather have to think in terms of the relation of the film with view towards the future, including the possibilities and the collective elements that the film images ensue. This becomes more obvious soon after Tarkovsky points out that the zone only signifies itself. He does not hesitate as to venture and say that the zone is life through which human beings are either capable of making their lives across it or not. Tarkovsky himself, therefore, only shows that the zone is not a signification of something else, but it is itselflife.

The coming god, insofar as the yet-to-be, invokes an inversion of the theological conception of revelation as the apriori message which is revealed onto a selected individual whose role is that of enlightening the society - in that sense, the artist would only be showing the prisoners the way instead of imparting on them any kind of message which he might have come across on his journey out of the platonic cave. Against that dogmatic worldview, aesthetics in the general sense would only be opening a new space for us in order to wonder about any new discoveries before which we might find ourselves, more often than not, in awe. This aesthetic view, which is based in matter as ground for the aesthetic activity yet-to-come in the sense 
of Schelling 185 , would suppose not the absence of any preconceptions about anything that we would perceive, but rather the willingness to adapt ourselves to the outburst of new views instead of trying to tailor that which is constantly emerging to an eternal fixed truth that we have dogmatically acquired.

Likewise, the self-recapitulation of Reality in the cinematic image becomes the ground for the emergence of new meaning and therefrom, grounded in the individual, insofar as human beings are understood as the identity of the Real and the Ideal, in turn, reflect upon it (the cinematic image) in order to create a novel interpretation which, as a collective sum, result in a more complex system. This perpetual process hints at an emergence of the novum out of nothingness ${ }^{186}$ and into being. That which is created or the actualization of such becoming is a creative leap the totality of which is more than just the collective parts in which it was grounded. ${ }^{187}$ This creative process is indicative of a certain kind of transcendence which is grounded in its antecedent but which is not reduced to it. Such transcendence is neither a religious one whereby the meaning is remote and apriori nor a transcendental one in the sense of Kant whereby the transcendental is relational to that which forms the conditions of possibility of our experience; however, it is a transcendence which is relational to that which is yet-to-come and is identical to itself.

\footnotetext{
185 "Humanity is incontrovertibly from the lowest of creations, i.e. from the material, from the part of matter in which the innermost root of selfhood - the wanting to be for itself (without the higher potency) of B - is overcome, but it is not therefore necessary that it is partial or parochial essence, it is the universal essence. Because it is the existent, all the potencies of the universe all these separate moments, are determined to be compacted into humanity as the final unity... Humanity is the starting point of a new process." Schelling, Exhibition of the Process of Nature. ${ }^{186}$ See Zimmermann, Rainer, Nothingness as Ground and Nothing but Ground. Schelling's Philosophy of Nature Revisited. Xenomoi Verlag, 2014.

${ }^{187}$ Beach, Eduard Allen, Op. cit., p. 85.
} 
Understood as such, the strict division between the Real and the Ideal, in the Schellingian analysis, is only possible in thought and discursively; otherwise, our apprehension of nature or its self-recapitulation in an aesthetic activity is one such experience whereby boundaries are dissolved, and that which is perceived is identical to itself, or in other words tautegorical. 


\section{Aesthetic Activity as the Negation of Negation}

I have thus far argued in favor of a tautegorical apprehension of the aesthetic image, more specifically the cinematic image, such that such conception would be a response to the problematic of ideology. Consequently, the image would thereby be liberated from any kind of reductionism proper to certain preconceptions in order to stimulate the process of categorization that human beings more often than not tend to be very fond of. In that sense, out of the image, the possibility of potentiation in the sense of Schelling becomes possible insofar as this potentiation is the quantitative repetition of the phenomena but the determination of which is different depending on the domain in which this potentiation takes place. The image as Absolute, therefore, becomes the very concretization of the indifference that Schelling proposed, 
or, for that matter the non-partisanship that Tarkovsky attributed to the cinematic image. Notwithstanding, this indifference is not one such deprived of meaning, but rather is the very source of the generation of meaning, in abundance. ${ }^{188}$

The image opens the possibility of the proliferation of more images ad infinitum ${ }^{189}$, inviting us to be absorbed into the fecund world of possibilities as we caress the infinite through imagination. Thus, facing an image that hosts many different elements that are diffused together in harmony awaiting in potentia to become actualized in a reflective endeavor symptomatic of the human intellectual activity, we find ourselves before a predicament clamoring for an ethical conduct which would not lead to a state of utter chaos. Nevertheless, one such preoccupation is not justifiable with regards to the interpretation of the image insofar as the image is not to be addressed as a tool but as an end in itself. Accordingly, the aesthetic domain becomes the domain of the consideration of the different possibilities, or scenarios, vis $a$ vis the sought response to a certain ethical conduct or behavior. It is in that sense that Tarkovsky saw an ethical role to art, considering that it prepares human beings for death. In this chapter, I will focus my analysis on Tarkovsky's Andrei Rublev with a twofold objective: on the one hand, I will show in what sense the interpretation of the image could be generative of meaning insofar as the image is viewed as tautegorical, and on the other hand, I will show that the analysis of the movie will allow us to understand better the ethical role of the artist (who engages in an act of

\footnotetext{
${ }^{188}$ David Ross, Stephen, Schelling Now: Contemporary Readings, ed. Jason M. Wirth, Indiana University Press, 2005, p. 54.

${ }^{189}$ David Ross, Stephen, Op. cit. p. 50
} 
poiesis) within the society. Not far out of the picture will also be Schelling's conception of artistic creation.

The implications of the Schellingian and the Tarkovskian conceptions of art is that the genius-category is not reserved to some sort of a chosen one by an a priori necessity, but is reserved to the future, as the passage of time impregnates the image with significance and as such would prove to be universal. Thus, when Schelling writes in The Ages of the World that the future is divined ${ }^{190}$ he is not so much relating it to individuals who would a priori know that they are engaging in an act of predicting the future, but they are divining it insofar as when a certain moment in the future becomes past, those who are discerning it in the present of their time would know that these individuals had divined the future. Hence Schelling's first sentence in The Ages of the World states "What is past is known, what is present is discerned, what is future is divined. ${ }^{191 "}$

"Only from the negative impulse, from the labyrinth of the No, can the writing of the future appear192", says Enrique Vila-Matas in his book Bartleby $\mathcal{E}$ Co. Later on, he mentions the book of Clement Rosset Les choix des mots (1995) to point out that the difference between an uncreative person and a creative one is that the latter

\footnotetext{
${ }^{190}$ Schelling, Friedrich, The Ages of the World, Op. cit., p. 83.

191 Ibid., p. 83.

${ }^{192}$ Vila-Matas, Enrique, Batleby \& Co., trans. Jonathan Dunne, New Directions Publishing, 2004, p. 3.
} 
has in fact the power to decide not to create. The project of Vila-Matas was to trace down eminent writers who suffered from the 'Bartleby Syndrome' as he calls it in hopes to investigate the reasons for which they decided to take the stance of saying 'No' unto writing. Nevertheless, the crux of the matter was not, as it might seem at first sight, the intention to impel other writers towards disengaging from creative activity, but rather the determination to emphasize the necessity of abnegation as the condition of possibility for an authentic artistic creation which paves the way for a further development and thereby evolution of literature. For that matter Vila-Matas says, a few lines into the introduction: "It is in my intention, therefore, to make my way through the labyrinth of the No, down the roads of the most disquieting and attractive tendency of contemporary literature: a tendency in which is to be found the only path still open to genuine literary creation; a tendency that asks the question, "What is writing and where is it?" and that prowls around the impossibility of the same and tells the truth about the grave, but highly stimulating, prognosis of literature at the end of the millennium. ${ }^{193 "}$

Vila-Matas' idea might have been intended as a prognosis for the literary world; nevertheless, upon extrapolating the same vision onto the artistic panorama, it could be deduced that the condition of a possibility for artistic creation is negating to create. The subsequent step would be a fecund explosion of artistic creation - the perpetual dialectical process of creation would consist of both at the same time:

\footnotetext{
${ }^{193}$ Vila-Matas, Enrique, Op. cit., p. 3.
} 
involution and evolution. ${ }^{194}$ The intricate decision of withdrawal is not, however, a speculative one where the artist decides to repudiate all that he has done in order to comprehend what it really means to engage oneself in a 'positive creation'. On the contrary, more often than not, it is stimulated by a traumatic incident after which the artist finds herself obliged to say "No" and isolate herself thereby to take a second glance at the bigger picture. The proper narrator of Bartleby $\mathcal{E}$ Co. decides to abstain from writing after the traumatic occasion when he was dictated to write what his father wanted him to write. This incident led the narrator to refuse to write for twenty five years before another occasion took place, a visionary-like occurrence, which stimulated him into writing the diary. Hence, the process by which artistic creation is governed is that of a hyperbolic spiral unfolding determined by a traumatic event, followed by an arduous and tedious reflection process and contemplation, which leads the artist to engage once again in artistic creation, only this time after taking a qualitative leap - at the level of self-expression, view and vision, technique and ideas.

The aforementioned three conditions to engage in positive artistic activity are well manifest in Andrei Tarkovsky's acclaimed movie Andrei Rublev (1966). The film adopts an original approach towards the biopic genre to depict the life of the acclaimed Russian icon painter Andrei Rublev. The scarce facts about Rublev's life gave the Russian director an excuse to proceed at his convenience in order to ingeniously construct a film which not only would narrate the facts of Rublev's life in the Middle Ages, but would also weave a poetic fabric that could be seen and

\footnotetext{
${ }^{194}$ See Schelling, Friedrich, System of Transcendental Idealism and The Ages of the World.
} 
analyzed at different levels as well as from different angles. Peter Green says on this issue: "The film can be viewed on a number of levels: as a depiction of a period of Russian history in which the foundations of a united state were laid and a sense of national identity was beginning to emerge; as a portrait of the icon painter Andrei Rublyov in his times; as the chronicle of a search for belief and a universal brotherhood of man in God through the idea of the Trinity; and as an examination of the role of the artist in society. ${ }^{195 "}$

In this section, it is the last level I will be addressing; that is, examining the role of the artist in the society. As I go along, I will analyze the voyage that Andrei Rublev sets off on. The point of departure will, for that matter, be the moment in which Andrei is traumatized as he faces the society outside after leaving the monastery on his way to Moscow. The trip serves him as both an adventure during which he is familiarized with the society on one hand; and an occasion for introspection, self-formation and self-development on the other. Whereas he chooses at first to take a vow of silence, he realizes that, in fact, uniting people above all their problems is best achieved through artistic creation (represented in the film by the boy who casts the bell). It is then that Rublev's unfolding evolutionary road takes him to a maturity level after which he is conscious of the necessity of a positive action - more specifically artistic creation - as a solution as opposite to a negative action, i.e. the vow of silence which he has taken. Nonetheless, as mentioned above, the Bildungsroman kind of voyage Andrei Rublev embarks on can only be viewed as the

${ }^{195}$ Green, Peter, Andrei Tarkovsky, The Winding Quest, Palgrave McMillan, 1992, p. 41. 
condition for the possibility of artistic creation. Throughout the section, I will not be giving a detailed description of the film's scenes for an abundant bibliography is available which provides a thorough and detailed analysis of those ${ }^{196}$; however, I will limit myself to directly treat the scenes which I think form a good example of the central thesis of this chapter.

\subsection{Journey and Trauma}

The invitation sent by the Great Prince's messenger to Andrei Rublev (Anatoly Solonitsyn), at the Andronikov Monastery, to become the apprentice of Theophanes the Greek (Nikolai Sergeyev) on the decoration of the Cathedral of the Annunciation in Moscow meant a new experience for the monk whose ideals where only limited to the confines of the monastery. Little he could foresee what was going on the other side of the railings. Unhesitant, he accepted the offer without even consulting with his mentor Daniil (Nicolai Grinko). This implied the independence of the disciple from his mentor, a split which meant that Rublev was ready to embark on a journey of initiation into becoming an artist himself.

The eventual progression to the culmination of the disassociation of Rublev from the society starts with the conversation he has with Theophanes the Greek at the river bank. Rublev couldn't understand how an artist would be determined to keep

\footnotetext{
${ }^{196}$ See for example Robinson, Jeremy Mark, The Sacred Cinema of Andrei Tarkovsky, Crescent Moon, 2006.
} 
on creating whilst he reaffirms and detests the ignorance of the people. The stimulating discussion is itself sufficient to make Rublev reconsider his conceptions as an artist. Notwithstanding, his discourse which was played in off-voice during the scene of crucifixion, in response to Theophanes, was intended to justify the evil and ignorance of human beings who, at the end of the day, are forgiven by the Most High. This discourse could be seen as the starting point of the unfolding of the absolute which is only to return to itself through creation ${ }^{197}$ - artistic creation in this case. In other words, in Andrei Rublev it is as though the end is present at the beginning in its absolute form, but it is not until it has started to unfold through the particular that the contingency of the beginning becomes actual. Andrei Rublev's ideas set the context within which he would be evolving during his excursion, as he witnesses a society filled with violence, war, hatred, famine and pestilence:

"Sadly, men do bad things. Judas sold Christ and who bought him? The people? Pharisee and scribes. A witness was never found, try as they would. And who would slander the innocent? The crafty Pharisees were old hands of bluffing. They had learned to read and write and used the people's ignorance to their advantage. People should be reminded that they are human beings that Russian people are of one blood and one land. Evil is everywhere around. And there are always those who would sell you for 30 coins. New and new trials are heaping on the Russian men: Tatars, famine, pestilence. But they keep on working, and carrying their cross humbly... They never despair but resign themselves to their fate. Only praying God to give them strength. Won't the Most High forgive them? You know it. Something goes wrong, or you get tired, and then you meet somebody's eyes and feel like you have received a communion and feel better." - Andrei Rublev

${ }^{197}$ See Schelling Friedrich, System of Transcendental Idealism, Op. cit. and The Philosophy of Art, Op. cit. 
Despite what he thinks, Rublev would then rend himself off these ideas to lose contact with both his fate and the society; as though his discourse was an artistic prophecy which would be fulfilled towards the end of the movie, during the episode of the bell casting. Right after the Tatars execute their raid alongside the Russian, in the church, Rublev decides to take a vow of silence as penitence for the sin he has committed - killing a fellow man. He is overwhelmed by what neighbor peoples could do to one another. He couldn't have imagined people killing each other over power. In a traumatic event, a sudden awakening, Rublev finds himself in an existential situation where he starts asking about the meaning of it all: why continue painting if at the end of the day people will burn these icons as though they hadn't existed in the first place? Why believe in the predominance of good nature in his fellow men when all one encounters is violence and rape? These questions where of the kind that Rublev was raising after the raid was over and he was left alone in the Church with the fool-girl. In what seems like a hallucination, an imaginary extrapolation of Rublev's mind, the figure of Theopanes the Greek materializes in front of him. As a result, he confesses that he has finally become aware of reality as is - the harshness of the outside world, in contrast to the life in the monastery. Although up until then, and during the whole movie, Rublev is but a passive observer, he nevertheless, as said in the introduction, shows self-determination and the courage to withdraw himself from society since he has lost faith in himself as an artist and in any possible bright future for the society. He renounces his figure as an artist, and rather decides to refrain from speaking because, put in the words of Theophanes 'everything is in decay'. 
What was effectively going on was a self-manifestation of the absolute through the particularity of the events in a natural process of actualization. Ontologically, this process entails a split as the first condition for the eventual 'concretization' of self that expresses itself as such. This split in the case of Andrei Rublev is rather traumatic. In a moment of clairvoyance he imposes on himself questions which he hadn't thought of before. The subsequent answers would lead him suspended in between the infinite and the finite. He has committed a crime and therefore he has sinned. However, Theophanes tells him not to worry about God's forgiveness, but never to forget that he has sinned impelling him to torment himself for what he committed.

From a 'being-in-the-world' kind of condition, and upon being shocked by the accumulation of horrid events, Rublev, as an active ' $\mathrm{I}$ ', sees himself in an act of selfreflection in order to assimilate reality. His aesthetic sensibility has become keener, and can thus relate to the society. He is, therefore, one step closer to disembogue into an actual artist who, before anything else, has been engaged in the misery of the society rather than theorizing about it from without. This traumatic episode serves as a transformation of the monk by his 'incorporation' in the society, a (tres)passing from the infinite into the finite, a movement from the absolute into the particular. The ascension of artistic sensibility is the factor which distinguishes artists from the nonartists, for the role of a genius is not so much bound to superiority, but rather to the 
acute aesthetical sensibility of the person who is able to perceive and better articulate what he perceives creatively into a work of art. ${ }^{198}$

Therefore, as proposed in the central argument of the thesis, contrary to what might be thought regarding the negative effect of a traumatic experience, existential traumas similar to that which Andrei Rublev endured could act as one of the many factors leading to the reflective activity of the ' $\mathrm{I}$ ', the result of which will be a qualitative leap into a deeper grasp of reality due to the abovementioned ascension of the aesthetic sensibility of the artist. Trauma, looked at from this angle, plays a crucial role in generating a dialectic development of the agent. The process carried out by this agent is similar to the Schellengian process of creation made up of three steps usually denominated as (A1), (A2) and (A3) ${ }^{199}$, where, simply exposed, A1 represents the potentiality of being, A2 the limitation of being and A3 the indifference between A1 and A2. Close similarities could be drawn between Schelling's system and the constant referral to the idea of Trinity throughout Tarkovsky's film. Throughout the movie more than one parallel is established with the Trinity - e.g. the three monks during 'The Muggers' episode Kyrill, Daniil and Rublev where Kyrill represents the passionate but untalented artist, Daniil the experienced but conservative artist and Rublev the solitary but determined seeker200. Consequently, insofar as the agent is

\footnotetext{
198 See Johnson, Vida T., The Films of Andrei Tarkovsky: A Visual Fugue, Indiana University Press, 1994.

${ }^{199}$ See Schelling, Friedrich, The Ages of the World.

${ }^{200}$ See Turovskaya, Maya, Tarkovsky. Cinema as Poetry, trans. Natasha Ward, Faber and Faber, 1989.
} 
aware of his creative potential, it is indispensable to leap onto the second level which would delimit and give order to the potentiality.

\subsection{The Vow of Silence}

This section will be a reflection on Andrei's Rublev vow of silence from the point of view of Taoist thought. What I hope to do in these lines is to shed the light on Tarkovsky's interest in the Eastern religions. This interest could be seen manifest throughout Tarkvosky's films. Even though he is considered to be and declared himself a Christian, nevertheless, his movies do show similarity with Eastern philosophical, mystical and religious thought and writings.

One of these examples could be one of the typical Tarkovskian motifs - water. One of the imagery descriptions used to depict the Original Chaos, the origin of the universe in the Taoist philosophy is water. ${ }^{201}$ Hence, the constant referral to water and the abundance of it throughout Tarkovsky's film could be understood as the origin from where everything flows and emanates.

Moreover, in his book Sculpting in Time, Tarkovsky talks about a return to the beginning and he formulates it in these words: "Underlying the concept of Andrey Rublyov's character is the schema of a return to the beginning; I hope this emerges in

\footnotetext{
${ }^{201}$ See Robinet, Isabelle, Lao Zi y el Tao, trans. Francesc Gutiérrez, La Aventura Interior, 1999.
} 
the film as the natural and organic progression of the 'free' flow of life created on the screen. For us the story of Rublyov is really the story of a 'taught' or imposed concept, which burns up in the atmosphere of living reality to arise again from the ashes as a fresh and newly discovered truth. ${ }^{202}$ " This concept of 'returning to the beginning' is yet another basic concept in the Taoist philosophy. ${ }^{203}$ This 'return' is a natural devolution to the origin, the chaos where everything is harmoniously united. It is usually depicted as a desert, nothingness, a groundless unground from where everything emanates and unfolds into the many; an undoing of oneself from all that there is around one in order to reach the state of emptiness, because at the origin the thesis and anti-thesis are one, hence the emphasis of silence at the center of everything. At the very core of existence, what lies is pure silence maintained by the harmonious union of what is and what is not, or between the thesis and the antithesis. ${ }^{204}$ We could, therefore, understand Rublev's situation as a regression to the original chaos undoing himself from himself determinately in order to say No. Thereafter, Rublev finds himself at the origin in an interior movement towards himself to first negate and then negate the negation. That is to say, by negating his self in penitence to God, he has taken a vow of silence in order not to paint again: this renouncement is the first step in the Taoism in order to reunite with the Original Chaos and thereafter accompany the flow of life creating itself and evolving. As soon as Rublev has figured out the importance of positive action - that is, artistic creation he is then not only ready to exuberantly and effervescently outburst into an unveiling

\footnotetext{
202 Tarkovsky, Andrei, Op. cit., p. 89

${ }^{203}$ See Robinet, Isabelle, Op. Cit.

${ }^{204}$ See Ibid.
} 
creative process painting what would then turn out to be icon masterpieces, but preemptively is able to renounce his renouncement in an outward positive movement.

In turn, before the encounter with the young bell caster Boriska (Nikolai Burlayev), the development of the events direct Rublev - consciously and unconsciously - into an overall grasp of the miserable condition of the dispersed society dominated by ignorance and violence in scattered particularities, on the one hand; and an overall grasp of the origin of integrated contingencies in constant actualization, on the other hand. The traumatic event, therefore, pave the way to an ontological leap, rather than a negative 'silencing' effect on Rublev.

Nevertheless, one question will persist and that is: why create something at all? As a spectator of the film, one can never get into Rublev's mind and know what exactly he was thinking throughout the voyage. It could be inferred from this passivity that Tarkovsky is not only narrating a simple story in which the protagonist makes a series of choices before finally deciding to engage himself in an activity; it is rather a calling to the spectator to identify herself with Rublev; it is a call for the spectator to return to the origin herself. The differential between passivity and activity, therefore, lies in the will to negate the negation. It is always easy to withdraw oneself, even by going back to the origin, but this withdrawal could eventually end up being a nihilistic activity by the thereby domineering power of involution in comparison to that of the outward energetic outflow. How did Rublev eventually 
come to that conclusion? Rublev's fascination by the persistence of Boriska and his fervor at casting the bell were enough to make him renounce the renouncement. At the end of the day Theophanes the Greek had told him that he didn't do what he did for the people, but out of his commitment for God. In other words, the artist's fortitude to create time and again does not limit itself to the acceptance or rejection of the people, or whether or not will it make any difference, but rather it emerges as an impulse to artistically articulate one's perception. The overflow of being is in constant flux and so each and every single individual - just like the overflowing water imprinted on the Tarkovskian celluloid - is in a constant flux and motion; hence, the constant drive to create does not bind the society as much as it binds the creator to the original chaos, to the origin of all that there is, to the groundless unground. Yet, the whole ritual of bell casting and inauguration saw the society, including the princes as well as international diplomats (or messengers) stand expectantly and in awe in a sublime-like moment before the masterpiece. However ephemeral this moment might be before people begin to slander Boriska for what once they had acclaimed him for, this single moment itself is able to drive the society forth into a new unity in a new leap, in a new calling to return for the origin. Therefore, "it is Boriska who shows Rublyov that silence and withdrawal are not the tools of the creative being $205^{\prime \prime}$, says Maya Turovskaya in Tarkovksy, Cinema as Poetry where she later on adds "Rublyov comes to see that the artist's only response to the abjection of the human condition is the creative act, the creation of ideals and an alternative reality towards which man

\footnotetext{
${ }^{205}$ Turovskaya, Maya, Op. Cit., p. 48.
} 
may strive.206" This creation of the ideal constitutes the basis of Andrei Tarkovsky's conception of art as a universal act where artistic creation is seen by him as a longing for the ideal. Based on my point of view, the creation of the ideal is not conscientiously intended to better the societies as much as it is intended to drive the natural course of evolution in its constant flux. It is as though creative Nature, or God, or Chaos or the Absolute, create through the artist unconsciously to paraphrase Schelling. ${ }^{207}$

"The bell-casting sequence in Andrei Roublyov provides another look at creativity, this time through a young boy's experience. He is an initiate, a neophyte, a young shaman-in-the-making. Here creativity is seen in religious and shamanic terms, because the boy doesn't really know the alchemical secret of making bells - he uses his intuition, his blind faith as the Stalker would put it. He feels his way into his creative role and his public post. Boriska is a believer, believing from his deeper self, working from his unconscious. One sees this happening very clearly - in every facial expression of the boy as he storms about the bell-casting site, in obsessive state of nervous energy. The workers get caught up by the boy's excited vision, just like the followers of shamans and preachers - and religious fanatics. When the molten liquid pours into the bell, it is filmed as a religious transformation - the channels of hot metal are blinding; smoke billows up; the boy stands in the foreground, transformed. It's like a religious vision, all that smoke and light - there is something Baroque about it, a vision of angels, clouds and cascades of light, like the ceiling of a Baroque church. It is kinetic and ancient. The boy is like the young Merlin the magician of Athrurian legend creating Stonehenge, or a young Paracelsus or Cornelius Agrippa, alchemists trying out their magic. ${ }^{208 "}$

The rising of the bell, same as in the prologue where the peasant flies in a balloon, depicts a striving for the unattainable 209 . Boriska's perseverance to cast the bell even though he did not know the 'magical recipe' to cast an impeccable one is an

\footnotetext{
${ }^{206}$ Ibid., pp. 48-49.

${ }^{207}$ See Schelling, Friedrich, The Philosophy of Art, Op. cit.

${ }^{208}$ Robinson, Jeremy Mark, Op. Cit., p. 367.

${ }^{209}$ See Green, Peter, Op. Cit.
} 
act of belief both in one's self and in God. Had he not the faith and belief in his own skills and in the driving force of being, he wouldn't have been able to commit himself laboriously in order to find what he thought to be the best amalgam of clay, direct the people working with him and even asking his friend to thump those who would not obey the orders. It might as well be worthy to note that Boriska was as well traumatized being the only survivor of his village to the Tatar's raid. He had no one to go to and had nothing to lose.

An artistic creation aspires for the unattainable, a break into the infinite through limitation, represented in the film by the flying peasant or the levitating bell. Each artistic oeuvre, Tarkovsky comments, is an absolute image of the world, a new calligraphy which represents an ideal that evokes new ideas and possibilities. The unfolding process is an interaction, as mentioned above, of an identity between an outward and an inward movement. Put in Kierkegaard's words, it is a process of a self becoming itself, for the self is a relation to itself and is not itself its self ${ }^{210}$. It follows from there that Rublev's discourse in response to Theopanes the Greek was what Rublev would inevitably become throughout his journey. The discourse is absolute and contingent, it is what Rublev would ought to be, but not until he passed through the series of 'initiative events' that he was able to become himself, reaching a level of maturity which would allow him to create - consciously and

\footnotetext{
${ }^{210}$ See Kierkegaard, Søren, The Sickness unto Death: A Christian Psychological Exposition of
} Edification \& Awakening by Anti-Climacus, trans. Alastair Hannay, Penguin Classics, 1989. 
unconsciously. ${ }^{211}$ At this moment, consequently, the first words that Rublev utters to Boriska, breaking his vow of silence, are: “We'll go off together, you and me. You'll cast bells, I'll paint icons. That will give people something to celebrate."

\subsection{Conclusion}

Trauma, at the end of the day, more often than not is an important condition amongst others which factor into an inevitable reformation of the 'traumatized' person. Unconsciously, trauma provides the inceptive crack leading to a subsequent awareness of the activity of the ' $\mathrm{I}$ '. The abstinence from creation is merely another step in the whole process of 'returning to the origin', driven by a withdrawal into the 'abysmal unground', the original chaos, and not reflecting upon oneself. Returning to the origin is what soaks the artistic work into an ontological dimension.

Rublev's transformation is configured in the film as the outburst from the black and white sequence to the painted icons in color. He has come to terms with himself sincerely believing in the necessity of active artistic creation even though his works might not last long enough, even though the society might come to deride them after a certain period of time. He has finally grasped the real meaning of Theophanes the Greeks' words when he told him that he was committed to God and not to the people. It is not surprising, therefore, that the last icon to be filmed was

\footnotetext{
${ }^{211}$ See, Schelling, Friedrich, The Philosophy of Art, Op. cit.
} 
Andrei Rublev's masterpiece, the Trinity. Andrei Rublev, therefore, is able to transcend human misery and depravity; he is finally capable of representing beauty in his paintings rather than human suffering - which was holding him at first from being able to create anything at all. What appears in his fresco The Last Judgement is not a depiction of tortured people but rather human beings who represent the good and have faith in the Most High. What is depicted are people who read, who converse and who reflect upon their status quo in the society. But that's where the role of the artist necessarily lies. The function of the artist in the society is not that of a preacher. In fact, the activity of the artist is a re-presentation of reality. It is not a mimesis in the sense of imitating nature, but rather a mimesis in the sense of creating in the same way that nature creates. What surprised Andrei Rublev was the unpredicted reaction of the people who were in a miserable situation. They might have come to their wits after all. By the ringing of the bell they were reminded of both faith and positive production.

Two important factors need to be present so that the artist is able to break the silence and proceed into a creative activity. The two factors could as well be considered a typical Tarkovskian conception of what the artist need do in order to really become an artist or be labeled as one. The first factor is faith, whether in God, or in oneself, in that what is being created is not in vain. What is meant by this is that the work of art, at the end of the day, grabs on its being by having a metaphysical dimension, i.e. an identity between the infinite and the finite in the finite. The other factor is the perseverance of the artist to constantly create. 
I would like to add that the reason why Tarkovsky radically detested experimental art and the new development of modern and contemporary art (from his time until today) is because, to understand it from Andrei Rublev's film, the journey itself is not an artistic creation. Hence, one cannot say that Rublev's life was itself artistic just because he went in search of or to experiment what the society was going through. Indeed, he had witnessed, perceived and even experienced all the misery of the world outside the confines of the monastery, but the outburst of his imagination was not a reflection of his research. Contrary to experimental art, which considers mere experimentation as an art, the thing that would really be accounted for as an artistic creation is an amalgam of imagination, faith, belief and a return to the origin. The suffering itself is not an artistic experience but rather a trigger of the possibility of artistically creating. Hence, the Bildungsroman kind of voyage merely serves as an initiation to Andrei Rublev rather than a material for his artistic activity. Thereafter, the artist would create while longing for an ideal depicting reality from a subjective point of view at the same time. This is why Tarkovsky establishes a difference between the black and white scenes, and those shot in color, because the journey lead to the eventual creation whereas the journey itself, the searching, served as a mere ground to what would later on be the start of an artist who would eventually become one of the acclaimed icon painters in the world. 


\section{Through the Rabbit Hole}

As a recapitulation of what has been said so far: by examining Schelling's late philosophy, and by focusing on what he later came to denominate positive philosophy, the construction of the arguments presented in the respective chapters have been building up in order to present a possible solution to the problem of ideology of which we have been prisoners for the past few decades, more specifically within the aesthetic domain. We cannot nowadays mention cinema, for example, without having to confront the problem of ideology, dogmatic messages and propaganda. Consequently, in trying to find a possible way out of this predicament, I saw in Schelling's philosophy of mythology and the concept of tautegorical interpretation an opportunity that would allow us to come out of a whirlpool that has 
overwhelmed us for quite some time now. Following that line of thought, I found in Tarkovsky an ideal candidate for a practical example of how it could be possible that through the aesthetic we would be able to venture on to conceptualize that which we wouldn't have been able to capture through discursive reasoning. Accordingly, I argued that the aesthetic could act as ground for the ethical and the rational insofar as the aesthetic is grounded in experience and is comprised of that which is unprethinkable and is dependent on a conscious decision to create and an unconscious outflow of that which cannot be apprehended directly in thought but which needs to be posited into consciousness before being reflected upon. We have also been able to see the importance of the ethics upon such inversion, because now meaning is not dogmatic but rather emergent. Thus the social agents are responsible to seek an adequate behavior according to the modality with which they are making sense of their Reality at any given time. ${ }^{212}$ In this chapter, I will argue that such inversion would render the theological conceptualization of Schelling's Ungrund useless insofar as the theological interpretation is dogmatic, and therefore that it could be substituted by aesthetics which would act as the generator of space that would subsequently pave the way for the conceptualization of the Ungrund. This argument will allow us to understand Schelling's conception of art (as an act of poesis) as the organ of philosophy, such that art becomes the object of speculation in a philosophical act of abstraction and conceptualization - and thereby perpetuate the continuous flux of human evolution as products of nature within the naturing nature.

${ }^{212}$ See Zimmermann, Rainer, Op. cit., 2015. 
In view of that, I will, towards the end of the chapter, argue that the aesthetic is that which actually creates the novum, which, in turn, becomes the space for the subsequent reflection of the social agents. This is in fact what Schelling refers to in The Philosophy of Art when he affirms that art is an act of poesis. The objective is to point out the subtle difference between poesis, as an artistic creation, and the philosophy of art (or philosophy of mythology) as a reflective, discursive act. With that in mind, I will be inviting the reader through the rabbit hole in order to appreciate the wonders of imagination by means of which humanity has been constantly creating new spaces and culturally approaching them to be able to make sense of their Reality such that what their activity was as Blumenberg argues an absolutism of Reality.

\subsection{The Emergence of Space through Aesthetic Activity}

In the following sections I will argue, following Schelling's Philosophy of Art, that the evolution of human beings is dependent on an aesthetic activity such that what is creatively produced becomes the organ of reflection and, accordingly, facilitates the complex development of the rational ability of the societies so as to acquire a new level of conceptualization vis a vis the mapping of the world experienced and made sense of at a certain time. The line of thought that will be followed through and through will be comprised of examples from different literature works including Homer's Odyssey, Dante's Divine Comedy, Proust's Remembrance of Time Past, Julio Cortázar's Hopscotch up to Tarkovsky's Stalker. By the 
end of this chapter, the topics discussed in the previous chapter (dialectics, imagination, aesthetic activity, image as tautegory) will be synthesized providing us with an overview of the importance of the speculative act of philosophy by taking an object as an organ of reflexion, as well as the importance of the fomentation and support of the emerging interdisciplinary studies in order to bring together different views within different domains looking thus for a more holistic approach to the underlying socio-economic problems facing different societies. This conclusion echoes the call for a new rational mythology as figures in the Old Systematic Program of German Idealism.

\subsection{Odysseus Descends to Hades}

In Madness and Mythology Markus Gabriel makes an important distinction between what he calls constitutive and regulative mythologies. ${ }^{213}$ Whereas the former, according to Gabriel, opens up the space for reason by generating absolute metaphors in the sense of Blumenberg, the latter is merely the normal myths, fables and folk stories as we know them: those stories that use the metaphors and images of the different gods and heroes with which societies define and identify themselves. This subtle distinction has an important implication with regards to the distinction between the generation of space mentioned above in a creative act, and the collective corpus of

\footnotetext{
${ }^{213}$ Gabriel, Markus and Zizek, Slavoj, Op. Cit., p. 67.
} 
myth which is transformed as such when the society eventually reaches the end of an era; in that situation the creative activity of the society as a whole wears itself out within the established axioms and metaphors, and what is called for is the generation of a new constitutive mythology.

Gabriel argues, furthermore, that constitutive mythologies open up a world, and relates that to the importance that Schelling attributes to Chaos as the space which is open to everything - an empty space which came to be as Hesiod puts it. Chaos, thus, Gabriel stresses, was not always there, but came to be, a space which was generated and then facilitated the emergence and manifestation of the universe. In line with what has been proposed above, we could conclude that Chaos was the absolute metaphor the Greeks formulated to present the coming-to-be of the world. Notwithstanding, the term is not to be understood as an allegory, but rather as the self-recapitulation of the beginning in terms of the absolute metaphors Gabriel has defined as constitutive mythologies.

Thus, the same severance which results in the creation of a space that would be the condition of possibility of the existence and the evolution of the universe presents itself in (according to Schelling) symbolical terms as Chaos out of which everything comes to be. In a similar manner, the same dynamics of creation in human beings generate a novel space that becomes the chaos out of which new possibilities emerge. 
In her book The Pearly Gates of Cyberspace, Margaret Wertheim, whom I mentioned in the first chapter, also approaches the subject of space and traces a history of the different cultural approaches to social space, skillfully sketching and discussing in detail the history of space from Dante to Cyberspace. Throughout the book one thesis becomes more and more visible, namely that the development and evolution of space in the Western societies was made possible due to the protagonism of the artists who were able to create genuine works of art that the scientists took as ground for their research. Among the many important contributions of the book, one of the interesting points to be emphasized is the fact that the different conceptions of space were not correct in purely contemporary scientific terms. Still, were it not for the creativity of the artists who embarked on a journey to make sense of their reality and embark on a journey to investigate new possibilities without preconceptions nor prejudices, science would not have been able to come all the way to the current state of affairs.

It is interesting to trace the distinction made between this monistic approach to the space of the afterlife, where it is treated as the realm to which all those who died were destined to, and its reception by Christianity on one hand, and Christianity's rigid dualism in its approach to the afterlife with the introduction of heaven and hell on the other.

In the Odyssey, Odysseus, following Circe's instruction, digs a hole in the ground with his sword and pours down the libations (honey, milk, wine and water) 
in honor of the gods and those who died in Troy. It was Odysseus' key into the underworld where he was going to be foretold his fate by Teiresias on his way back to Ithaca. The very fact that Odysseus was able to descend to the underworld (which is an epic theme $)^{214}$ and make it out from there alive is characteristic of the Greek hero who would come out initiated - or enlightened, as is the case with Odysseus, after he was foretold his destiny. Nevertheless, the discussion of such topic is beyond the scope of this thesis, and therefore I will only limit myself to give a few remarks on the subject of the space Odysseus created in order to 'open the door' into the underworld. Such a passage hints at how the Greeks viewed the other dimension to be like: it was not a world detached from the universe, but rather one which was to be found within the very same world which they inhabited. However, the way that would lead one into the underworld would have to be by digging through the ground, severing the ground in order to find the passage of the shadows from the underworld upwards or the entrance of those standing outside inwards. As it turns out, the descent was not only about the Teiresias' prophecy, but an event whereby Odysseus was able to meet again with the ghosts of Achilles and Agammemnon who also fought in Troy. ${ }^{215}$ However, this interaction with the underworld wouldn't have been possible had it not been for the creation of a space that would facilitate the occurrence of such episodes. This act becomes the establishment of the mythic Centre which Mircea Eleade talks about in relation to the magicians who, in order to perform their rituals,

\footnotetext{
${ }^{214}$ De Jong, Irene, A Narratological Commentary on the Odessey, Cambridge University Press, 2004, pp. 277-295.

${ }^{215}$ Ibid., p. 271.
} 
draw a nine foot circle thus creating and delimiting the sacred center as such. ${ }^{216}$ This is very much similar to the hole Odysseus digs in the ground before interacting with the realm of the dead. However, the Greek conception of the underworld was hardly dualistic. The dead become will-less shadows floating around in the underworld which is within the inhabited world itself. But in order to access it one ought to 'dig a hole in the ground' in order to create that mythical space that would grant one access into the other dimension. This dimension, archaically, was considered to be a sacred space through which humans were able to communicate with the gods in the heavens or in the underworld. Mircea Eliade attributes this to the establishment of a sacred space out of which a whole new universe is created, a universe (or cosmos) which is really real as opposed to the profane space. ${ }^{217}$

The cosmic vision of that of the Greeks as figures in their mythology, more specifically, in Hesiod and in Homer, is one such whereby the three dimensions are not physically separated, but rather existentially or qualitatively so. Their view was rather monistic such that the openings to the other dimensions did not suppose transmigration through different physical dimensions, but rather a qualitative one. This passage entails an encounter with the formless as opposed to the well-ordered and defined cosmos of those involved. The crossing is, thus, an act of severance against an order which has become stagnant in search of a renewal whether at the

\footnotetext{
${ }^{216}$ Mark Robinson, Jeremy, The Sacred Cinema of Andrei Tarkovsky, Creschent Moon, 2006, p. 157.

${ }^{217}$ Eliade, Mircea, The Sacred and the Profane: The Nature of Religion, trans. Willard R. Trask, Harcourt, Brace and Company, New York, 1959, p. 30.
} 
personal level or at the social level, etc. It is in this self-renewal (at all the levels) that the stability of the different systems lies, Heraclitus affirms. At the corporeal level, for example, this stability is constantly maintained by our body cells as they perpetually renew themselves cyclically while old cells die and are sloughed off. Cell cycles, however, are internally well-controlled such that in case they stop dividing or they accelerate their division the entire balance is destroyed and the body would become diseased.

In The Sacred and the Profane Eliade compares and contrasts the different approaches to space of the religious and the secular, industrial people. He points out that even the most strictly secular person still shows religious characteristics in his relation to certain spaces with which he develops a certain kind of affinity such as the place of his birth, the place where he had his first kiss, etc. Nevertheless, what I will argue throughout the rest of the chapter is that this distinction still stands only insofar as one takes "religious" only in the most general sense of the term, as religare, or a reunion with; in that sense, the terms the "sacred" and the "profane" would have not so much religious connotation, but rather could be looked at in terms of that which has become stagnant and that which is yet-to-come and is dependent on the perpetual human creation (poesis). Consequently, there will always be a dynamic tension between the sacred (understood as that which is eternal) and the profane (understood as that which is temporal) such that both act as ground for each other - this is an approximation to the Schellingian symbol whereby there's an identity between the infinite and the finite in the finite. 
We find one such beautiful example of the tension between the sacred and the profane in Paolo Sorrentino's movie The Great Beauty (La grande belleza). Jep Gambardella (Toni Servillo) is a journalist who was experiencing a writer's block ever since he published his first book. The cause of his block was the failure of the search for great beauty he was preoccupied with. Having settled in the city of Rome at an early age, and after having fallen for a girl, the relation with whom led to a dead-end, he would decide to spend his nights bar-hunting waking up when all the people would have gone to sleep. Gambardella is constantly up-to-date with the latest cultural developments and activities, and he maintains a certain intellectual engagement with a group of his friends. The arduous pursuit of that ephemeral moment of the encounter with the great beauty did not unveil itself, however, until Gambardella had an epiphany-like moment towards the end of the movie, when he realized that the great beauty was not an object to be pursued but rather comprised the totality of the minute episodes of our everyday lives, represented in the movie as the tension between the sacred and the profane within the city of Rome. The great beauty, as it turns out, springs out from the identity of the sacred and the profane, between the fleeting moments of Rome's night life, in between the bars and the night clubs, and the eternal moments of the historical presence of Rome with its sacred ruins that have passed the test of time and have been elevated to a transcendent status before which a tourist is overwhelmed as he blacks-out smitten by its beauty in the first scene of the movie. Amidst this continuous tension a new space is generated in the imagination of Gambardella as he skillfully relates his story throughout the 
movie - the story which he will have written after his encounter with the great beauty. Thus, it is out of this tension that he magically 'digs a hole' to communicate with the underworld before he engages in the creative endeavor of writing his second book, creating a whole new world out of the chaos of his scattered memories into a cosmos of poetic and sublime beauty.

The creation process brings about, out of chaos, a new world - an imago mundi that will act as a point of orientation for the individual or the society. ${ }^{218}$ Not only this, but this new world is real and acquires validity; these realities, in turn, disclose themselves as timeless entities. ${ }^{219}$ Consequently, the gods that created the world of the Greeks are themselves, in Schellingian terms, the physical potencies that created the actual world. In other words, the creation of the gods is mentally posited into human consciousness as human beings try to make sense of their reality. Nevertheless, the process of creating the gods imitates the way in which the gods created the universe (in contemporary terms, explaining the universe through the big bang theory.)

Throughout this section, I have traced the distinction between constitutive and regulative mythologies as proposed by Markus Gabriel. The constitutive mythologies are those mythologies that create a whole new world, and this creation is dependent on the creation of new space as Mircea Eliade has argued. I will now move to how art

\footnotetext{
${ }^{218}$ Eliade, Mircea, Op. cit. p. 21.

219 Jung, C.G. and Kerényi, C., Op. cit., p. 149.
} 
played an important role in the creation of such spaces and how that affected the evolution of thought in a perpetual intertwining between science and art.

\subsection{Dante's Purgatory}

Margaret Wertheim writes the following about Dante's Purgatory: “The coming into being of Purgatory is a rare instance in which we can see clearly the emergence of a new space of being. As such, there are important parallels with the creation of cyberspace today, and it is thus fascinating to see how this new medieval space emerged.220" The coming to existence of the purgatory posed a puzzling concept as such for those who could only think in terms of either heaven or hell. What does it mean not to be sufficiently bad or good so as to either be condemned to hell or heaven respectively? It is in that sense that the instance which supposed the generation of a new image, a new space of being, is rare. This kind of instances establishes the concretization of that which was unthinkable in conceptual terms. After the surging of such space, thus, the domain of free-play is made available for the different conceptualizations vis $a$ vis the absoluteness of the image.221

The instance of the birth of the Purgatory as a socio-theological space presented the kind of puzzlement as the example of Schrödinger's cat which was formulated by Schrödinger in order to make an approximation of what the

\footnotetext{
${ }^{220}$ Wertheim, Margaret, Op. cit., p. 69.

${ }^{221}$ See Wirth, Jason, Op. cit. 2013.
} 
Heisenberg principle could have really meant; in other words, when the superposition of states become actualized - this topic has been discussed in detail in the second chapter. The electron shows both, a wave pattern and a particle pattern when the slit-experiment is performed. The manifestation of one pattern or the other depends on the collapse of the state into one or the other insofar as it is consciously perceived, otherwise, the superposition will remain intact. The puzzlement with which the physicists reacted to Heisenberg's principle is the same as that of the people when they first read Dante's Divine Comedy. The reason why I have brought up Heisenberg's principle in relation to the purgatory is because of the difference in the perception of both in our modern times. The question which poses itself when we talk about the generation of a space which was denominated as purgatory is to what extent is it real or what does it mean that the surging of such a clearly imaginative space is real? Wertheim asserts that in modern times we cannot help but associate anything that is real in physical terms. ${ }^{222}$ We have been brainwashed, she asserts, to think in such terms every time we are discussing what is real. The reality of what exists, however, is not so much to be associated with a certain physicality of the object thought, hence Eliade and Kerényi's affirmations that the bringing about of the world/mythology supposes the coming to be of a real entity. Obviously, the reality of such creations is not so much dependent on whether or not they have a physical extension in the Cartesian sense, but insofar as they are posited in our consciousness.

\footnotetext{
${ }^{222}$ Wertheim, Margaret, Op. cit., p. 71.
} 
Similarly, we don't go into the movie session thinking to ourselves that what we are about to experience is unreal. What we experience throughout the movie session is an indulgence of a sort, such that we really do perceive the movie actors and the different episodes in the movies as really real. Our descent into the cinematic cave, thus, is after having been enlightened by the higher reality of the outer universe into the shadows. Nevertheless, what Plato might have missed is that the shadows that participate of the Forms are not shadows as opposed to what is really real, but that they are really real in their own right as they are constitutively presented on the screen. Accordingly what is real is not that which is remote and fixed and imposes a certain form onto the objects which partake of it, but rather a construction, a poesis that imitates the creation of nature as naturing; hence the image created is not a shadow of but is rather real in and of itself. What is real is, therefore, not only the concept, or the Form or the Idea; but, in the sense of Schelling, what is real is the fact of existence out of which essence is to be produced. This dynamic process, nevertheless, cannot take place without the incessant tension that results from the first split of an outward movement and an inward one resulting in an evolutionary spiral movement. Movement becomes an essential factor in the coming to be of the cosmos. In one of his poems, which I will quote it in its entirety, Paul Klee writes,:

In the beginning there was...?

Things moved freely, so to speak, neither in a curve nor in a straight line. Think of them 
as moving elementally, they go

wherever they go, in order to go

destination-less intent-less disobedient

with movement the only certainty,

a "state" of elemental motion.

It is at first only a principle: to move,

not a movement principle,

no particular intent,

nothing special, nothing organized.

Chaos and anarchy, murky seething.

Intangible, nothing heavy nothing

light (heavy-light) nothing white

nothing black nothing white (only greyish) nothing

red nothing yellow nothing blue (only greyish)

not even directly grey, nothing at all

distinct only indeterminate, vague.

No here, no there, only an everywhere

No long short only an everywhere

No distant near

No today, yesterday tomorrow only a tomorrow-yesterday

No doing only being

No marked rest no marked movement

only "shadow formation" 
only a something: motion as a prerequisite

to change from this elemental state. - Paul Klee

The movement of the primordial elements results in a radical change from one state to another with movement as the condition of possibility of the change of this elemental state. It is important to note, though, that the movement is not a principle of movement. In other words, the change of state of being, the very fact of being, is neither directional nor intentional. There is nothing special about it except the fact that it is a movement. Whether the coming to be of the cosmos out of chaos in the universal sense, or the coming to be of the cosmos out of the chaos subsequently generated after the surging of the rare instance of the coming to be of a new space, they both suppose the generation of an absolute world which acts as an orientation because the movement is directionless in the first place. The act of poesis is nothing more than an absolutism of reality vis a vis chaos, vis a vis our fear of the formless, vis $a$ vis the fecundity which lurks dormant in the realm of that which is in potentia and is waiting for our creative imagination to tear it apart and bring it out into existence as a real entity. I exist, it's sweet, so sweet, so slow...

\subsection{Following Swan's Way}

Mircea Eliade, whom we get back to in this section, asserts the following:

"Even for the most frankly nonreligious man, all these places still retain an 
exceptional, a unique quality; they are the "holy places" of his private universe, as if it were in such spots that he had received the revelation of reality other than that in which he participates through his ordinary daily life." 223 Perhaps this idea of the holy places evokes the concept of life space or hodological space as proposed by Kurt Lewin, which Deleuze defines it as "a field of forces, oppositions and tensions between these forces, resolutions of these tensions according to the distribution of goals, obstacles, means, detours.224"

The field of forces and of tensions is evoked in Proust's Remembrance of Things Past. Not only did Proust beautifully show us that the past is dependent upon a creative and imaginative reformulation 225 but also that these evocations are inspired by the concreteness of the places towards which the narrator had developed a certain affinity. In Swan's Way we are able to realize in what way the different episodes of Swann's childhood were forged deep into the sediments of his memories and which were induced as he passed by certain places, castles, roads, trees. This is represented interestingly in the two ways that the narrator and his family used to take to go for a walk on the weekends depending on the weather and the time they had before they had to be back for lunch. These two ways which are accessed from the front door or the backyard door respectively, eventually represented the different ways (geographical and societal) of Swan's family and the family of the Guermantes. These

\footnotetext{
${ }^{223}$ Eliade, Mircea, Op. cit., p. 24.

${ }^{224}$ Deleuze, Gilles, Cinema 2. The Time-Image, trans. Hugh Tomlinson, University of Minnesota Press, 1989, p. 127.

${ }^{225}$ See Wirth, Jason, The Conspiracy of Life: Meditations on Schelling and His Time, SUNY Press, 2003.
} 
two roads which, as we discover throughout the first volume, comprised of two different worlds that did not overlap at the beginning of the novel, because of Swan's lifestyle and the fact that he was in love and eventually married Odette who was a prostitute, but eventually meet again when Gilberte, Swan's daughter, is accepted into the high-class societies and ends up getting married to Robert de Saint-Loup, a Guertmantes. Accordingly, towards the end of the novel in Time Regained, when the narrator is staying at Gilberte's place, he discovers when he goes for a walk that the two ways had been linked. This is an interesting demonstration in the personal biography of the narrator as he remembers the past episodes of his life of how the hodological space is constructed as the life space of the individual as a psychological construct.

In a different example, Julio Cortázar also develops a contemporary version of the reception of hodological space in his acclaimed novel Hopscotch. The table of instruction of the sequence of the chapters of the novel mentioned at the beginning is already making it clear that the novel will not be an easy ride through but will consist of tensions and detours as the narration is constantly jumping back and forth alternatively between the expendable chapters and the main narrative. Not only this but also, as with Proust, we have two parts whereby the first one takes place in the streets of Paris, and the second one is set in Argentina. The first part relates the life of Horacio Oliveira and La Maga as well as the tension that was underlying their relationship. We are also introduced into the dynamics of Horacio's everyday life: he is a member, along with some friends, of the Serpent's club: they form a group 
discussing all sorts of intellectual and cultural topics, including music and art. The sudden disappearance of La Maga plays an important role in the decision Horacio, whose life is governed chaotically, takes to go back to Argentina stopping at La Maga's home city, Montevideo. Now the point of tension is Horacio himself as he pops up in the life of his childhood friends Manolo Traveler and his girlfriend Thalita with whom Horacio ends up having an affair leading to the deterioration of the relationship between Horacio and Traveler.

The very fact that the novel has many endings is in a sense Cortázar's statement to the reader that we have to go through it as suits our hodological space best. As for Horacio, the protagonist, the evocation of these spaces in the streets of Paris is obvious at the very beginning of the novel when he roams the streets looking for his beloved La Maga. Horacio's memoirs are marked by these concrete places, landmarks and even music. Hopscotching through the novel is an invitation into these discrete and concrete moments that constituted Horacio's life. All this arduous process requires an engagement on behalf of the reader in order to creatively participate in these spaces following the organic narrative of the story. ${ }^{226}$ The novel itself contains different metaphysical, epistemological and aesthetic reflections on the nature of reality, knowledge and art. Similar reflections are presented articulately in chapter 28 about the absurdity of the world and the human approximation of Reality during one of the meetings of the Serpent club at Horacio and La Maga's apartment. The whole chapter is constructed exquisitely around existence and the representation

${ }^{226}$ Deuleuze, Gilles, Op. cit., p. 127. 
of Reality as a human construct, culminating in the existential anxiety at the death of La Maga's baby. Such unpredictable episodes govern the life of Horacio who would eventually look for meaning to life in the mundaneness of his daily experiences.

Cortázar strives to twist the Spanish language and take it to its limit such that the expressiveness of the concreteness of the situations that Horacio and La Maga experience would be justly and be roughly consolidated in the novelistic text. Not only does Cortázar drive the Spanish language to its limits, but he goes all the way so as to invent his own lexicon in order to describe an intimate scene between Horacio and La Maga in chapter 68. The text gives birth to a whole new space for the imagination of the readers to wander through in their attempt to recreate the same intimate scenario. Whereas Cortázar could have resorted to a very complicated lexicon had he wanted the description to be intelligible in the conventional sense; nevertheless, he invents an entire new set of vocabulary to express that which cannot be expressed in ordinary language. Thus, underneath the hopscotching, as we go back and forth through the novel, we also delve into a novel literary space whereby the proper meaning of the words is not to be found apriori by seeking the help of the dictionary, but the words could be viewed as tautegorical in that they actually strive to mean and signify what they mean; they are in themselves the literal potentiation of the concrete experience of Horacio and La Maga. Accordingly, the reader is asked to understand the experience itself, while in their own terms, by taking the text itself for what it is. The key point to be taken into consideration here, however, is the fact that Hopscotch is yet another creative intent at a poesis whose meaning is not 
predetermined but is rather generated as it 'divines the future' while it stirs the system seeking for a new equilibrium in the Heraclitian sense.

Based on the above, I have argued that one of the conditions of possibilities of the novum in the sense of Bloch is the generation of a new space through which we would make sense of Reality in a perpetual evolutionary flux. Within these lines of thought, Margaret Wertheim writes:

“Throughout history new kinds of space have come into being as older ones have disappeared. With each shift in our conception of space also comes a commensurate shift in our conception of our universe - and hence of our own place and role within that universe. In the final analysis, our conception of ourselves is indelibly linked to our conception of space. As I noted at the start of this work, people who see themselves embedded in both physical space and spiritual space cannot help but see themselves in a dualistic sense, as physical and spiritual beings. But a people who conceive of space in purely physical terms are virtually compelled to see themselves as purely physical beings. This, of course, is not the only choice; people in non-Western cultures have conceived entirely different options. What is universal is that conceptions of space and conceptions of self mirror one another. In a very real sense, we are the products of our spatial schemes. ${ }^{227 "}$

\footnotetext{
${ }^{227}$ Wertheim, Margaret, Op. cit., p. 308.
} 
The previous passage has two facets in relation to what I have been arguing in the previous sections. On the one hand, we see how the emergence of a new spatial framework within the artistic domain eventually stimulated the development of the conceptual frameworks for new scientific theories with regards to space - which hints at what Schelling calls for when asserting that art is the organ of philosophy. On the other hand, as Wertheim argues, 'we are the products of our spatial schemes'. In other words, our approach to space in the artistic sense ends up shaping us and affecting our worldview. This is most clear in the transition from the Christian dualistic view of Heaven and Hell and the introduction of the Purgatory by Dante. While Wertheim refers to cyberspace as the newly contemporary cultural approach to social space, we can conceive of cinema as the emerging social space through which we can also, contemporarily, make sense of Reality. An interesting example could be found in Andrei Tarkovsky's Stalker which I will be treating in the next section.

\subsection{A Peak into the Tarkovskian Zone}

The emergence of space is a recurrent motif in the cinema of Andrei Tarkovsky.228 In his cinematography, space is not the medium where the events of the movie occur, but rather cinema forms the space based on the different characters in the movie, accordingly, Bird asserts that space does not so much form the receptacle

\footnotetext{
${ }^{228}$ Bird, Robert, Andrei Tarkovsky: Elements of Cinema, Reaktion Books, 2008, p. 51.
} 
for the filmic events but space is their consequence. ${ }^{229}$ Moreover, the constitution of space in cinema supposes the return to material reality. 230

A similar line of thought could be traced in Siegfried Kracauer's Film Theory where he argues that in our contemporary world, and after the pure abstraction as exerted upon reality by the sciences and the different fields of arts and humanities, cinema could be the very medium through which physical reality would eventually be redeemed from this predicament. Accordingly, he argues that the difference between cinema as an autonomous art and the other arts is that in the latter, the raw material that constitute the object of art is used as means to the end of the object intended to be created by the artist, whereas in cinema, that which is presented on the screen is the raw material itself. What the camera does, Kracauer affirms, is record physical reality in such a way as we might have not been able to view in a mundane life situation. ${ }^{231}$ Cinema, thus, allows us to view and experience in a different way than we would have in real life due to the fragmentary lives that we are currently living. A poetic film that presents us with an organic image such as the films of Tarkovsky evokes the Absolute in an image irreducible to the collection of its elements. The cinematic imagery, therefore, presents us with the flow of our world and calls for a return to physical reality. ${ }^{232}$ For Tarkovsky, this is characteristic of

\footnotetext{
${ }^{229}$ Ibid., p. 54

${ }^{230}$ Ibid., p. 57

${ }^{231}$ Kracauer, Siegfrid, Film Theory: The Redemption of Physical Reality, Princeton Paperback edition, 1997, p. 299

${ }^{232}$ Ibid., p. 300.
} 
cinema which is able to alchemically transform the mundane into something alien to us.

Furthermore, Kracauer compares cinema to the myth of the Gorgon Medusa whose head was severed by Perseus. Perseus was warned by Athena that he would not be able to look at Medusa's head except through its reflection in a polished shield that she had given him. Kracauer argues that the moral of the story is that we cannot possibly assimilate the horrors and the fears evoked by certain situations or else we would be paralyzed. And just like Athena warned Perseus to look into the reflected image of the head of Medusa, cinema acts as a mirror for nature. Through cinema we could thus experience the possibilities of different horrors and dreads that might befall us through an approximation of what would it be like to experience similar catastrophes in real life. Notwithstanding, Kracauer points out that these images should not be acting as means to an end, rather they should be presenting themselves as such, in other words tautegorically in order to be assimilated by the spectator who would become more familiar with how the situation would be should things occur in real life. With that in mind, Kracauer argues that perhaps Perseus' greatest merit was not so much the beheading of Medusa's head as much as the ability to overcome his fears and look at its reflection in his shield - an act that subsequently allowed him to actually decapitate the monster. ${ }^{233}$ The point that Kracauer is trying to make is that cinema could act as Perseus' polished shield enabling us to look into and contemplate, among other things, all the possible scenarios of catastrophic or evil

${ }^{233}$ Ibid., p. 306. 
episodes that might ensue in our daily life and upon incorporating these images we would thereby confront our fears and proceed in such a way that would prevent similar events in the first place. Conceiving of the cinematic domain as such implies, as argued in the fourth chapter, an ethical responsibility on behalf of the spectators vis a vis making sense of reality and the actions to be subsequently taken with respect to the state of affairs. Such ethical responsibility is very nicely presented in Andrei Tarkovsky's Stalker (1979). Tarkovsky insisted that the Zone in the movie does not signify anything other than itself, and the conditions in order to be able to pass through the zone depends on the person's self-respect and one's ability to distinguish that which is passing and that which really matters. ${ }^{234}$ Robert Bird makes an interesting comparison between the Zone as the space where one goes with their innermost desires and cinema. ${ }^{235}$ We are thus faced with a stoic-like decision before, during and after we cross the Zone in order to quench our desires first and then prevent ourselves from any hasty judgments based on our desires. The problem of the ethical is yet again evoked upon such understanding of cinema as an aesthetic field. The ethical responsibility that ensues when dealing with such a field is so preposterously overwhelming, that neither the Stalker nor the Scientist nor the Writer would actually overcome their fears to trespass the Zone. They were so paralyzed by the story of the other Stalker who once entered the Zone wishing for his brother to be revived, but returned home to find, to his surprise, a lump-sum of money and consequently committed suicide. He was faced with his real utmost desire and was

\footnotetext{
${ }^{234}$ Tarkovsky, Andrei, Op. cit. p. 200.

${ }^{235}$ Bird, Robert, Op. cit. p. 69.
} 
not able to handle it. Hence Tarkovsky affirms that in order to be able to make it through the Zone, without any possible self-deceptions, one should have self-respect and be able to determine that which really matters. Notwithstanding, in order not to be transformed into stone upon entering the Zone, it would be better to look at its reflection.

The cinematic space is able to provide us with such a reflection. Cinema, consequently, can be viewed as Perseus' polished shield through which we would have a sneak-peak into our utmost desires by allowing a free flow of our creative imagination vis a vis a certain social problem or an inadvertent problematic or a yetto-come social catastrophe. But in order to be able to achieve that, one has to overcome one's fears first so that one would be able to look at the reflection of such desires on the cinematic screen. This entails an ethical responsibility, as argued in the previous chapters, as societies strive to behead contingent behavior that would prove to be unethical when reflected upon through the cinematic medium. Additionally, not only are we able to evade and resolve possible social problems and predicaments, but we are also able to make sense of our reality insofar as the flow of the movie redeems our physical reality in the Kracauer's sense, and we are thus able to experience it differently than we are usually accustomed to. It is this emergent space which results with the production of a cinematic image that would subsequently become the organ of philosophical reflection in the sense of Schelling. 
I have been arguing throughout the present chapter that the condition of the possibility of the novum is the creation of a novel space that would eventually stimulate us into reflecting upon it resulting in the emergence of new meaning and therefrom into the creation of new concepts. I will now argue, based on the aforementioned that it is essential that there be an object of art to be reflected upon in order to stimulate the generation of that which is conceptual or that which is abstract (understood as that which is yet-to-be). This would entail a change in steering humanity with a view towards the future, as the abstract and the conceptual, becomes the yet-to-come in the future grounded in the concreteness of that which is actualized in an aesthetic activity of poesis in the process of Absolutism of Reality through which human beings tend to make sense of their Reality.

It wouldn't be that much of leap therefrom to understand what Schelling meant when he declared art to be the organ of philosophy. Neither subject acquires an elevated status with respect to the other in any sort of way. However, they both are intertwined in such a way that neither could be possible without the other. There is on the one hand, an objective manifestation in the object of art whose dynamics of productions, at the bottom of it, form a part of the whole process of the naturing of nature; and on the other hand, there is the subjective manifestation of that which was objectively created and which is expressed discursively by the philosopher. What we have here is, therefore, a return to reality as Kracauer said in relation to cinema. Art, as an aesthetic activity, thus, allows us to redeem physical reality in Kracauer's sense in order to rationalize it and extract new concepts that would drive us onto a new 
level of understanding of our reality such that we would be making sense of it vis a vis our present moment neither in relation to the future nor in relation to the past. The two basic activities that would underlie the overall process are poesis and speculation. The former entails, as argued previously, the emergence of a fecund space through which we consider new possibilities and the latter entails an act of rationalization and discursive reasoning, an act of abstraction that would lead to the generation of new meaning and significance. Accordingly, abstraction becomes future oriented as meaning becomes dependent on that which is yet-to-come and not that which is imposed from without. The dynamicity of this process entails an evolutionary line whereby we are constantly making sense of our reality (Absolutism of Reality, Constitutive Mythologies, Emergence of Space) always seeking a balance of the respective systems through which we make sense of our reality.

From the previously mentioned, philosophy as a speculative activity is evoked as an ultima scientia which is dependent on the different scientific and artistic domains of a certain society. Schelling's attempts at describing the different activities between negative and positive philosophies, thus, underlie the distinction between philosophy as a prima scientia and as an ultima scientia. Following this distinction, we are able to distinguish between a skeptical philosophy which is generative of nothing more than the limits of thought and concepts in the Kantian sense, and a speculative philosophy which is generative of concepts in the Schellingian sense. The former has its ground in reason and the latter has its ground in the non-rational insofar as it is generative of the rational; in other words it is what stimulates the generation of new concepts based 
on the scientific and artistic activities available to the respective societies. In a similar vein of thought Rainer E. Zimmermann asserts the importance of speculative philosophy in extracting "conceptual information about what is grounding the sciences and providing a proper foundation of the whole conceptual architecture.236"

While Zimmermann focuses on the onto-epistemicity of the mapping of the world so as to make sense of it, and relates that to the logic and the hermeneutic approaches which human beings adapt in their endeavor to systematize and rationalize their Reality; notwithstanding, there is still a gap between the logic and the hermeneutic. The bridging of the gap, Zimmermann argues, is achieved through the realization of the importance of poetical contexts, taking it in the sense of autopoesis. 237 Nevertheless, the poetical contexts do not highlight or elevate one field over the other. Autopoesis as discussed in the previous chapter is the underlying principle of nature itself from inorganic to organic matter, and underlies the human creative process as well. The concept of mythopoesis in the sense of Schelling has been previously examined whereby what was understood by it was the form through which human beings make sense of their reality through an act of aesthesis that would stimulate the generation of the artistic image or object (in our case the cinematic image.) However, poesis and aesthesis alike underlie the scientific and the logical domains as Zimmermann points out. Yet, by bridging the gap between the logical and the hermeneutic and the ethical responsibility that underlie it, it is

\footnotetext{
${ }^{236}$ Zimmermann, Rainer, Op. cit., 2014, p. 164.

${ }^{237}$ Ibid., p. 201.
} 
necessary that we establish a new poetical space that would act as ground for the emergence of existence from the universal unground in the Schelling's sense. ${ }^{238}$ This, in turn, yet again, hints towards the need for establishing an interdisciplinary approach between the different fields of study and between the different social and cultural domains: or what Schelling would have termed positive philosophy, in other words, speculative philosophy.

\footnotetext{
${ }^{238}$ Zimmermann, Rainer, Op. cit., p. 201.
} 


\section{Conclusion}

The core of the present work has focused on the tautegorical interpretation of the cinematic image. The argument stemmed from Schelling's conception of myths as tautegorical, and was applied to Tarkvosky's conception of the cinematic image whereby he calls for an interpretation of the image such that no hidden or remote meaning must be implied from what the image shows because the image is and is what it means.

The arguments put forward in the previous chapters were based on Schelling's thought with regards to the symbolic interpretation of the image. Accordingly, in order to ground the main argument of the thesis - the interpretation of the cinematic image as tautegory - it was thought necessary to treat certain subjects 
which were considered to be more important and in agreement with the thought of both Schelling and Tarkovsky.

The first chapter included a discussion of Schelling's conception of mythology, the dynamics of artistic creation and the Schellingian dialectic. In the second chapter the concept of the Schellingian dialectic was further developed in order to explain the role of the creative imagination as a mediator between the infinite and the finite. At the end of the second chapter certain concepts and conclusions were drawn, which served as a point of reference for the rest of the thesis. In the third chapter a survey of the contemporary theories of mythology was given in order to trace a certain line of thought which would support the thesis' main argument. A critical view was also given in order to synthesize the discussed theories; the main goal of the chapter was to argue for a grounding of the ethical and the political in the aesthetic. Therefrom a discussion of film as an aesthetic activity was put forward based on Andrei Tarkvosky's conception of film. In the fourth and fifth chapter Andrei Tarkovsky's conception of film and cinematic activities was discussed in order to show that, at the bottom of it, what Tarkovsky was arguing for when he called for an interpretation of the cinematic image based on what the image is could as well be traced back to Schelling's interpretation of mythology as tautegory. Moreover, this concept was applied to a selection of Tarkovsky's movies such as Andrei Rublev, Stalker and Mirror. In the sixth chapter a discussion of the generation of space and the novum based on aesthetic narrative was given whereby it was argued furthermore that the aesthetic acted as ground for reason and the generation of concepts; the arguments were 
supported by giving examples from a selection of literary as well as cinematic examples and were also supported by discussing the concept of transcendental materialism as argued for by Rainer E. Zimmermann.

Both Schelling and Tarkovsky, as we saw, called for an interpretation of the image insofar as the image is viewed for what it is and not what it could be possibly referring to. Such a proposition would be contrary, as we saw previously, to any theory of ideology whereby the aesthetic is political par excellence and is used as a tool to manipulate rather than to generate a new space of the novum. However, the aesthetic can only be the ground of the political insofar as the aesthetic would act as ground for the ethical as well. This, therefore, highlights Tarkovsky's view of art as having an ethical role. ${ }^{239}$

All the arguments that have been given during the course of the present work have led us to conclude that the aesthetic, insofar as it is always accompanied with an ethical responsibility, would act as a substitute for the dogmatic-religious. However, the aesthetic activity would have to be dynamic in order to avoid any possible follies and become itself dogmatic. Notwithstanding, an aesthetic activity that constantly acts as a ground for the ethical would be less prone to falling for the same kind of error of any dogmatic doctrine precisely because of the nature and the characteristics of tautegorical interpretation.

${ }^{239}$ Tarkovsky, Andrei, Op. cit. p. 43. 
The Schellingian conception of revelation, as argued in the sixth chapter, is not one such whereby God is a transcendent entity that reveals a certain dogmatic message, but is rather a coming god that is generated from within the Nature itself as part of the collective system of societies240 (e.g. The Deities of Samothrace). Tarkovsky argues for a similar conception of art whereby art is religious insofar as it preoccupies itself not only with the material but also the spiritual side of human beings as rational animals. Therefore, when the dogmatic is substituted with a dynamic form of aesthetic activity, the novum is generated from within rather than from outside the system of any given field. In the case of cinematic activity, the novum is dependent on an interpretation of the cinematic image insofar as it is viewed for what it is and not by imposing a dogmatic interpretation.

The following however can only remind us that there is no work that is impeccable, and that every argument or theory that is put forward has its own limits as well. To begin with, Schelling scholars have varied widely in their understanding and interpretation of his philosophy of mythology and that of revelation; moreover, it is only recently that Schelling saw resurgence in the Anglo-Saxon tradition. On the other hand, Andrei Tarkovsky is but one director and theoretician of cinema amongst many other cinematic directors, who would categorically disagree or criticize his thought.

\footnotetext{
${ }^{240}$ See also Wirth, Jason, Op. cit., 2015.
} 
The main problematic that was continuously present as the thesis was being written was that of ideologies and dogmas. Thus the solution sought and the conclusion that has been reached tackle a certain aspect of the problematic and could only be one amongst many other solutions that could be provided and that would be based on different philosophical traditions other than the ones chosen herein. And based on the proposed arguments, cinema as an aesthetic activity can be yet another domain through which we can express, interpret and make sense of reality.

Accordingly, aware of the different approaches that address this relation, I have tried to offer a synthesis between two parts, a theoretical one in the tradition of Schelling, and a practical one based in Tarkovsky's cinema. The attempt to relate these two parts calls for an actualization of some of the aesthetic concepts like mythology and tautegory recognizing in the concrete example of Tarkovsky's cinematic image their potential contemporary contributions. I've considered, therefore, that the methodological tension derived from it is a productive approximation, and one that is able to illuminate the function of cinema in today's societies. 


\section{Mitopoésis, estética y creación artística Hacia una interpretación Tautegórica de la imagen cinematográfica}

\section{Índice}

Introducción

1. La filosofía de la mitología

1.1 La mitología como un proceso necesario

1.2 Necesidad y la libertad en la creación artística

$1.3 \mathrm{El}$ inconsciente como agente activo

1.4 La dinámica de la creación artística

1.5 Una aproximación a la dialéctica Schellingian

2. La imaginación como mediador entre lo infinito y lo finito

2.1 La reintroducción del sujeto cognoscitivo

2.2 Sobre las aproximaciones órficas y prometeicas al conocimiento

2.3 Corolario: Del espacio y tiempo hacia la atemporalidad

2.4 Imaginación creativa: Una síntesis de la intuición intelectual y estética

2.5 Steppenwolf: Mitología y la imaginación creadora

2.6 Un comentario final y conclusión

3. La mitología contemporánea

3.1 Sobre la estética

3.2 Las divinidades de Samotracia de Schelling

3.3 Una crítica de Lenguaje y mito de Cassirer

3.4 Sobre los arquetipos y el inconsciente colectivo

3.5 El absolutismo de la realidad de Blumenberg

3.6 Roland Barthes : Sobre mitopoésis y el mitización de las narrativas

3.7 Desde Naturphilosophie a la filosofía de la mitología

3.8 El cine como una actividad estética 
4. La dimensión trascendental del cine

4.1. Esculpir en el tiempo de Takovsky: el arte como un anhelo por lo Ideal 4.1.1 La película y la idea evolutiva

4.1.2. El cine poético

4.1.3. El cine como un dominio artístico autónomo

4.1.4. Sobre la relación entre verdad y belleza

4.1.5. Sobre el valor ético del arte

4.2. Una lectura Schellinguiana de Esculpir en el tiempo de Tarkovsky

4.2.1. Sobre la libertad y la necesidad de la creación estética

4.2.2. Imágenes como cifras del infinito

4.2.3. Sobre la concepción tautegórica de la imagen cinematográfica

5. La actividad estética como la negación de la negación

5.1 Viaje y Trauma

5.2 El voto de silencio

5.3 Conclusión

6. A través de la madriguera del conejo

6.1 La generación del espacio a través de la actividad estética

6.2 Odiseo desciende al Hades

6.3 El purgatorio de Dante

6.4 Siguiendo el camino de Swann

6.5 Sobre la zona de tarkoskiana

Conclusión 


\section{Resumen}

El núcleo del presente trabajo se ha centrado en la interpretación tautegórica de la imagen cinematográfica. La discusión surgió desde la concepción de Schelling de los mitos como tautegoría y se ha aplicado a la concepción de Tarkvosky de la imagen cinematográfica por la que pide una interpretación de la imagen de manera tal que ningún significado oculto o remoto debe estar implícito en lo que muestra la imagen porque la imagen es y es lo que significa.

Los argumentos presentados en los respectivos capítulos se basaban en el pensamiento de Schelling con respecto a la interpretación simbólica de la imagen. En consecuencia, para fundamentar el principal argumento de la tesis -la interpretación de la imagen cinematográfica como tautegoría- se ha creído necesario tratar a ciertos temas que fueron considerados como de mayor importancia y de acuerdo con el pensamiento de Schelling y Tarkovsky.

El primer capítulo incluye un tratamiento del concepto de Schelling sobre mitología, la dinámica de la creación artística y la dialéctica Schellinguiana. En el segundo capítulo el concepto de la dialéctica Schellinguiana ha sido desarrollado con

el fin de explicar el papel de la imaginación creativa como mediador entre lo infinito y lo finito. Al final del segundo capítulo ciertos conceptos y conclusiones se han delineado sirviendo como un punto de referencia para el resto de la tesis. En el tercer 
capítulo, se aborda un estudio de las teorías contemporáneas de la mitología para rastrear una cierta línea de pensamiento que apoyaría el argumento principal de la tesis. También, es propuesta una visión crítica para sintetizar las teorías discutidas; el objetivo principal del capítulo es defender un fundamento de lo ético y lo político en la estética. A partir de ahí, se ha tratado el ámbito del cine como una actividad estética basándonos en el concepto del cine en la obra de Andrei Tarkvosky. En el cuarto y quinto capítulo la concepción Tarkovskiana de la actividad cinematográfica se ha analizado con el fin de demostrar que, en el fondo, lo que Tarkovsky defendía cuando proporcionaba una interpretación de la imagen cinematográfica basada en lo que la imagen es, se podría remontar a la interpretación de Schelling de la mitología como tautegoría. Por otra parte, este concepto fue aplicado a una selección de películas de Tarkovsky como Andrei Rublev, Stalker y Mirror. En el sexto capítulo una discusión de la generación del espacio y el novum basada en la narrativa se presenta bajo la premisa de que la estética actúa como un medio para la razón y la generación de los conceptos. Las discusiones han sido apoyadas por una selección de ejemplos tanto literarios como cinematográficos y también abordadas bajo el concepto de materialismo transcendental defendido por Rainer E. Zimmermann.

Tanto Schelling como Tarkovsky, como hemos visto, defienden una interpretación de la imagen en la medida en que ésta se ve por lo que es y no por aquello a lo que posiblemente podría estar refiriéndose. Tal proposición sería contraria, como vimos anteriormente, a cualquier teoría de la ideología que fundamente la estética en lo político y es utilizada como una herramienta para 
manipular en lugar de generar un nuevo espacio del novum. Sin embargo, la estética sólo puede estar en el terreno de lo político, en la medida en que actúa como fundamento para la ética también. Esto, por lo tanto, destaca que la visión de Tarkovsky sobre el arte tiene un papel ético.

Todos los argumentos que se han dado a lo largo del presente trabajo nos han llevado a concluir que la estética, en la medida en que siempre está acompañada con una responsabilidad ética, actuaría como un sustituto de la dogmática religiosa. Sin embargo, la actividad estética tendría que ser dinámica para evitar que se convierta en sí misma en dogmática. No obstante, una actividad estética que constantemente actúa como un fundamento para la ética sería menos propensa a caer en el mismo tipo de error de cualquier doctrina dogmática precisamente por la naturaleza y las características de la interpretación tautegórica.

La concepción Schellinguiana de la revelación, como se argumentó en el sexto capítulo, no es una donde el concepto de dios se entiende como una entidad trascendente que revela un cierto mensaje dogmático, sino es más bien un dios venidero generado desde dentro de la naturaleza como parte del sistema colectivo de las sociedades (por ejemplo Las deidades de Samotracia). Tarkovsky aboga por una concepción similar del arte porque éste es religioso en la medida en que se preocupa, no sólo con la parte material, sino también con la parte espiritual de los seres humanos como animales racionales. Por lo tanto, cuando lo dogmático se sustituye con una forma dinámica de la actividad estética, el novum se genera desde dentro en 
lugar de ser impuesto desde afuera del sistema. En el caso de la actividad cinematográfica, el novum es dependiente de una interpretación de la imagen cinematográfica en la medida en que está vista por lo que es.

Lo siguiente, sin embargo, nos recuerda que no hay trabajo que sea impecable, y que cada argumento o teoría que se ponen adelante tienen sus propios límites también. Para comenzar, los expertos sobre Schelling han variado ampliamente en su comprensión e interpretación de su filosofía de la mitología y la de revelación; por otra parte, sólo recientemente Schelling ha tenido una especial atención en la tradición anglosajona. Por otro lado, Andrei Tarkovsky es solo un director y teórico del cine entre muchos otros directores cinematográficos, que podrían categóricamente estar en desacuerdo o criticar su pensamiento.

La principal problemática que ha estado constantemente presente mientras se llevaba a cabo la tesis fue de las ideologías y dogmas. Así la solución buscada y la conclusión que se presenta abordan un cierto del aspecto de la problemática y podrían ser solamente una entre muchas otras soluciones que podrían ser aportadas y que se basarían en otras diferentes tradiciones filosóficas que no han sido elegidas en nuestro trabajo. $\mathrm{Y}$ basado en los argumentos propuestos, el cine como una actividad estética puede ser otro dominio más a través del cual podemos expresar, interpretar y darle sentido a la realidad. 
Por todo lo expuesto, conscientes de la diversidad de enfoques con los que podría abordarse esta relación, hemos tratado de ofrecer una síntesis entre dos modelos, uno teórico procedente de la tradición estética en Schelling, y otro práctico asentado en la producción cinematográfica de Tarkovsky. El intento de poner en relación estos modelos contiene, como conclusión, una apuesta por la actualización de algunos conceptos estéticos como el de mitología y tautegoría reconociendo en la imagen cinematográfica de un caso concreto, Tarkovsky, sus potenciales incidencias contemporáneas. Hemos considerado, por ello, que la tensión metodológica derivada de ello es una aproximación productiva y capaz de iluminar la función del cine en las sociedades actuales. 


\section{Bibliography}

After the Postsecular and the Postmodern: New Essays in Continental Philosophy of Religion, eds. Paul Smith Anthony and Daniel Whistler, Newcastle: CSP, 2010.

Agamben, G., Potentialities: Collected Essays in Philosophy, trans. D. Heller-Roazen, Stanford University Press, 1999.

Aitken, Iain, European Film Theory and Cinema : A Critical Introduction, Indiana University Press, 2001.

Alexander-Garrett, Layla, Andrei Tarkovsky: The Collector of Dreams, Glagoslav Publications, 2012.

Anne Doane, Mary, The Emergence of Cinematic Time, Harvard University Press, 2002.

Artaud, Antonin, Antonin Artaud: Selected Writings, Ed. S. Sontage, trans. H. Weaver, University of California Press, 1976.

Aumont, Jacques; Bergala, Alain; Marie, Michael; Vernet, Marc, Aesthetics of Film, ed. trans. Richard Neupert, University of Texas Press, 1992.

Badiou, Alain, Cinema, Polity, 2013.

Barthes, Roland, Mythologies, trans. Sian Reynolds, Vintage Books, 1993.

Bazin, André, What is Cinema, trans. Hugh Gray, University of California Press, 1972.

Beach, Eduard Allen, The Potencies of God(s). Schelling's Philosophy of Mythology, State University of New York, 1994.

Beiser, Frederick, German Idealism. The Struggle against Subjectivism, Harvard University Press, 2002.

Benjamin, W. [1936] 1968. "The Work of Art in the Age of Mechanical Reproduction". In Illuminations, H. Arendt (ed.), H. Zohn (trans.), 217-52. New York: Harcourt, Brace \& World.

Berman, Morris, The Reenchantment of the World, Cornell University Press, 1981.

Bersani, L. \& U. Dutoit, Forms of Being: Cinema, Aesthetics, Subjectivity, BFL, 2004.

Bird, Robert, Andrei Tarkovsky: Elements of Cinema, Reaktion Books, 2008. 
Blumenberg, Work on Myth, trans. Robert M. Wallace, MIT Press, 1985.

Bordwell David, Making Meaning. Inference and Rhetoric in the Intepretation of Cinema, Harvard University Press.

Botz'Bornstein, Thorsten, Films and Dreams. Tarkovsky, Bergman, Sokurov, Kubrick, and Wong Kar-Wai, Lexington Books, 2007.

Bowser, Eileen, The Transformation of Cinema, 1907-1915, University of California Press, 1990.

Carrera, Pilar, Andrei Tarkovski. La imagen total, F.C.E., 2008.

Cassirer, Ernst, Language and Myth, trans. Susanne L. Langer, Dover Publications Inc. New York, 1953.

Cavell, Stanely, The World Viewed: Reflections on the Ontology of Film, Harvard University Press, 1979.

Ciria, Alberto, El Rastreador. Extrañeza y pertenencia en la poesía filmica de Tarkovski, Akademischer Verlag München, 1995.

Copanna Pablo, Andrei Tarkovski: El icono y la pantalla, De La Flor, 2003.

De Jong, Irene, A Narratological Commentary on the Odessey, Cambridge University Press, 2004.

Film, Theory and Philosophy: the Key Thinkers, Ed. Felicity Coleman, Acumen Publishing, 2009.

Frank, Manfred, El Dios Venidero. Lecciones sobre la Nueva Mitología.Trad. Helena Cortés y Arturo Leyte, Ediciones del Serbal, 1994.

Gabriel, Markus and Zizek, Slavoj, Mythology, Madness and Laughter. Subjectivity in German Idealism, Continuum International Publishing Group, 2009.

García Gual, Carlos, Introducción a la mitlogía griega, Alianza Editorial, 1993.

Geldard, Richard, Parmenides and the Way of Truth, Monkfish Publishing, 2007.

Goulding, Daniel J., Post New Wave Cinema in the Soviet Union and Eastern Europe, Indiana UniversityPress, 1989.

Grant, Iain Hamilton, How Nature Came to be Thought: Schelling's paradox and the problem of location. Journal of the British Society for Phenomenology, 44 (1), 2013. 
Philosophies of Nature after Schelling, Continuum International Publishing Group, 2006.

------- The Universe in the Universe. German Idealism and the Natural History of Mind. Royal Institute of Philosophy Supplement, 72, 2013.

Green, Peter, Andrei Tarkovsky; The Winding Quest, Palgrave McMillan, 1992.

Hesse, Herman, Steppenwolf, trans. David Horrocks, Penguin Books, 2012.

Hoerman, J., Film after Film: or, What Became of 21 ${ }^{\text {st }}$ Century Cinema, VERSO, 2012.

Jameson, F., Political Unconscious: Narrative as a Socially Symbolic Act, Methuen, 1981.

-------- The Geopolitical Aesthetic: Cinema and Space in the World System, BFI, 1992.

Johnson, Vida T, The Films of Andrei Tarkovski: A Visual Fugue, Indiana University Press, 1994.

Jung, C.G. and Kerényi, C., The Science of Mythology. Essays on the Myth of The Divine Child and the Mysteries of Eleusis, trans. R.F.C. Hull, Routledge Classics, 2002.

Books, 1959.

Kracauer, S., Theory of Film: The Redemption of Physical Reality, Princeton University Press, 1960.

Lacan, J. 2006. "The Mirror Stage as Formative of the / Function as Revealed in Psychoanalytic Experience". In Ecrits: The First Complete Edition in English, B. Fink (trans.), 75-81. New York: Norton.

Levi-Strauss, C., Tristes Tropiques, trans. J. Russell, Atheneum, 1967.

López-Domínguez, Virginia, Schelling (1775-1854), Del otro ediciones, 1995.

Luca, Tiago de, Realism of the Senses in Contemporary World Cinema: The Experience of Physical Reality, TAURIS, 2013.

Malin, Shimon, Nature Loves to Hide. Quantum Physics and the Nature of Reality, a Western Perspective, World Scientific, 2012.

Mark Robinson, Jeremy, The Sacred Cinema of Andrei Tarkovsky, Creschent Moon, 2006. Martin, Sean, Andrei Tarkovsky, Old Castle Books, 2011. 
Mathews, Bruce, Schelling's Organic Form of Philosophy. Life as the Schema of Freedom, SUNY Press, 2011.

Maturana, Humberto and Varela, Francisco, Autopoesis and Cognition. The Realization of Living, D. Reidel Publishing, 1972.

------- The Tree of Knowledge. The Biological Roots of Human Understanding, trans. Robert Palucci, Shambala, 1987.

McGowan, Todd, Out of Time: Desire in Atemporal Cinema, University of Minnesota Press, 2011.

Mengs, Antonion, Stalker, de Andrei Tarkovski, RIALP, 2004.

Merleau-Ponty, M., Phenomenology of Perception, trans. C. Smith, Routledge \& Kegan Paul, 1962.

Metz, C., Film Language: A Semiotics of the Cinema, trans. M. Taylor, Oxford University Press, 1974.

Metz, Language and Cinema, Mouton, 1974.

Mitry, Jean, The Aesthetics and Psychology of the Cinema, Indiana Uniersity Press, 1997.

Morina, Edgar, The Cinema or the Imaginary Man, trans. Lorraine Mortimer, University of Minnesota Press, 2005.

Nancy, J.-L, Ground of the Image, trans. J. Fort, Fordham University Press, 2005.

Nietzsche, Friedrich, The Birth of Tragedy, trans. Douglas Smith, Oxford University Press, 2000.

Perez, G., The Material Ghost: Films and their Medium, Johns Hopkins University Press, 1998.

Phillips, J., Cinematic Thinking: Philosophical Approaches to the New Cinema, Stanford University Press, 2008.

Porton, R, Film and the Anarchist Imagination, Verso, 1999.

Prigogine, I. \& I. Stengers, Order Out of Chaos: Man's New Dialogue with Nature, Bantam, 1984.

Ranciere, J., Film Fables, trans. E. Battista, Berg, 2006. 
The Future of the Image, trans. G. Elliot, Verso, 2007.

Rascaroli, Laura, The personal Camera: Subjective Cinema and the Essay Film, Wallflower Press, 2009.

Redwood, Thomas, Andrei Tarkovsky's Poetics of Cinema, Cambridge Scholar Publishing, 2010.

Rosenbaum, J. \& A. Martin 2003, Movie Mutations: The Changing Face of World Cinephilia, BFI, 2003.

Safranski, Rüdiger, Romanticismo. Una odisea del espíritu alemán, trad. Raúl Gabás, Tusquets Editores, 2009.

Schelling, Friedrich, Historical-critical Introduction to the Philosophy of Mythology, trans. Mason Richey, Markus Zisselsberger, State University of New York Press, 2007.

--------- Philosophical Investigations into the Essence of Human Freedom, trans. Love, Jeff and Schmitt, Johannes, State University of New York Press, 2007.

System of Transcendental Idealism, trans. Heath, Peter, University Press of Virginia, 1978.

------ The Ages of the World, trans. Wirth, Jason M., State University of New York Press, 2000.

The Grounding of Positive Philosophy. trans. Matthews, Bruce, State University of New York Press, 2007.

-------- The Philosophy of Art, trans. Stott, Douglas W., University of Minnesota Press, 1989.

Schrader, Paul, Transcendental Style in Film, Da Capo Press, 1988.

Schrödinger, Erwin, What is Life? The Physical Aspect of the Living Cell; Mind and Matter, Cambridge University Press, 2012.

Singer, Irving, Cinematic Mythmaking, MIT Press, 2008.

Feeling and Imagination: The Vibrant Flux of Our Existence, Rowman \& Littlefield, 2001.

Reality Transformed: Film as Meaning and Technique, MIT Press, 1998. 
Skakov, Nariman, The Cinema of Andrei Tarkovsky. Labyrinths of Space and Time, I.B. Tauris, 2012.

Taleb, Nassim Nicholas, The Black Swan, Random House Trade Paper Backs, 2010.

Tarkovksi, Andrei, Esculpir en el tiempo. Reflexiones sobre el arte, la estética y la poética del cine, RIALP, 2008.

Tarkovsky, Andrei, Sculpting in Time, trans. Kitty Hunter-Blair, University of Texas Press, 1989.

Tejeda, Carlos, Andrei Tarkovski, Cátedra, 2010.

Textos y Manifiestos del cine. Estética. Escuelas. Movimientos. Discliplina. Innovaciones, eds. Joaquim Romaguera I Ramió, Homero Alsina Thevenet, Cátedra, 2007.

Turovskaya, Maya, Tarkovsky: Cinema as Poetry, Faber and Faber, 1990.

Vacariu, Mihai, Tarkovsky and the Function of Art, Analele Universtitatii Bucuresti, Filosofie, 2002.

Vera, Pascual, Único testigo: El espectador ante el fenómeno cinematográfico, Universidad de Murcia, 2008.

Vila-Matas, Enrique, Bartleby y compañía, Anagrama, 2002.

Wetheim, Margaret, The Pearly Gates of Cyberspace. Ahistory of Space from to the Internet. W.W.Norton, 2000.

Wirth, Jason, Schelling and the Future of God: Analecta Hermeneutica, V. 5 (2013).

------- Schelling's Practice of the Wild: Time, Art, Imagination, SUNY Press, 2015.

------- The Conspiracy of Life: Meditations on Schelling and His Time, SUNY Press, 2003.

Woll, Josephine, Real Images: Soviet Cinema and the Thaw, TAURIS, 2000.

Zimmermann, Rainer, A Metaphysics of Emergence, College Publications London, 2015, Forthcoming.

------- Nothingness as Ground and Nothing but Ground. Schelling's Philosophy of Nature Revisited. Xenomoi Verlag, 2014.

Zunzunegui, S., Pensar la imagen, Catedra, 1989. 